\title{
The vitamin $\mathrm{K}$ dependent enzymatic properties of blood coagulation factor $X$
}

Citation for published version (APA):

Lindhout, M. J. (1977). The vitamin K dependent enzymatic properties of blood coagulation factor $X$. [Doctoral Thesis, Maastricht University]. Rijksuniversiteit Limburg.

https://doi.org/10.26481/dis.19771111ml

Document status and date:

Published: 01/01/1977

DOI:

10.26481/dis.19771111ml

Document Version:

Publisher's PDF, also known as Version of record

\section{Please check the document version of this publication:}

- A submitted manuscript is the version of the article upon submission and before peer-review. There can be important differences between the submitted version and the official published version of record.

People interested in the research are advised to contact the author for the final version of the publication, or visit the DOI to the publisher's website.

- The final author version and the galley proof are versions of the publication after peer review.

- The final published version features the final layout of the paper including the volume, issue and page numbers.

Link to publication

\footnotetext{
General rights rights.

- You may freely distribute the URL identifying the publication in the public portal. please follow below link for the End User Agreement:

www.umlib.nl/taverne-license

Take down policy

If you believe that this document breaches copyright please contact us at:

repository@maastrichtuniversity.nl

providing details and we will investigate your claim.
}

Copyright and moral rights for the publications made accessible in the public portal are retained by the authors and/or other copyright owners and it is a condition of accessing publications that users recognise and abide by the legal requirements associated with these

- Users may download and print one copy of any publication from the public portal for the purpose of private study or research.

- You may not further distribute the material or use it for any profit-making activity or commercial gain

If the publication is distributed under the terms of Article $25 \mathrm{fa}$ of the Dutch Copyright Act, indicated by the "Taverne" license above, 


\section{THE VITAMIN K DEPENDENT}

\section{ENZYMATIC PROPERTIES}

\section{OF BLOOD COAGULATION FACTOR X}

\section{PROEFSCHRIFT}

ter verkrijging van de graad yan doctor in de geneeskunde aan de Rijksuniversiteit Limburg, op gezag van de Rector Magnificus Dr. H. A. Tiddens, hoogleraar in de faculteit der geneeskunde, volgens besluit van het college van dekanen in het openbaar te verdedigen op vrijdag 11 november 1977 des namiddags om 4 uur precies, in de aula der universiteit.

door

\section{Mattheus Jan Lindhout}

geboren te Bergen op Zoom in 1944 

Promotor: $\quad$ Prof.Dr.H.C.Hemker
Co-referenten: Prof.Dr.G.H. de Haas
Dr.M.P.Esnouf

Dit proefschrift werd bewerkt in het laboratorium voor Cardiobiochemie en Bloedstollingsbiochemie van het Academisch Ziekenhuis te Leiden en het laboratorium voor Biochemie van de Rijksuniversiteit Limburg, onder de leiding van Prof.Dr.H.C.Hemker.

Deze onderzoekingen werden gedeeltelijk uitgevoerd onder auspicien van de Stichting voor Medisch Wetenschappelijk Onderzoek FUNGO met financiële steun van de Nederlandse Organisatie voor Zuiver Wetenschappelijk Onderzoek 

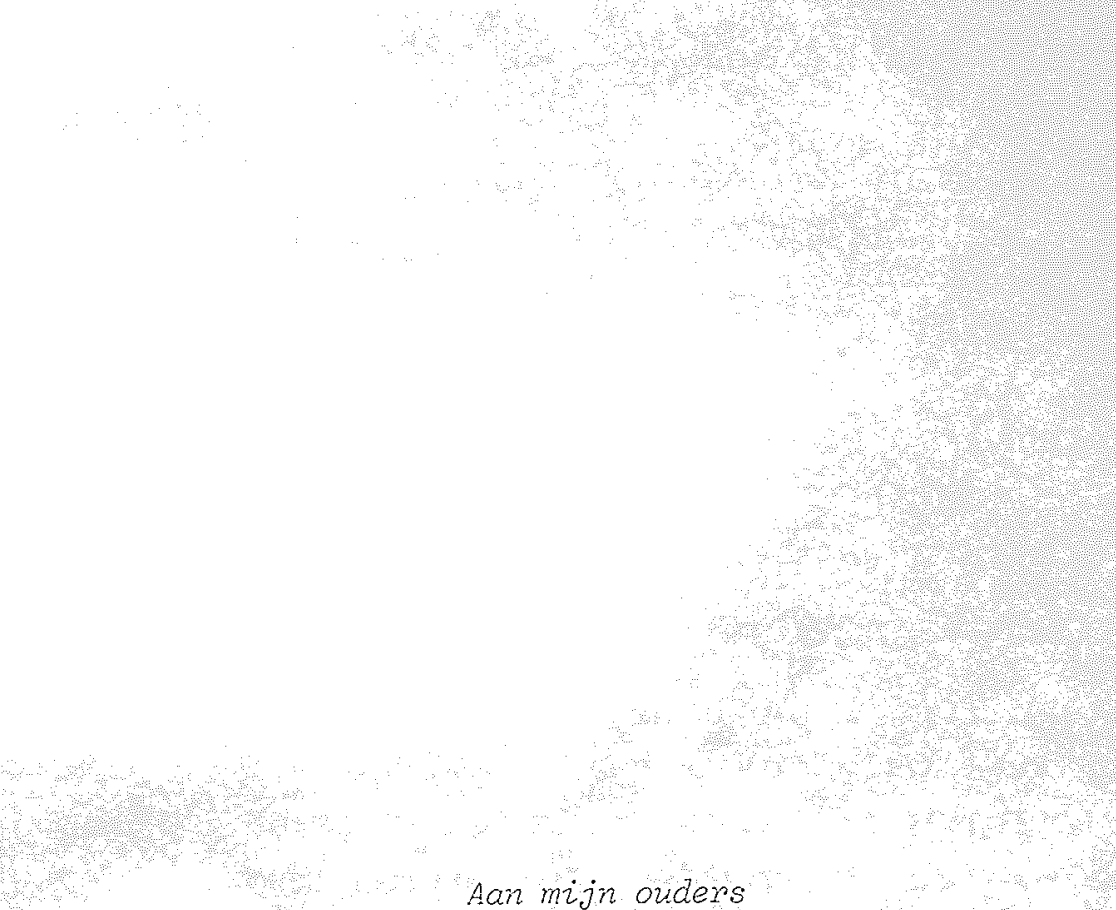

\section{Aan mijn ouders}

\section{Ankie}

Marition 
Manuscript: Mevr.H.Vermeer-Knulst

Tekeningen: Mevr. B.H.M. Kop-Klaassen

Foto's : AV Centrum, Rijksuniversiteit Limburg

Drukkerij : Krips-Repro N.V., Meppel 
Contents

$\begin{array}{lll}\text { Chapter I General introduction } & 7\end{array}$

Introduction to this thesis 18

Chapter II Identification, purification and properties

of the phenprocoumon induced decarboxy

factor $X$ (PIVKA-X) from bovine plasma

A comparison to normal factor $X$

Chapter III The role of $\gamma$-carboxyglutamyl residues in the positive cooperative binding of $\mathrm{Ca}^{2+}$ to blood coagulation factor $X$

Chapter IV Activation of decarboxy factor X (PIVKA-X) by a protein from Russel's Viper venom Purification and partially characterization of activated PIVKA-X

Chapter $V$ The effect of $\gamma$-carboxyglutamyl residues on the enzymatic properties of the activated blood clotting factor $X$ A comparison of the normal and the decarboxy enzym 



\section{CHAPTER I}

\section{GENERAL INTRODUCTION}

Thrombin generation. The enzyme thrombin plays a key role in human pathology because it stands at the centre of events that govern hemostasis and thrombosis. It causes platelets to aggregate irreversibly and it causes fibrinogen to form fibrin.

Irreversible platelet changes and fibrin formation accompany normal hemostasis as well as all forms of thrombosis. Diseases that arise from a lack of adequate thrombin formation are relatively scarce. The hemophilias and vitamin $K$ deficiency do not account for a large percentage in the morbidity and mortality pattern of man. They are of paramount importance though, as they enable us to study the mechanism of thrombin formation and thereby the mechanism of the undue thrombin formation, that leads to thrombosis and other pathological forms of the hemostasis mechanism. The importance of the latter abberations for human pathology can hardly be exagerated. Thrombosis plays the central role in both the genesis and the acute complications of arterial atherosclerosis and by this fact alone accounts for about $40 \%$ of all deaths in The Netherlands. At this moment venous thrombosis, once a much feared complication of any major surgical intervention or other immobilizing disease by now can be adequately treated on basis of diminishing the thrombin forming power of the blood. other conditions remain to be adequately treated: coagulation as mediator of immune damage and all forms of intravascular coagulation are among them.

It is clear that the study of thrombin formation is an essential part of pathology and merits to be studied in detail. Physiologically, thrombin formation can be initiated via two different pathways, e.g.:

1. the surface catalyzed transformation of the zymogen factor XII into an activated form (factor XII ${ }_{a}$ ), which is the primary step 


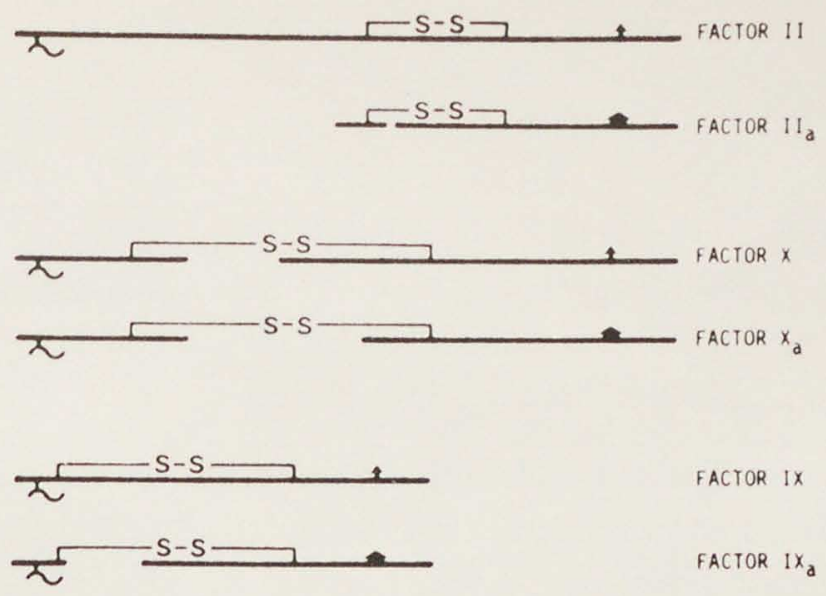

Fig. 1 .

Analogies between clotting proteases (after Magnusson, ref. 2). The arrows indicate the active serine (bold: activated; small: not activated). The squiggle is the $\mathrm{Ca}^{2+}$ binding site.

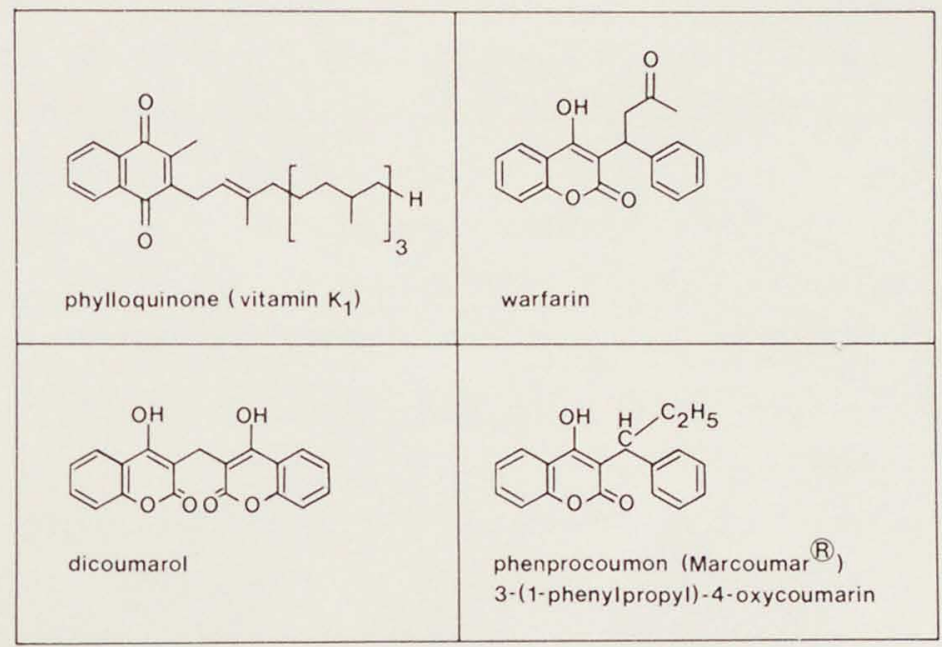

Fig. 2 .

Structures of the active form of vitamin $K$ and coumarin based anticoagulants. 
in the formation of factor $\mathrm{XI}_{\mathrm{a}}$. In this step also high molecular weight kininogen and prekallikrein are involved. It initiates the so-called intrinsic pathway.

2. the transformation of factor VII into factor VII a by tissue factor (T.F.), a lipoprotein released by injury which initiates the extrinsic pathway.

After initiation, the reaction sequence leading to thrombin formation can be visualized as is shown below (1):

intrinsic pathway

$I X \stackrel{X I_{a}}{\longrightarrow} I X_{a}$ extrinsic pathway

$\mathrm{VII} \longrightarrow \mathrm{VII}_{\mathrm{a}}$

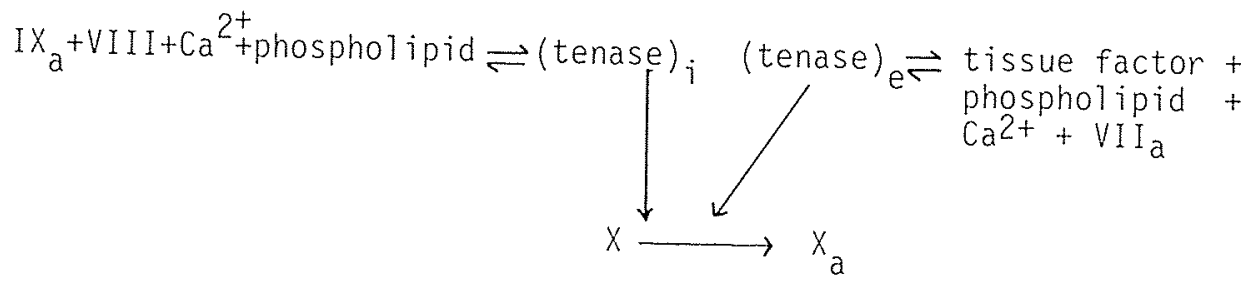
$x_{a}+v_{a}+$ phospholipid $+C a^{2+} \rightleftharpoons$ prothrombinase

prothrombinase

II $\longrightarrow I_{a}$ (= thrombin)

Two features are characteristic for this scheme:

1. The cascade sequence: the product of one reaction acts as (part of) the enzyme in the following step. Most of the reactions are characterized now as activation by limited proteolysis. Fig. 1 shows the molecular aspects of this proteolysis for several clotting factors.

2. The complex enzymes. An essential feature of the activation mechanism is the participation of phospholipid micelles by offering a phospholipid-water interface to the interacting coagulation factors.

This thesis contributes to the knowledge of prothrombinase, the 
enzyme that converts prothrombin into thrombin. It is a complex enzyme and mediates the last step in the cascade.

Role of vitamin $k$ in blood coagulation factor synthests. The only known function of vitamin $k$ in animals is the biosynthesis of the blood coagulation factors II, VII, IX, and X (3). Vitamin $K$ was discovered by Dam (4) because of its relation with blood coagulation. The appearance of a haemorrhagic diathesis by chickens on a cholesterol free diet, was related to a deficiency of the fat soluble vitamin $K$. In 1936 it was found that vitamin $K$ deficiency resulted in a decrease of prothrombin activity (5). In the early fifties when other proteins involved in blood coagulation were discovered, the role of vitamin $K$ was ascertained also in the biosynthesis of the factors VII, IX, and $X(6-8)$. The early work on the vitamin $K$, its chemical and physiological properties is excellently reviewed by Wiss, Dam and Grimminger (9). Anderson and Barnhart (10) demonstrated with immuno-fluorescence techniques that the four vitamin $K$ dependent coagulation factors were synthesized in the lever parenchyma cells. The discovery of components with an anti-vitamin $K$ activity by Campbell and Link (11) stimulated further investigations on the action of vitamin $k$ (structures are shown in fig. 2).

Thierry et al. (12) have shown that compounds with a 4-hydroxycoumarin structure, like dicoumarol, warfarin and phenprocoumon interfere with the vitamin $K$ action in hepatocytes. The mode of action of these coumarins is not yet known, however. Several authors suggested a competition of these compounds with vitainin $K$ on a receptor protein involved in the biosynthesis of coagulation factors $(13,14)$. More recently, Bell and Matschiner (15) reported the accumulation of the 2,3-epoxide derivative of pinylloquinone in rat liver after administration of warfarin. They postulated that an increase of the epoxide/vitamin $K$ ratio in the liver causes a decrease of the activity of the four vitamin $K$ dependent coagulation factors. Accumulation of 2,3-epoxide-phylloquinone is probably due 
precursor

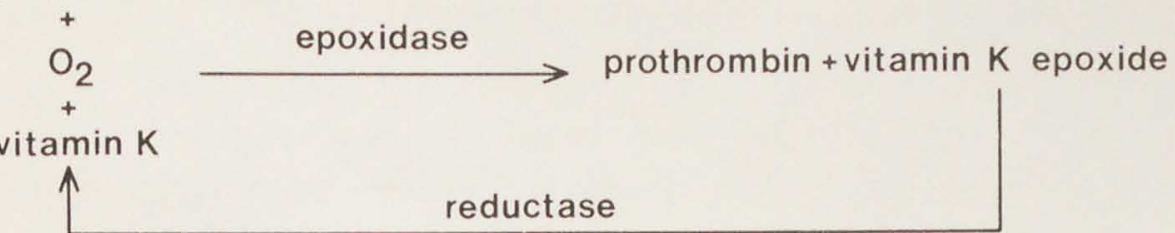

inhibited by warfarin

Fig. 3,

Involvement of vitamin $K$ epoxidase in the formation of prothrombin.

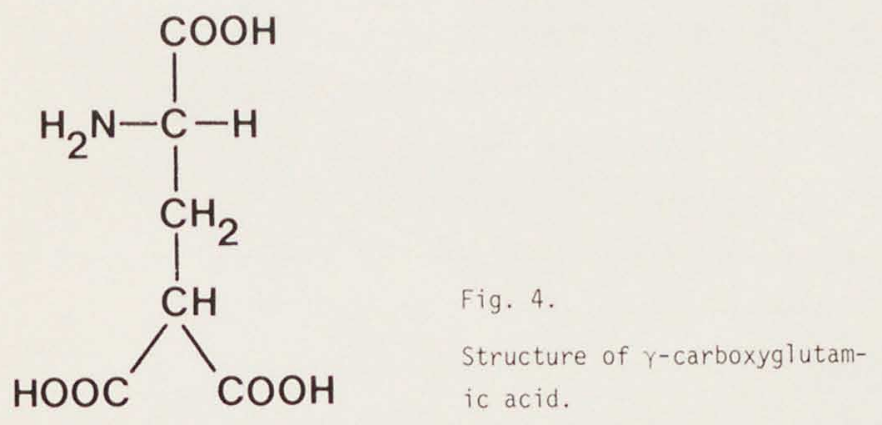

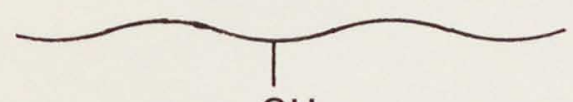

$\mathrm{CH}_{2}$

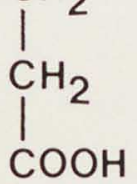

precursor

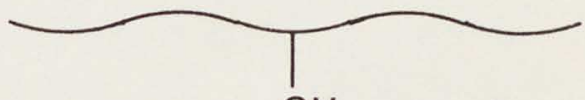

$\mathrm{CH}_{2}$

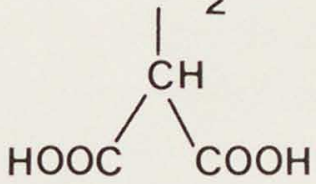

prothrombin

\section{Fig. 5 .}


to inhibition of phylloquinone reductase by warfarin. The hypothesis of Bell et al. (16) is summarized in fig. 3. Sadowski (17), however, reported the stimulation of prothrombin synthesis after treating vitamin $K$ deficient rats with the epoxide. The development of an in vitro system for the synthesis of prothrombin will make it possible to study this question in more detail (see page 17 and further).

Indirect evidence for a prothrombin precursor molecule. During the last twenty years several groups of investigators worked intensively on the elucidation of the mechanism of vitamin $K$ action and several suggestions to explain its mode of action have been put forward. The preliminary work on the role of vitamin $k$ will not be discussed here and the reader is referred to reviews by Pennock (18) and Hemker (19). The investigations during the last ten years focussed on two alternate hypotheses, e.g.: 1. Vitamin $K$ acts at a ribosomal site to regulate the de novo synthesis of prothrombin (20-23).

2. Vitamin $K$ functions in the modification of the prothrombin polypeptide chain of a postribosomal stage: the precursor hypothes is $(24-26)$.

The relation between vitamin $K$ action and de novo synthesis has been studied with inhibitors of protein syr thesis reaction at the ribosomal level, namely puromycin and cycloheximide.

It is difficult to interpret the results of these experiments and so conflicting data have been obtained on the stimulation of prothrombin synthesis by vitamin $K$ in vitamin $K$ deficient rats treated with cycloheximide $(25,27-29)$.

It is now clear that cycloheximide when administered to vitamin $K$ deficient rats before vitamin $K$ will only partially inhibit prothrombin synthesis, whereas general protein synthesis will be almost completely blocked (30).

These data suggest that even when the synthesis of the polypeptide 
chain is inhibited, vitamin $K$ still affects the production of prothrombin from an intracellular pool. Work from Prydz's group (31) gives also evidence for a "factor VII like" pool.

Further support for the existence of a precursor pool came from the investigations of Suttie et a1. (32-34). In the microsomal fraction of liver obtained from rats treated with warfarin, they could generate thrombin with the aid of a non-physiological prothrombin activator (Echis Carinatus venom). The amount of thrombin was inversely proportional with the prothrombin activity in plasma. They also demonstrated a vitamin $K$ dependent synthesis of prothrombin in microsomal preparations obtained from vitamin $K$ deficient rats. This prothrombin synthesis could be inhibited with warfarin but not cycloheximide.

Recently, Esmon (35) was able to isolate a precursor of prothrombin from the liver of vitamin $K$ deficient rats. Unlike the precursor of prothrombin, identified in rat livers, the precursor molecules of coagulation factors in the human and bovine plasma will appear in the circulation. The first evidence for such an inactive prothrombin precursor in human plasma was obtained by Hemker et al. (36). They reported that in plasma of patients treated with vitamin $K$ antagonists a protein appears which inhibits the blood coagulation in specific coagulation assays, and which was called protein induced by vitamin $\underline{K}$ absence (antagonists), abbreviated to PIVKA (36). Already in 1963 they postulated that vitamin $K$ antagonists block the prothrombin synthesis at a postribosomal step so that the polypeptide precursors reach the circulation.

Using immunochemical techniques several laboratories reported the existence of proteins analogous to each of the four vitamin $K$ dependent coagulation factors. The precursors corresponding to the normal factors II, VII, IX, and X that appear in the plasma and are purified from there, wi11 be referred to as PIVKA-II, PIVKA-VII, PIVKA-IX, and PIVKA-X, respectively, which is the nomenclature used 
by Hemker. The name proposed for al 1 forms of precursors of vitamin $K$ dependent clotting factors is decarboxy protein. This refers to al1 forms and thus comprises several intracellular as well as plasmatic variety. PIVKA designates the plasmatic variety only.

Immunochemical evidence for precursor protein. The first immunological evidence for the existence of PIVKA-II in human plasma was reported by Ganrot (37) and Josso (38). Goodnight (39) and Denson (40) demonstrated the appearance of an inactive factor VII in the plasma of patients treated with oral anticoagulants. Levanon (41) and Brozovic (42) reported a higher level of factor VII antigen than expected from a factor VII activity assay. Patients treated with vitamin $K$ antagonists also show higher levels of antigen related to factor IX and factor $X$ than was to be expected on basis of bioassays (40, 43-47). Reekers (48) and Lindhout (49) demonstrated with crossed immunoelectrophoresis that treatment of cattle with phenprocoumon results in a decrease of the normal factors IX and $X$ with a parallel increase of PIVKA-IX and PIVKA-X.

Characterization of PIVKA-II. The identification of PIVKAs stimulated further irvestigations on the action of vitamin $K$ on the chemical nature of the postribosomal modification of prothrombin. It was assumed that vitamin $k$ affects the incorporation of carbohydrates in the precursor molecule of prothrombin (50-52). Glycolipid derivates of vitamin $k$, which may be the carbohydrate donors, could be formed by incubation of phylloquinone and UDP-N-acetylglucosamine (53) with smooth endoplasmic reticulum obtained from rat liver. Differences in carbohydrate content of human prothrombin and human PIVKA-II were reported by Morrison (54).

Chemical analysis of highly purified bovine prothrombin and PIVKA-II by Stenflo $(55,56)$ and Nelsestuen (57) indicated that the carbohydrate content and the structure of both proteins are probably similar. The observation (58) that asialo- and aglycoprothrombin retain biological activity and that the carbohydrate part of thrombin 
is not essential for its activity $(59,60)$ made the hypothesis that the vitamin $k$ dependent step in the formation of prothrombin involves glycosylation of the protein unlikely.

Although PIVKA-II has no biological activity it was possible to generate thrombin rapidly using non-physiological activators of prothrombin, like trypsin (57), Echis Carinatus venom (57), and staphylocoagulase $(61,62)$. These observations suggest that the PIVKA-II molecule contains an intact thrombin. The differences in the rate of thrombin formation between PIVKA-II and prothrombin must account for the difference in biological activity with the physiological activator.

Prothronbin activation is enhanced by calcium and phospholipids $(63,64)$ which is discussed in more detail in chapter $V$. The lack of any effect of $\mathrm{Ca}^{2+}$ ions on the electrophoretic mobility of PIVKA-II, PIVKA-IX and PIVKA-X (48,49,65-67) and the absence of $\mathrm{Ca}^{2+}$-dependent immunochemical properties $(56,68)$ as is fourici in the normal factors suggested a difference in calcium binding properties. Horeover, the observations (69) that PIVKA-II does not bind to phospholipids in the presence of $\mathrm{Ca}^{2+}$ ions and that addition of phospholipids has no effect on the rate of thrombin formation from PIVKA-II favor the hypothesis that a vitamin $K$ dependent mechanism brings about a change in a precursor molecule that affects its calcium binding properties and by so doing converts it into prothromin.

Identification of $y$-carboxyglutamic acid. Nelsestuen and Suttie (70) isolated an acidic peptide from a tryptic digest of bovine prothrombin (so cailed fragnent 1 region of prothrombin) that binds calcium ions. The work of Stenfio (71) on the calcium binding region of prothrombin revealed two acidic peptides with an electrophoretic mobility much higher than would be expected from the amino acid composition. The same observation was done by Magnusson (72). An analogous peptide with an anomalous high electrophoretic mobility could not be identified in the amino terminal region of PIVKA-II. 
Several other investigators have reported the existence of abnormally acidic peptides in prothrombin $(67,73)$. With 'Hnuclear magnetic resonance spectroscopy and mass-spectroscopy Stenflo (74) identified two residues of;-carboxyglutamic acid (fig. 4) in a tetrapeptide (residues 6-9) from the amino terminal region of prothrombin. At the same time Nelsestuen (75) characterized y-carboxyglutamic acid from a dipeptide (residues 33-34). It was shown by Magnusson (76) that all 10 of the first 33 glutamic acid residues in prothrombin are modified to a $r$-carboxy derivative. It is interesting to note that several investigators (77-80) report the existence of various prothrombin-like molecules differing in calcium binding and activation properties induced in cattle by prolonged administration of warfarin. This suggests the existence of partially carboxylated forms of prothrombin.

The similarity in amino acid sequence of the aminoterminal region of the vitamin $K$ dependent coagulation factors prothrombin, factor IX and factor $X(81)$ suggest the presence of $\gamma$-carboxyglutamic acids in both factor $I X$ and $X$. Howard et a $1 .(82)$ reported that the vitamin $K$ dependent peptide of factor $X$ contains 14 extra carboxyl groups and it was assumed that most glutamic acid residues in this peptide were modified to $\gamma$-carboxyglutamic acids. Recently, Frykiund (83) identified $\gamma$-carboxyglutamic acids in factor IX.

Functional role of $\gamma$-carboxyglutamic acid. The similarity in structure and amino acid composition of the vitamin $k$ dependent coagulation factors and other members of the chymotrypsin family, like trypsin, plasmin and chymotrypsin suggests that they have an ancesteral gen in common. The fact that the calcium binding by the vitamin $K$ dependent region has been conserved, suggests an important functional role of this region. The relation between structure and function might be underlined by the occurrence of the $Y$-carboxyglutamic acid residues in pairs. A 'cage-like' structure was suggested as a model for the calcium binding by a 
pair of, -carboxyglutamic acids $(82,84)$. The importance of the calcium mediated binding of coagulation factors to phospholipid surfaces is well known, but an explicit mechanism to explain its function is still lacking (85).

Function of vitamin $k$. In the past few years it became clear that vitamin $K$ promotes the carboxylation of a microsomal precursor to prothrombin (fig. 5). Sutties group (86) found that the postiiltochondrial supernatant of vitamin $K$ deficient rats incorporates $\mathrm{H}^{14} \mathrm{CO}_{3}{ }^{-}$in a microsomal protein after administration of vitamin $\mathrm{K}$ and depending on the presence of the prothrombin precursor in the microsomal preparation. All radioactivity was found primarily in the amino terminal region of prothrombin. Moreover, they give evidence that the radioactivity is associated with the r-carboxyglutamic acids.

The so-called vitamin $K$ dependent carboxylase studied in microsomes required the presence of PIVKA-II, vitamin $\mathrm{K} \mathrm{HCO}_{3}{ }^{-}\left(\mathrm{CO}_{2}\right)$, oxygen, an energy source and the postmicrosomal supernatant containing NADH or NADP reductase (87-91). The stimulating factor present in the postmicrosomal supernatant could be replaced by the reduced form of vitamin $K$ (phylloquinol) (87). Investigations $(16,92)$ on the metabolism of the vitamin $K$ epoxide suggest the existence of a coupling between the vitamin $K$ - vitamin $K$-epoxide conversion and vitamin $K$ stimulated carboxylation. 
As explained on page 7 and further, it is important to know the details of the thrombin forming reaction. In practice this reaction is damped by anticoagulation. Both oral anticoagulation by vitamin $K$ antagonists and heparin therapy are used for this purpose. A study of the role of factor $X$ and PIVKA-X in the function of prothrombinase thus serves a double purpose. In the first place it will help in elucidating the fine mechanism of prothrombinase action and more precisely of the role of $\mathrm{Ca}^{2+}$ binding $y$-carboxyglutamic acid residues there. In the second place it will give an insight in the abnormalities induced by oral anticoagulation.

In chapter II the purification and characterization of PIVKA-X are described and in chapter III its $\mathrm{Ca}^{2+}$ binding properties. The latter by both flow dialysis and $\mathrm{Ca}^{2+}$ dependent spectral changes. In chapter IV it is investigated under what conditions PIVKA-X can be converted into an active enzyme analogous to factor $x_{a}$ : the role of $\mathrm{Ca}^{2+}$ ions and hence the role of $y$-carboxyglutamic acid residues in this process is investigated.

In order to elucidate the role of $\%$-carboxyglutamate residues in the catalytic action of factor $x_{a}$, we compared the catalytic properties of normal factor $X_{a}$ and an analogous decarboxy factor $x_{a}$, PIVKA-X $X_{a}$ (chapter $V$ ).

Prothrombin activation by factor $x_{a}$ is enhanced several orders of magnitude by the so-called accessory components, like factor $V\left(V_{a}\right)$, $\mathrm{Ca}^{2+}$ and phospholipids. This rate enhancement can be accounted for by several mechanisms, e.g.:

1. Interaction of factor $x_{a}$ with $\mathrm{Ca}^{2+}$, phospholipids and factor $v_{a}$ may affect the catalytic efficiency of the proteolysis.

2. Binding of phospholipids, $\mathrm{Ca}^{2+}$ and factor $\mathrm{V}_{\mathrm{a}}$ may cause changes in the susceptibility of the substrate.

3. Localization and orientation of the reaction components by protein- 
protein and/or protein-phospholipid interactions.

Use of PIVKA-X $x_{a}$, the factor $x_{a}$ analogue which probably does not bind to phospholipids since the $\mathrm{Ca}^{2+}$ binding sites are lacking, in activation tests of prothromin, may help to distinguish between these mechanisms. 


\section{REFERENCES}

1. Hemker, H.C., Lindhout, M.J. and Vermeer, C. Ann.H.Y.Acad.Sci. 283 (1977) 104

2. Magnusson, S., Sottrup-Jensen, L., Ellebaek-Petersen,T. and Claeys, H. (1975) In "Proceedings of a Boerhaave Course on Prothrombin" Leiden, Univ. Press

3. Stenf10, J. J.Biol.Chem. 251 (1976) 355

4. Dam, H. Nature 135 (1935) 652

5. Dam, H., Schönheyder, F. and Tage-Hansen, E. Bioch.J. 30 (1936) 1075

6. Owren, P.A. and Aas, K. Scand.J.Clin.Lab. Invest. 3 (1951) 1

7. Koller, F., Loeliger, E.A. and Duckert, F. Acta Haemat. 6 (1951) 1

8. Spaet, T.H. and Kropatkin, H. Arch.Int.Med. 102 (1958) 558

9. International Symposium on recent research on vitamin $K$ and relation quinones Vitam. Horm. 24 (1966) 291

10. Anderson, G.F. and Barnhart, M.I. Am.J.Physiol. 206 (1964) 929

11. Campbe11, H.A. and Link, K.P. J.Biol.Chem. 138 (1941) 21

12. Thierry, M.J., Hermodson, M.A. and Suttie, J.H. Am.J.Physiol. 219 (1970) 854

13. O'Reilly, R.A., Pool, J.G. and Aggeler, P.i.l. Ann.N.Y.Acad.Sci. $151(1968) 913$

14. Ulson, R.R. (1970) In The Fat Soluble Vitamins. De Luca, H.F. and Suttie, J.W. Eds. Madison Wis. University of Wisconsin Press 463-489

15. Be17, R.G. and Matschiner, J.T. Arch.Biochem.Biophys. 141 (1970) 473

16. Willingham, A.K., Laliberte, R.E., Bel1, R.G. and Matschiner, J.「. Biochem.Pharm. 25 (1976) 1063

17. Sadowski, J.A. and Suttie, J.W. Biochem. 13 (1974) 3696

18. Pennock, J.F. (1969) in "Vitamin A, E und K". H.Frhr. von Kress and K.U.Blum, Eds. F.K.Schattauer Verlag, Stuttgart, 181 
19. Hemker,H.C., v.d.Meer, J., Hodge, R. and Loeliger, E.A. (1969) In "Vitamin A, E und K" H.Frhr. von Kress and K.U.Blum, Eds. F.K.Schattauer Verlag, Stuttgart, 199

20. 01 son, R.E. Vit.Horm. 32 (1974) 483

21. 01son, R.E., Kipfer, R.K., Morrisey, J.J. and Goodman, S.R. Thrombos.Diathes.haemorrh. Supp 1. 57 (1974) 31

22. Johnston, M.F.H. and 01son, R.E. J.Biol.Chem. 247 (1972) 4001 23. Johnston, M.F.H. and 01son, R.E. J.Biol.Chem. 247 (1972) 3994 24. Hemker,H.C., Veltkamp, J.J., Hensen, H. and Loeliger, E.A. Nature 200 (1963) 589

25. Hil1, R.B., Gaetoni, S., Paolucci, A.il., Rana-Rado, P.B., Alden, R., Ranhotra, G.S., Shah, D.V., Shah, V.H. and Johnson, B.C. J.Biol.Chem. 243 (1968) 3930

26. Lowenthal, J. and Simmons, E.C. Experientia 23 (1967) 421

27. Polson, J. and Wosilait, W.D. Proc.Soc.Exp.Biol.Med. 132 (1969) 963

28. 01 son, R.E. Nutr.Rev. 28 (1970) 171

29. Suttie, J.W. Fed.Proc. 28 (1969) 963

30. Shah, D.V. and Suttie, J.W. Proc.Natl.Acad.Sci. USA 68 (1971) 1653

31. Rez, G. and Prydz, H. Biochim.Biophys. Acta 244 (1971) 495

32. Suttie, J.W. Arch.Biochem.Biophys. 141 (1970) 571

33. Suttie, J.W. Science 179 (1973) 192

34. Shah, D.V. and Suttie, J.W. Biochem.Biophys.Res.Commun. 60 (1974) 1397

35. Esmon, C.T., Grant, G.A. and Suttie, J.W. Biochem. 14 (1975) 1595

36. Hemker,H.C. and Muller, A.D. Thrombos.Diathes.haemorrh. 20 (1968) 78

37. Ganrot, P.0. and Nilehn, J.E. Scand.J.Clin.Lab. Invest. 22 (1968) 23

38. Josso, F., Lavergne, J.M. and Soulier, J.P. Nouv. Res.Fr. Hēmatol. 10 (1970) 633 
39. Goodnight, S.H., Feinstein, D.I., Osterud, B. and Rapaport, S.I. Blood 38 (1971) 1

40. Denson, K.W.E. Brit.J.Haemat. 20 (1971) 643

41. Levanon, M., Rimon, S., Shari, M., Ramot, B. and Golberg, E. Brit.J.Haematol. 23 (1972) 669

42. Brozovic, M. and Howarth, D.J. In "Prothrombin and related coagulation factors" Proceedings of a Boerhaave Course. Hemker,H.C. and Veltkamp, J.J. Eds. Leiden Univ.Press 1975, 252-263

43. Larrieu, M.S. and Meyer, O. Lancet 11 (1970) 1085

44. Veltkamp, J.J., Muis; H., Muller, A.D., Hemker, H.C. and Loeliger, E.A. Thrombos.Diathes.haemorrh. 25 (1971) 312

45. Lechner, K. Thrombos.Diathes.haemorrh. 27 (1972) 19

46. Gaudernack, G., Gladhaug, B.A., Osterud, B. and Prydz, H. Thrombos.Diathes. haemorrh. 31 (1974) 40

47. Gaudernack, G. and Prydz, H. Thrombos.Diathes.haemorrh. 34 (1975) 455

48. Reekers, P.P.M., Lindhout, M.J., Kop-Klaassen, B.H.M. and Hemker, H.C. Biochim.Biophys. Acta 317 (1973) 559

49. Lindhout, M.J., Kop-Klaassen, B.H.M. and Hemker, H.C. J.Mol.Med. 1 (1976) 223

50. Johnson, H.V., Martinovic, J. and Johnson, B.C. Biochem. Biophys. Res.Commun. 43 (1971) 1040

51. Pereira, M.A. Fed.Proc. 29 (1970) 382

52. Pereira, M.A. and Couri, D. Biochim.Biophys.Acta 237 (1971) 348

53. Johnson, B.C. and Valkowich, G. Biochem. Biophys. Res.Commun. 48 (1972) 1437

54. Morrison, S.A. and Esnouf, M.P. Nature 242 (1973) 92

55. Stenflo, J. and Ganrot, P.0. J.Biol.Chem. 247 (1972) 8161

56. Stenflo, J. J.Biol.Chem. 247 (1972) 8167

57. Nelsestuen, G.L. and Suttie, J.W. J.Biol.Chem. 247 (1972) 8176

58. Nelsestuen, G.L. and Suttie, J.W. Biochem.Biophys.Res.Commun. 45 (1971) 198

59. Skaug, K. and Christensen, T.B. Biochim.Biophys.Acta 230 (1971) 627 
60. Henriksen, A., Christensen, T.B. and Helgeland, L. Biochim. Biophys. Acta 421 (1976) 348

61. Josso, F., Lavergne, J.M., Gouault, M., Prou-Wartelle, 0. and Soulier, J.P. Thrombos.Diathes.haemorrh. 20 (1968) 88

62. Bas, B.M., Muller, A.D. and Hemker, H.C. Biochim.Biophys.Acta 379 (1974) 164

63. Esmon, C.T., Owen, W.G. and Jackson, C.i. J.Biol.Chem. 249 (1974) 7798

64. Gitel, S.H., Owen, W.G., Esmon, C.T. and Jackson, C.M. Proc.Nat1. Acad.Sci. USA 70 (1973) 1344

65. Stenflo, J. and Ganrot, P.0. Biochem. Biophys.Res.Commun. 50 (1973) 98

66. Nelsestuen, G.L. and Suttie, J.W. Biochem. 11 (1972) 4961

67. Benson, B.J., Kisiel, W. and Hanahan, D.J. Biochim.Biophys.Acta 329 (1973) 81

68. Bjork, I. and Stenf10, J. FEBS Letters 32 (1973) 343

69. Henriksen, R.H. and Jackson, C.H. Arch.Biochem.Biophys. 170 (1975) 149

70. Nelsestuen, G.L. and Suttie, J.W. Proc.Nat1.Acad.Sci. USA 70 (1973) 3366

71. Stenflo, J. J.Biol.Chem. 249 (1974) 5527

72. Magnusson, S. Thrombos.Diathes.haemorrh. Suppl. 54 (1973) 31

73. Skotland, T., Holm, T., Osterud, B., Flengsrud, R. and Prydz, H. Biochem.J. 143 (1974) 29

74. Stenflo, J., Fernlund, P., Egan, W. and Roepstorff, P. Proc.Nat1. Acad.Sci.USA 71 (1974) 2730

75. Nelsestuen, G.L., Zytkovicz, T.H. and Howard, J.B. J.Biol.Chem. 249 (1974) 6347

76. Magnusson, S., Sottrup-Jensen, L., Petersen, T.F., Morris, H.R. and Dell, A. FEBS Letters 44 (1974) 189

77. Morrison, S.A. and Esnouf, M.P. Nature 242 (1973) 92

78. Halhotra, O.P. Thrombos.Diathes.haemorrh. Supp1. 57 (1974) 69

79. Prowse, C.V., Mattock, P., Esnouf, M.P. and Russell, A.M. Biochim.Biophys.Acta 434 (1976) 265 
80. Esnouf, M.P. and Prowse, C.V. Biochim. Biophys. Acta 490 (1977) 471

81. Fujikawa, K., Coan, M.H., Enfield, D.L., Titani, K., Ericsson, L.H. and Davie, E.W. Proc.Natl.Acad.Sci.USA 71 (1974) 427

82. Howard, J.B. and Nelsestuen, G.L. Proc.Nat1.Acad.Sci. USA 72 (1975) 1281

83. Fryklund, L., Borg, H.and Andersson, L.0. FEBS Letters 65 (1976) 187

84. Enfield, D.L., Ericsson, L.H., Walsh, K.A., Neurath, H. and Titani, K. Proc.Natl.Acad.Sci. USA 72 (1975) 16

85. Esmon, C.T., Suttie, J.W. and Jackson, C.M. J.Biol.Chem. 250 (1975) 4095

86. Esmon, C.T., Sadowski, J.A. and Suttie, J.W. J.Biol.Chem. 250 (1975) 4744

87. Friedman, P.A. and Shia, M. Biochem. Biophys.Res.Commun. 70 (1976) 647

88. Girardot, J.l., Mack, D.0., Floyd, R.A. and Johnson, B.C. Biochem. Biophys.Res.Commun. 70 (1976) 655

89. Sadowski, J.A., Esmon, C.T. and Suttie, J.W. J.Biol.Chem. 251 (1976) 2770

90. Suttie, J.W., Hageman, J.M., Lehrman, S.R. and Rich, D.H. J.Biol.Chem. 251 (1976) 5827

91. Vermeer, C., Soute, B.A.M., Govers-Riemslag, J. and Hemker,H.C. Biochim.Biophys.Acta 444 (1976) 926

92. Willingham, A.K. and Matschiner, J.T. Biochem.J. 140 (1974) 435. 
IDENTIFICATION, PURIFICATION AND PROPERTIES OF THE PHENPROCOUMON INDUCED DECARBOXY FACTOR $X$ (PIVKA-X) FROM BOVINE PLASMA A comparison to normal factor $X$

\section{SUMMARY}

1. An abnormal blood coagulation factor (PIVKA-X) analogous to factor $X$ was identified in plasma from phenprocoumon treated cows by immunological techniques.

2. By a procedure involving adsorption to barium sulfate, chromatography on DEAE-Sephadex and QAE-Sephadex and preparative polyacrylamide gel electrophoresis, PIVKA-X was purified from plasma of phenprocoumon treated cows. No contaminants could be detected in the final preparation by polyacrylamide gel electrophoresis and zone-electrophoresis.

3. The molecular weight of PIVKA-X as determined by SDS polyacrylamide ge 7 electrophoresis is approximately 55,000 which is equal to that of factor $x$. The protein consists of two polypeptide chains with molecular weights of 44,000 and 17,000.

4. PIVKA-X has antigenic determinants in common with normal factor $X$.

5. The amino acid composition and amino-terminal amino acids of normal factor $X$ and PIVKA-X are identical.

6. Less than one residue of $y$-carboxyglutamate could be detected per mole of PIVKA-X

7. In the absence of $\mathrm{Ca}^{2+}$ ions, normal factor $X$ has a slightly higher electrophoretic mobility than PIVKA-X. In the presence of $\mathrm{Ca}^{2+}$ ions the mobility of factor $X$ decreases considerably while the mobility of PIVKA-X remains unaltered. 


\section{INTRODUCTION}

In several laboratories a decarboxy prothrombin (PIVKA-II) present in plasma of dicoumarol treated cows has been extensively purified and characterized (1-4). The structural comparison of normal and dicoumarol induced prothrombin has been the subject of intensive investigation in recent years (5-9). Prothrombin contains a number of $\gamma$-carboxyglutamic acid residues in the amino-terminal region, whereas glutamic residues are found in the amino-terminal region of PIVKA-II.

Recently, it has been reported that two other vitamin $K$ dependent coagulation factors (i.e. factor $I X$ and factor $X$ ) also contain $\gamma$-carboxyglutamic acid residues (10-13).

Experiments on the biosynthesis of prothrombin (14-16) confirm the earlier suggestion of Hemker et al. (17) that PIVKA-II is a precursor of normal prothrombin accumulating because of a decreased turnover of the vitamin $K$ dependent conversion of PIVKA-II into prothrombin.

Since there are four vitamin $K$ dependent coagulation factors, one can postulate the existence of four PIVKAs. These proteins will be referred to as PIVKA-II, PIVKA-VII, PIVKA-IX, and PIVKA-X.

We reported earlier the demonstration of both PIVKA-IX and PIVKA-X $(18,19)$. In this chapter we describe the identification, purification, and partial characterization of PIVKA-X. Because of the low concentration of factor $X$ in plasma $(10-15 \mathrm{mg} / 1)$ large amounts of plasma are needed as a starting material and therefore bovine plasma was used. Moreover, well established procedures are available for the purification of normal bovine factor $X(20,21)$. Another reason to study the bovine system is that more is known about the structure of bovine factor $x$ than that of human factor $x(12,22,23)$. MATERIALS

Normal bovine factors II, IX, and $X$ used for the inmunization of 
rabbits were purified according to the method of Reekers (24). Common inorganic chemicals (reagent grade), barium sulfate, acrylamide, $N^{\prime}, N^{\prime}$-methylene bisacrylamide and benzamidine hydrochloride were obtained from Merck, Darmstadt, GFR.

Marcoumar was a kind gift of Dr.M.Kunz (Hoffmann-La Roche, Basle, Switzerland). DEAE-Sephadex and QAE-Sephadex (Pharmacia, Uppsala, Sweden) were equilibrated according to the instructions supplied by the manufacturers. Agarose was a product of Koch-Light Laboratories Ltd. Aluminum hydroxide, moist gel was purchased from British Drug Houses Ltd. Sodium dodecyl sulfate (Koch-Light laboratories Ltd.) was recrystallized from ethanol. Bovine serum albumin, glutamate dehydrogenase, ovalbumin, carbonic anhydrase, lysozyme, myoglobin, a-chymotrypsin-A, soybean tryps in inhibitor, di isopropylfluorophosphate and dansylchloride were obtained from Sigma Chemical Co. Reference dansylamino acids were supplied by Calbiochem A.G. Polyamide layer sheets were obtained from Merck. Vitamin $K$ and heparin were purchased from Hoffmann-La Roche.

METHODS

Preparation of rabbit antibovine factor II and IX antiserum. Antisera were prepared in rabbits by injection of purified preparations of bovine factor II and factor IX (18). Antisera were adsorbed with barium sulfate $(100 \mathrm{mg} / \mathrm{ml})$ for $30 \mathrm{~min}$ at room temperature and heat inactivation was performed for $30 \mathrm{~min}$ at $56^{\circ} \mathrm{C}$ in order to remove procoagulant activity. The adsorbed and inactivated antisera were centrifuged for one hour at $105,000 \mathrm{~g}$ at $4^{\circ} \mathrm{C}$. Sodium merthiolate $(0.01 \%$ final concentration) was added before storage at $-20^{\circ} \mathrm{C}$.

Preparation of rabbit anti-bovine factor $x$ antiserum. The first intramuscular injection was given with $1.0 \mathrm{ml}$ factor $x_{2}(0.2 \mathrm{mg} / \mathrm{ml})$ mixed with $1.0 \mathrm{ml}$ complete Freund adjuvant. A second and third intramuscular injection of $1.0 \mathrm{ml}$ factor $x_{2}(0.2 \mathrm{mg} / \mathrm{ml})$ mixed with $1.0 \mathrm{ml}$ incomplete Freund adjuvant was given after intervals of 3 weeks. Plasmaphoresis was performed after the second month. Antisera were 
treated as described above.

Gel electrophoresis. Analytical polyacrylamide gel electrophores is was performed according to Ornstein (25) using a Tris-HClglycinate buffer system as described by Davis (26). Polyacrylamide gel electrophoresis in sodium dodecyl sulfate was carried out according to Weber and Osborn (27). Bovine serum albumin, glutamate dehydrogenase, ovalbumin, carbonic anhydrase, a-chymotrypsinogen $A$, myoglobin, and lysozyme were used as markers for the molecular weight estimation, using molecular weights given by Weber and Osborn (27). The gels were stained according to Fairbanks (28). Equipment for analytical polyacrylamide gel electrophoresis was obtained from Buchler Instruments (Polyanalyst).

Agarose gel electrophoresis was carried out in 1.5 mill thick $1 \%$ agarose gels in $0.05 \mathrm{M}$ barbital buffer $\mathrm{pH} 8.6$ containing $2.0 \mathrm{mM}$ Ca-lactate or $2.0 \mathrm{mM}$ EDTA according to Johansson (29). Electrophoresis was run at 15 volts per $\mathrm{cm}$ on a glass plate and cooled by water of $10^{\circ} \mathrm{C}$. The gels were fixed in $10 \%$ trichloroacetic acid and stained with Coomassie Brilliant blue G (Sigma Chem.Co) in 10\% acetic acid. A LKB Multiphor 2117 apparatus was used.

Immunochemical methods. PIVKA- $X$ was immunochemically quantitated with the technique of Laurell (30). Electrophoresis was performed (10 volts/cm for 3 hours) into a $1 \%$ agarose gel containing $1 \%$ antibovine factor $X$ antiserum, using $0.05 \mathrm{M}$ barbital buffer $\mathrm{pH} 8.6$ in the presence of $2.0 \mathrm{mM} \mathrm{Ca-lactate.} \mathrm{As} \mathrm{standard} \mathrm{was} \mathrm{used} \mathrm{a} \mathrm{plasma}$ obtained from a cow under deep anticoagulation (factor $X$ activity less than $5 \%$ ). One unit is arbitrarily defined as the concentration of factor $X$ related antigen in $1.0 \mathrm{ml}$ of standard plasma.

The crossed immunoelectrophores is was carried out according to Laurell (31) on glass plates $(10 \times 20 \mathrm{~cm})$. Agarose gel $1 \%$ in $0.05 \mathrm{M}$ barbital buffer $\mathrm{pH} 8.6$ containing $2.5 \mathrm{mM}$ Ca-1actate or EDTA in the first dimension was used. After the first dimension run, the agarose gel $0.5 \mathrm{~cm}$ above the slit was replaced by $1 \%$ agarose containing $0.5 \%$ anti-bovine factor $X$ antiserum and $1.0 \mathrm{mM}$ 
Ca-lactate. Electrophoresis in the second dimension was continued for 4 hours at 10 volts $/ \mathrm{cm}$. After the completion of the electrophoresis the gel was washed overnight in saline-phosphate solution, then washed in distilled water for 2 hours, dried and stained with 0.025, Coomassie Brilliant blue $R$ in methanol-water-acetic acid (450:450:100). Analyses were performed in a LKB multiphor 2117 apparatus. Double immunodiffusion was carried out according to Ouchterlony (32).

For coagulation factor neutralization tests, plasma samples were incubated for $30 \mathrm{~min}$ at $37^{\circ} \mathrm{C}$ with antiserum. The mixture was left overnight at $4^{\circ} \mathrm{C}$ and centrifuged for one hour at $18,000 \mathrm{~g}$. Coagulation factor activities in the supernatant were assayed in one-stage assays using human deficient plasmas as reagents. In control experiments the antiserum was replaced by normal rabbit serum treated in the same way as described for the antiserum.

Coagulation factor assay. Coagulation times specifically dependent on the concentrations of factor II, VII, and $X$ were obtained by mixing in a test tube at $37^{\circ} \mathrm{C}: 0.1 \mathrm{ml}$ bovine plasma artificially deficient in either factor II, VII, or $X, 0.1 \mathrm{ml}$ sample and $0.1 \mathrm{ml}$ bovine brain thromboplastin, prepared according to owren (33). The coagulation reaction was started by adding $0.1 \mathrm{ml} \mathrm{CaCl}_{2}$ solution (33 m/li). Coagulation factor concentrations are expressed as a percentage of the content in a normal bovine plasma pool, obtained from 20 cows. The concentrations were calculated from the coagulation times in specific tests as described by Hemker et al. (34). It is defined that $1 \mathrm{ml}$ bovine plasma with a blood coagulation factor activity of $100 \%$ contains 1 unit activity of each of the factors.

Preparation of normal bovine factor $X$. Bovine factor $X$ was prepared by a modified method of Jackson (20) and Fujikawa (21). Bovine blood was collected in an anticoagulant solution, containing $0.1 \mathrm{M}$ sodium oxalate, $0.01 \mathrm{M}$ benzamidine hydrochloride, two units heparin per $\mathrm{ml}$ and $5 \mathrm{mg}$ crude soybean trypsin inhibitor per litre. The plasma was 
separated by centrifugation in a MSE Mistral 61 centrifuge for $20 \mathrm{~min}$ at $2500 \mathrm{rpm}$ and $4^{\circ} \mathrm{C}$. In a representative purification 30 litres of bovine plasma were used.

Step 1: barium sulfate adsorption. Barium sulfate suspended in $0.45 \%(\mathrm{~W} / \mathrm{v}) \mathrm{NaCl}$ in $1 \mathrm{mM}$ Tris buffer $\mathrm{pH} 7.5$ was added to the plasma $(10 \mathrm{mg} / \mathrm{ml})$ and stirred for $30 \mathrm{~min}$ at $4^{\circ} \mathrm{C}$ followed by centrifugation at $1500 \mathrm{~g}$ for $5 \mathrm{~min}$. The barium sulfate cake was dispersed with an UTtra Turrax (IKA type TP 18/10) at high speed for 2 min. in $500 \mathrm{ml}$ $0.45 \%(\mathrm{w} / \mathrm{V}) \mathrm{NaCl}$ in $1 \mathrm{mM}$ Tris buffer $\mathrm{pH} 7.5$. The barium sulfate was removed by centrifugation and the dispersion-washing procedure was repeated three times. Protein was eluted from the barium sulfate with $1500 \mathrm{ml} 0.06 \mathrm{M}$ trisodium citrate buffer $\mathrm{pH} 5.8$ containing $0.01 \mathrm{M}$ benzamidine hydrochloride and $40 \mathrm{mg}$ purified soybean trypsin inhibitor per litre, by stirring at $4^{\circ} \mathrm{C}$ for $30 \mathrm{~min}$. This step was repeated once.

Step 2: DEAE - Sephadex adsorption and elution. The combined eluates (3000 $\mathrm{ml})$ were adjusted with $1 \mathrm{M} \mathrm{NaOH}$ to $\mathrm{pH} \mathrm{7.1.} \mathrm{A} \mathrm{slurry} \mathrm{settled}$ by gravity of DEAE-Sephadex $(75 \mathrm{ml})$ equilibrated in $0.06 \mathrm{M}$ trisodium citrate in $0.05 \mathrm{M}$ Tris-HCl buffer $\mathrm{pH} 7.1$ was added to the eluate and stirring was continued for about 30 min at room temperature until factor $X$ activity was bound to the DEAE-Sephadex. The DEAESephadex was removed from the solution by filtration on a Buchner funnel on a 60 mesh nylon cloth and washed with $1000 \mathrm{ml} 0.06 \mathrm{M}$ trisodium citrate in $0.05 \mathrm{M}$ Tris-HCl buffer $\mathrm{pH} 6.8$, followed by $1000 \mathrm{ml}$ of the same buffer adjusted to $\mathrm{pH} \mathrm{8.0.} \mathrm{The} \mathrm{DEAE-Sephadex}$ was resuspended in last buffer and packed into a column $(45 \times 2.5 \mathrm{~cm})$ onto a $3 \mathrm{~cm}$ high DEAE-Sephadex layer.

Factor $X$ was eluted with a linear gradient of $0.1-0.6 \mathrm{M} \mathrm{NaCl}$ in $0.05 \mathrm{M}$ Tris-HCl buffer containing $0.1 \mathrm{M}$ trisodium citrate and $1 \mathrm{mM}$ benzamidine hydrochloride at $\mathrm{pH}$ 8.0. Each gradient chamber contained $300 \mathrm{ml}$ solution. A flow rate of $50 \mathrm{ml} /$ hour was maintained during elution and $5 \mathrm{ml}$ fractions were collected. 
Step 3: QAE-Sephadex chromatography. The factor $X$ containing fractions eluted from the DEAE-Sephadex column were pooled, dialyzed overnight against $0.05 \mathrm{M}$ trisodium citrate $\mathrm{pH} 7.0$ containing $1 \mathrm{mM}$ benzamidine hydrochloride and applied to a column $(30 \times 2.5 \mathrm{~cm})$ of QAE-Sephadex equilibrated with the same buffer. The column was washed with $250 \mathrm{ml} 0.1 \mathrm{M}$ trisodium citrate buffer $\mathrm{pH} \mathrm{7.0.} \mathrm{Factor}$ $X$ was eluted with a linear gradient of $0.10-0.35 \mathrm{M}$ trisodium citrate buffer $\mathrm{pH} 7.0$ containing $1 \mathrm{mM}$ benzamidine hydrochloride with $400 \mathrm{ml}$ in each gradient chamber. The flow rate was $20 \mathrm{ml} /$ hour and $5 \mathrm{ml}$ fractions were collected. The factor $x_{1}$ and $x_{2}$ containing fractions were pooled separately and concentrated in a Diaflow ultrafiltration cell equipped with a PM-10 membrane (Amicon Corp. node1 202). The concentrate was adjusted to $\mathrm{pH} 8.1$ with $1.0 \mathrm{M}$ Tris-HCl buffer $\mathrm{pH} 8.6$. DFP (1.0 M in 2-propano1) was added to a final concentration of $1 \mathrm{mM}$ and incubated for $60 \mathrm{~min}$. at $4^{\circ} \mathrm{C}$. After dialys is against $0.025 \mathrm{M}$ Tris- $\mathrm{HCl}$ buffer $\mathrm{pH} 7.4-0.12 \mathrm{M}$ in $\mathrm{NaCl}$ during 48 hours at $4{ }^{\circ} \mathrm{C}$ with four changes, the factor $X_{1}$ and $X_{2}$ preparations were stored at $-80^{\circ} \mathrm{C}$.

Induction of PIVKA-X in the cow. Four cows, weighing about $500 \mathrm{~kg}$ each, were orally given $600 \mathrm{mg}$ Marcoumar the first day, followed by $200 \mathrm{mg}$ daily for 4-6 days. Blood samples were drawn from a jugular vein each day during the treatment and collected into polyethylene tubes $(50 \mathrm{~m} 7)$ containing $0.8 \mathrm{ml}$ of a $20 \%(w / v)$ trisodiun citrate solution. The effect of Marcounar was monitored by the assay of factor II, VII, and $X$ activity and by crossed immunoelectrophoresis of plasma samples. At a factor $X$ activity of about $10 \%$ of the normal activity, 5 1itres of blood were collected from a jugular vein of each cow in 1 litre polyethylene bottles containing $100 \mathrm{ml} 0.1 \mathrm{M}$ sodium oxalate, $10 \mathrm{mg}$ heparin, $10 \mathrm{mg}$ benzamidine hydrochloride and $5 \mathrm{mg}$ crude soybean trypsin inhibitor. Afterwards the animals were given $50 \mathrm{mg}$ vitamin $K$ intramuscularly. Plasma was obtained by centrifugation in a MSE Mistral 61 centrifuge at 2500 rpm during $20 \mathrm{~min}$. at $4^{\circ} \mathrm{C}$. 
Preparation of PIVKA-X. Bovine PIVKA- $X$ was prepared by a modified method as described for bovine factor $X$ by Jackson (20) and Fujikawa (21).

Step 1: Removal of normal factor X. Marcoumar plasma (21 1) was stirred with $30 \mathrm{~g}$ moist gel $\mathrm{Al}(\mathrm{OH})_{3}$ in $150 \mathrm{ml}$ water during $10 \mathrm{~min}$. at room temperature. The $\mathrm{Al}(\mathrm{OH})_{3}$ was removed by centrifugation at $2,000 \mathrm{~g}$ for $10 \mathrm{~min}$. at $4^{\circ} \mathrm{C}$.

Step 2: Adsorption of PIVKA-X on barium sulfate. The supernatant $(21,150 \mathrm{ml})$ was stirred with $400 \mathrm{~g}$ barium sulfate suspended in a minimal amount of $0.45 \%(\mathrm{w} / \mathrm{V}) \mathrm{NaCl}$ in $1 \mathrm{mM} \mathrm{Tris}$ buffer $\mathrm{pH} 7.5$ for $30 \mathrm{~min}$. at $4^{\mathrm{O}} \mathrm{C} . \mathrm{BaSO}_{4}$ was removed by centrifugation at $1500 \mathrm{~g}$ for $5 \mathrm{~min}$. The washing procedure of the $\mathrm{BaSO}_{4}$ cake was performed as described for the factor $X$ preparation. Protein was eluted from the $\mathrm{BaSO}_{4}$ with $1050 \mathrm{ml}$ of $0.12 \mathrm{M}$ trisodium citrate in $0.05 \mathrm{M}$ Tris$\mathrm{HCl}$ buffer pH 5.8 containing $0.01 \mathrm{mM}$ benzanidine hydrochloride and $40 \mathrm{mg}$ purified soybean trypsin inhibitor per litre, by stirring at $4^{\circ} \mathrm{C}$ for $30 \mathrm{~min}$. This step was repeated once.

Step 3: DEAE-Sephadex adsorption and elution. The combined $\mathrm{BaSO}_{4}$ eluates $(2100 \mathrm{ml})$ were diluted with an equal volume of distilled water and adjusted to $\mathrm{pH} 7.1$ with $1.0 \mathrm{M} \mathrm{NaOH}$. The batchwise adsorption and washing of the DEAE-Sephadex were carried out as described for the factor $X$ purification. In addition the DEAESephadex was washed with $1000 \mathrm{ml}$ of $0.1 \mathrm{M} \mathrm{NaCl}$ in $0.02 \mathrm{M}$ potassium phosphate buffer of $\mathrm{pH}$ 6.8. The DEAE-Sephadex was packed into a column $(45 \times 2.5 \mathrm{~cm})$ onto a $3 \mathrm{~cm}$ high DEAE-Sephadex layer equilibrated in the final washing buffer. PIVKA- $X$ was eluted using a linear gradient of $0.1-0.6 \mathrm{M} \mathrm{NaCl}$ in a $0.02 \mathrm{M}$ potassium phosphate buffer of $\mathrm{pH} 6.8$ containing $1 \mathrm{~mm}$ benzamidine hydrochloride. Each chamber contained $250 \mathrm{ml}$ of the solution. The effluent of the DEAE-Sephadex column was monitored by rocket immunoelectrophoresis according to Laurel1 (30) using a monospecific anti-bovine factor $X$ antiserum. Step 4: QAE-Sephadex chromatography. The PIVKA-X fractions from the 
DEAE-Sephadex column were pooled, dialyzed overnight against $0.05 \mathrm{M}$ trisodium citrate, $1 \mathrm{mM}$ benzamidine hydrochloride $\mathrm{pH} \mathrm{7.0.} \mathrm{The}$ same QAE-Sephadex chromatography procedure as described for factor $X$ purification was followed. PIVKA-X contailling fractions were identified by rocket immunoelectrophoresis.

Step 5: Preparative polyacrylamide gel electrophoresis. The PIVKA$x$ containing fractions from the QAE-Sephadex column were dialyzed against $2 \mathrm{mM}$ Tris-HCl-glycinate buffer $\mathrm{pH} 8.7,10 \mathrm{mM}$ in benzamidine hydrochloride and concentrated in a Diaflow 41 trafiltration cell equipped with a PM-10 membrane (Amicon Corp. model 202). Genera1ly, $40 \mathrm{mg}$ of protein in 3-4 $\mathrm{ml}$ dialysis buffer containing $20 \%(\mathrm{v} / \mathrm{V})$ sucrose was subjected to preparative polyacrylamide gel electrophoresis on a gel bed of $10 \mathrm{~cm}$ in the LKB 7900 Uniphor apparatus. Fractions of $3.0 \mathrm{ml}$ were collected. The elution buffer was pumped at a flow rate of $30 \mathrm{ml} /$ hour. Electrophoretic conditions were $700 \mathrm{~V}$ and $18 \mathrm{~mA}$.

Composition of the gel solutions: Solution A: $30 \mathrm{mg}$ acrylamide and $0.9 \mathrm{~g}$ bisacrylamide dissolved in $100 \mathrm{ml}$ water. Solution $\mathrm{B}: 0.08 \mathrm{M}$ Tris-glycine buffer $\mathrm{pH} 8.7$ and $4 \mathrm{mM}$ benzamidine HCl. Solution C: $140 \mathrm{mg}$ anmonium persulfate dissolved in $100 \mathrm{ml}$ water. Final gel solution was obtained by mixing 1 volume $A, 1$ volume $B$ and 2 volumes $C$. According to the nomenclature of Hjerten (35) $T=7.5 \%$ and $\mathrm{C}=3 \%$. Electrode chambers contained $20 \mathrm{mM}$ Tris-glycine and $1 \mathrm{mM}$ benzamidine hydrochloride at $\mathrm{pH}$ 8.7. The elution buffer was the same as the electrode buffer. The PIVKA-X containing fractions were pooled and concentrated in a Diaflow ultrafiltration cell equipped with a PM-10 menbrane (Amicon Corp. Hodel 202). The concentrate was adjusted to $\mathrm{pH} 8.1$ with $1.0 \mathrm{M} \mathrm{Tris-HCl} \mathrm{pH} 8.6$. 1.0 $\mathrm{M}$ DFP in 2-propanol was added to a final concentration of $10^{-3} \mathrm{~m}$. After dialysis against $0.025 \mathrm{M} \mathrm{Tris-HCl} \mathrm{pH} 7.40 .12 \mathrm{M} \mathrm{NaCl}$ during 48 hours with four changes, the PIVKA-X preparation was stored at $-80^{\circ} \mathrm{C}$. 
Detemination of amino-terminal amino acid. Aminoteminal amino acids were determined qualitatively by the dansylchloride procedure of Gray (36). Dansylamino acids were identified on polyamide sheets using the procedure of Weiner et al. (37).

Amino acid analysis. The amino acid composition was determined according to Spackman (38). The proteins $(0.5-1.5 \mathrm{mg})$ were hydrolyzed in $6 \mathrm{~N} \mathrm{HCl}$ in evacuated Pyrex tubes at $110^{\circ} \mathrm{C}$ for 24 hours. The analyses were performed on a LKB amino acid analyzer 3201 using the one-column system of Hamilton (39).

$\gamma$-Carboxyglutamate was determined according to a modification of the method of Zytkovicz (40). Prior to hydrolysis, proteins $(1.0 \mathrm{mg})$ were completely reduced in ${ }^{3} \mathrm{H}$-diborane after 96 hours of incubation at roon temperature. The three identified ${ }^{3} \mathrm{H}$-diborane reduction products are: homoserine (HSE), arising from the aspartic acid, 5-hydroxynorvaline (HNV) arising from glutamic acid and 5,5'-dihydroxyleucine (DHL) arising from $y$-carboxyglutamate. The specific activity of DHL is equal to haif of the specific activity of HSE and HNV. The number of $y$-carboxy glutamate residues was estimated from the calculated specific activity of DHL (49). 
RESULTS

Preparation of monospecific antisera against bovine factors II, IX, and $x$. Undiluted rabbit anti-bovine factor $x$, anti-bovine factor $I X$, and anti-bovine factor II antiserum were allowed to diffuse against undiluted bovine plasma (fig. 1). Single precipitation lines were formed, showing a monospecificity of each of the antisera. This experiment shows that factor II, factor IX, and factor $X$ have no antigenic determinants in common, because all reactions have the non-identity of both antigens and antibodies.

Neutralization test of coagulation factor activity by the antisera shows that the activities are specifically inhibited by their antibodies (table I).

TABLE I. Neutralization of coagulation factor activity by antisera.

\begin{tabular}{|l|c|l|c|c|c|}
\hline & $\begin{array}{l}\text { antiserum } \\
\text { against } \\
\text { factor }\end{array}$ & \multicolumn{4}{|l|}{$\begin{array}{l}\text { coagulation times obtained in a specif- } \\
\text { ically deficient system: }\end{array}$} \\
\cline { 2 - 6 } & f.II def. & f.VII def. & f.IX def. & f.X.def. \\
\hline bovine plasma & II & 49.3 & 23.8 & 138 & 34.1 \\
bovine plasma & $I X$ & 27.3 & 23.4 & 450 & 31.4 \\
bovine plasma & $X$ & 28.1 & 25.2 & 142 & 133.7 \\
bovine plasma & control & 27.6 & 23.8 & 135 & 34.4 \\
buffer time & & 133.0 & 126.3 & 365 & 135.5 \\
\hline
\end{tabular}

a: factor IX was assayed according to the method of Veltkanp et al.(50). 
6
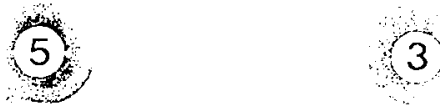

fig. 1.

Double imnunodiffusion pattern of the anti-

bodies used. Centre vell: normal bovine plasma; wells 1 and 4 : anti-factor II antiserum; viells 2 and 5: anti-factor $1 X$ antiserum; wells 3 and 6 : anti-factor $x$ antiserum.

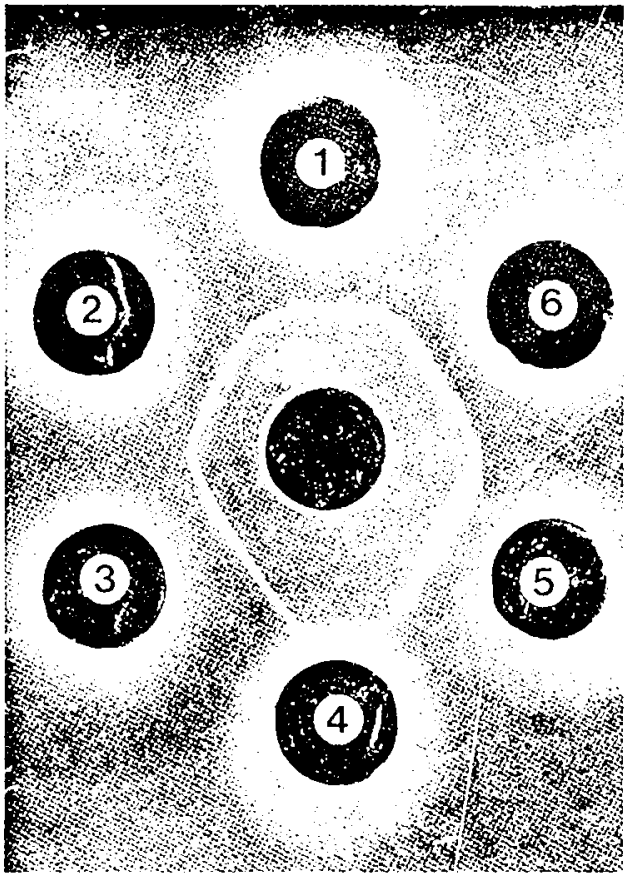

Fig. 2 .

Double immunodiffusian. Centre well: contains anti-bovine factor $x$ antiserum. 1: nomal plasma; 2: coumarin plasma; 3: $\mathrm{Al}(\mathrm{OH})_{3}$-adsorbed coumar in plasma; a. $\operatorname{il}(\mathrm{OH})_{3}$-adsorbed normal plasnia; 5: normal serum; 6: coumarin serum. 
Demonstration of PIVKA-X after administration of phenprocoumon. Imunodiffusion. In a double immunodiffusion test (fig. 2) antibovine factor $x$ antiserum revealed single and completely identical precipitation lines against: a. normal bovine citrated plasma; b. bovine citrated plasma obtained after oral anticoagulation of a cow (less than 5 factor $X$ activity); $c$. the same plasma adsorbed with $\mathrm{Al}(\mathrm{OH})_{3}(2 \mathrm{mg} / \mathrm{ml})$; d. serum of an anticoagulated cow and $e$. the same serum adsorbed with $\mathrm{Al}(\mathrm{OH})_{3}(2 \mathrm{mg} / \mathrm{ml})$. No precipitation line is seen with normal plasma adsorbed with $\mathrm{Al}(\mathrm{OH})_{3}(2 \mathrm{mg} / \mathrm{ml})$. It is shown that the factor $X$ related antigen present in phenprocoumon plasma (PIVKA-X) has antigenic determinants in common with factor $X$ in normal plasma.

Crossed inmunoelectrophoresis. Two-dimensional immunoelectrophores is of normal plasma (factor $X$ activity 100;) performed in the presence of $2.5 \mathrm{mM}$ Ca-lactate, showed one peak but the plasma taken 24 hours after the start of the phenprocoumon treatment (factor $x$ activity 4G.) showed a second peak with a higher anodical mobility. In the plasma of the same cow after 4 days of phenprocoumon treatment only the anodical peak remained and less than $5 \%$ factor $X$ activity was measured (fig. 3).

The gradual increase of an abnormal factor $X$ with antigenic determinants in common with normal factor $X$ but with a higher electrophoretic mobility was accompanied by a decrease of factor $x$ activity during phenprocoumon treatment.

Complete blocking of factor $X$ synthesis, resulting in the appearance of PIVKA-X parallel with the disappearance of factor $X$ was also confirmed by rocket immunoelectrophoresis analysis of plasmas obtained at different stages of anticoagulation. As shown in fig. 4, factor $x$ activity decreased after starting the anticoagulant treatment, but no alterations could be demonstrated in the immunochemically determined concentration of factor $X$ related antigen. However, after adsorption of these plasmas onto $\mathrm{Al}(\mathrm{OH})_{3}(2 \mathrm{mg} / \mathrm{ml})$ an increasing amount of unadsorbable factor $X$ related antigen (PIVKA-X) is observed during the time course of the treatment. 
b

iig. 3 .

Crossed immunoelectrophores is of bovine plastia in the presence of calcium (first dimension, norizontal) and anti-factor $x$ antiserum (second dimension, vertical). a: normal plasma, b: plasma after $24 \mathrm{~h}$ anticoagulation, $c$ : plasma after 100 h anticoagulation.

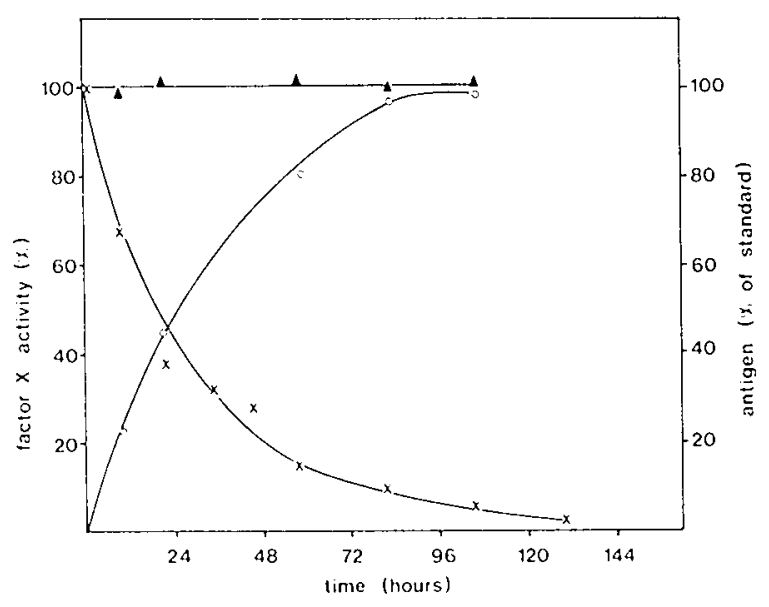

Fig. $\dot{4}$.

Effect of phenprocoun tren treatment on factor $x$ activity.

A cow weighing $600 \mathrm{~kg}$ was anticoagulated with $600 \mathrm{kilg}$ phenprocoumon the first day and furtheron $200 \mathrm{~m}$ daily. Factor $i$ was detemined with the one-stage assay $\{\mathbf{x}\rangle$. Determination of factor $x$ related antigen in plasila by rocket imirunoelectrophoresis $(\mathbf{A})$. Detemination of factor a related antigen in plasma adsorbed with 0.2 (w/v) Ailoii) 3 by rocket immoelecirophoresis $(0)$. Detailed experimental conditions are described under rethods. 
TABLE II. Purification of factor $x$ from bovine oxalated plasma. Results of a representative experiment starting with 30 litres of bovine plasma.

\begin{tabular}{|l|c|c|c|c|c|c|}
\hline Fraction & $\begin{array}{c}\text { Volume } \\
(\mathrm{ml})\end{array}$ & $\begin{array}{c}\text { Concentration } \\
\text { (units / ml })\end{array}$ & $\begin{array}{c}\text { Protein } \\
\text { (mg/ml) }\end{array}$ & $\begin{array}{c}\text { Spec.act. } \\
\text { (units/ } \\
\text { (mg) })\end{array}$ & $\begin{array}{c}\text { Yield } \\
\text { (c) }\end{array}$ & $\begin{array}{l}\text { Purific- } \\
\text { ation } \\
\text { (fold) }\end{array}$ \\
\hline Plasma & 30,000 & 1.0 & 75 & 0.013 & 100 & 1 \\
BaSO $_{4}$ eluate & 3,000 & 4.1 & 1.5 & 2.7 & 40 & 210 \\
DEAE-Sephadex & 250 & 30 & 0.50 & 37 & 25 & 2,900 \\
QAE-Sephadex $x_{1}$ & 115 & 30 & 0.40 & 75 & 12 & 6,000 \\
QAE-Sephadex $x_{2}$ & 110 & 20 & 0.35 & 74 & 9 & 6,000 \\
\hline
\end{tabular}

TABLE III. Purification of PIVKA-X from coumarin bovine oxalated plasma. Results of a representative experiment starting with 21 litres of bovine plasma.

\begin{tabular}{|l|r|c|c|c|c|c|}
\hline Fraction & $\begin{array}{r}\text { Volume } \\
(\mathrm{ml})\end{array}$ & $\begin{array}{c}\text { Concentration } \\
\text { (units/m1) }\end{array}$ & $\begin{array}{c}\text { Protein } \\
(\mathrm{mg} / \mathrm{ml})\end{array}$ & $\begin{array}{c}\text { Spec.act. } \\
\text { (Units/mg) }\end{array}$ & $\begin{array}{c}\text { Yield } \\
(\text { ) })\end{array}$ & $\begin{array}{l}\text { Purific- } \\
\text { action } \\
\text { (fold) }\end{array}$ \\
\hline plasma & 21,000 & 1.0 & 77 & 0.013 & 100 & 1 \\
BaSO 4 eluate & 2,100 & 2.5 & 5.9 & 0.4 & 25 & 33 \\
DEAE-Seph. & 237 & 13.3 & 1.2 & 11.0 & 15 & 850 \\
QAE-Seph. & 220 & 10.3 & 0.4 & 25.0 & 10 & 1,900 \\
Prep.p.a.a.e. & 56 & 4.3 & 0.1 & 43.0 & 1 & 3,000 \\
\hline
\end{tabular}

a: One half of the PIVKA-X preparation after QAE-Sephadex was submitted to preparative polyacrylamide gel electrophoresis. 


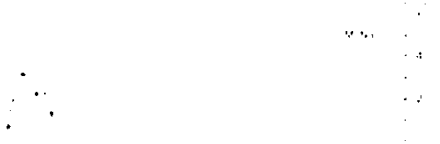

Fig. í.

Step 2 in factor $x$ preparation. DEAE-Sephadex chromatography of $\mathrm{BaSO}_{4}$-eluate in 0.06 it trisodium citrate, $0.05 \mathrm{MT} \mathrm{Tris}-\mathrm{liCl}$ buffer, pH 8.0. After washing the column with 175 ml of a solution of $0.1 \mathrm{H} \mathrm{HaCl}, 0.1 \mathrm{H}$ trisodium citrate, $0.05 \mathrm{M}$ Tris-HCl buffer $\mathrm{pH} 8.0$, a gradient of $2 \times 300 \mathrm{ml}$ was started, ranging from $0.1 \mathrm{if}$ to $0.6 \mathrm{H} \mathrm{NaCl}$ in $0.1 \mathrm{int}$ tri-

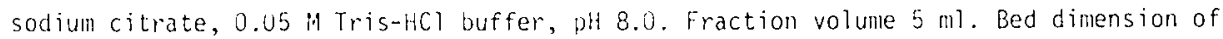
anion exchanger $40 \times 2.5 \mathrm{~cm}$. Flow rate of $50 \mathrm{ml} /$ hour. Absorbance at $280 \mathrm{~nm}(\bullet)$; factor $x$ activity $(0)$; gradient $(-)$.

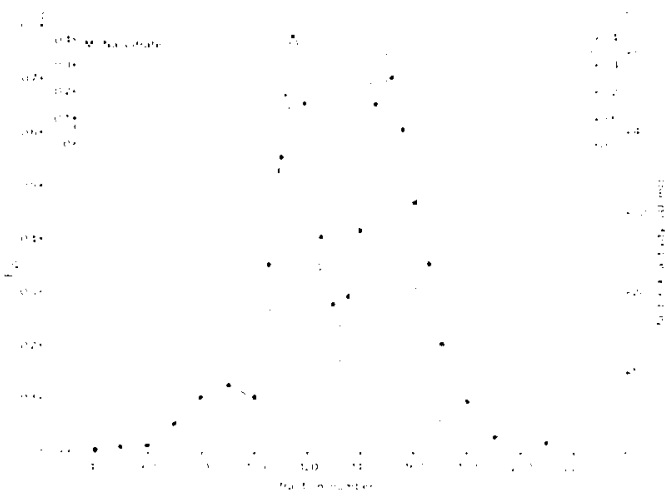

Fig. 6 .

Step 3 in factor $X$ preparation. QAE-Sephadex chromatography of factor $X$ containing fractions from DEAE-Sephadex. $250 \mathrm{~m} /$ of protein solution $(0 . \hat{\sigma} \mathrm{mg} / \mathrm{ml})$ in $0.05 \mathrm{H} \mathrm{tri-}$ sodium citrate buffer pH 7.0 was applied to QAE-Sephadex equilibrated in the same buffer. After washing the column with $250 \mathrm{ml}$ of 0.1 in trisodium citrate buffer $\mathrm{pH} 7.0$, a gradient was applied ranging from $0 . \mathrm{i}-0.35 \mathrm{H}$ trisodium citrate buffer pH 7.0. Each charber contains $400 \mathrm{ml}$ solution. Bed dimensions of anion-exchanger $30 \times 2.5 \mathrm{~cm}$. Flow rate of $20 \mathrm{ml} /$ hour and fraction volume $5 \mathrm{ml}$. Absorbance at $280 \mathrm{~nm}(\bullet)$, factor $x$ activity (o), gradient $(-)$. 
Preparation of factor $X$. The preparation of normal factor $X$ is summarized in table II. The purification is based on the method of Jackson (20) and Fujikawa (21). The amount of $\mathrm{BaSO}_{4}(10 \mathrm{mg} / \mathrm{ml})$ used, adsorbed nearly quantitatively factor $X$ activity, Teaving 40, factor I I activity in the supernatant. In our hands elution of the $\mathrm{BaSO}_{4}$ cake with $0.06 \mathrm{M}$ trisodium citrate buffer $\mathrm{pH} 5.8$ results in a considerable loss in yield. Higher citrate concentrations and higher $\mathrm{pH}$ of the elution buffer does not give better results. Inactivation by $\mathrm{BaSO}_{4}$ may be a possibility (41).

Baichwise adsorption of factor $X$ activity from the $\mathrm{BaSO}_{4}$ eluate onto DEAE-Sephadex was chosen to make possible handling of larger volumes of solution. Moreover, under the conditions used, factor II activity does not adsorb and factor VII activity adsorbs approximately for $60 ;$ to DEAE-Sephadex. In fig. 5 the elution profile of the DEAE-Sephadex column is shown. Factor $X$ activity was eluted as a double peak at $0.18 \mathrm{M} \mathrm{NaCl}$ and $0.22 \mathrm{M} \mathrm{NaCl}$.

Chromatography of the combined factor $X$ eluted from the DEAE-Sephadex on QAE-Sephadex equilibrated in $0.05 \mathrm{M}$ trisodium citrate buffer $\mathrm{pH} 7.0$ revealed two factor $X$ preparations eluted at 0.20 and $0.25 \mathrm{M}$ trisodium citrate respectively (fig. 6). According to Jackson (42) and Fujikawa (21) they were identified as factor $x_{1}$ and $x_{2}$. Both factor $X$ preparations have about the same specific activity. The work of Neal et al. (43) suggested a difference in y-carboxyglutamate content of the factor $X$ preparations.

The bovine factor $x_{1}$ and $x_{2}$ preparations were free of the vitamin $k$ dependent coagulation factors II, VII, and IX. Jackson reported a high susceptibility of factor $x$ to proteolytic enzymes (44). In our hands a proper yield of factor $X$ could only be obtained by collection of the blood in the presence of heparin, benzamidine and soybean trypsin inhibitor and by addition of benzamidine to all buffers used. Preparation of PIVKA-X. The purification of PIVKA-X was based on the method described for factor $X$ preparations. A representative purification 


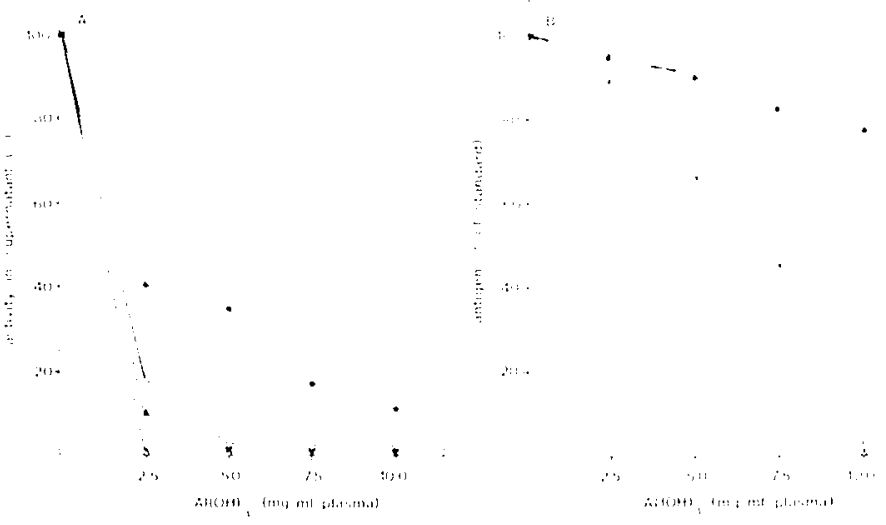

rig. 7.

Adsorption studies of factor $I I, I X$, and $X$ and their analog PIVKAs onto $A 1(O H)_{3}$ from oxala ted plasma.

A. factor Il activity $(\bullet)$, factor $V I$ l activity $(\mathbf{A})$, factor IX activity $(\mathbf{0})$, and factor $X$ activity $(\mathbf{x})$. Activity in the supernatant was determined by one-stage assays.

B. PIVKA-II ( $)$, PIVKA-IX $(0)$, and PIVKA-X $(x)$, concentrations in the supernatant. The adsorption experiments were carried out with coumarin piasma with less than 5 of the normal factors $I i, I X$, and $X$. The concentration of the PIUKAs was determined by rocket immunoelectrophores is $(30)$.

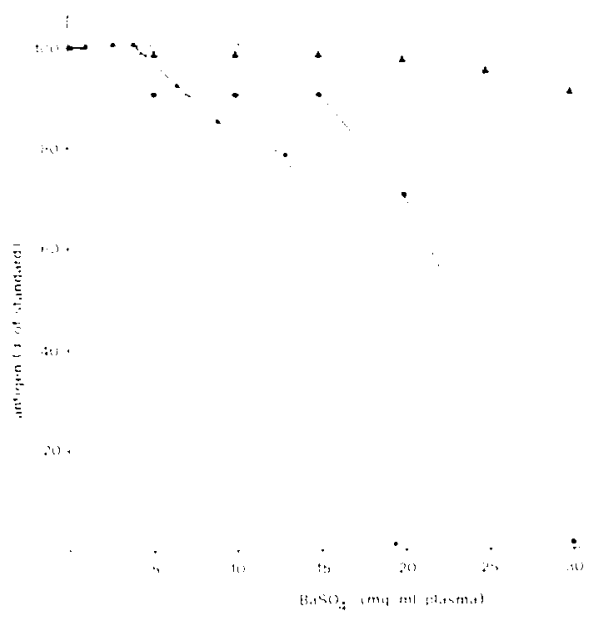

Fig. 8. BaSO ${ }_{4}$ adsorption of PIVKA-II (o), PIVKA-IX (A), and PIVKA-X (•) from oxalated couriarin plasma and factor $x$ ( $*$ from oxalated normal plasma. Concentrations in the supernatant as detemined by rocket immunoelectrophores is (30). Letailed experimental conditions are described under irethods. 
of PIVKA- $X$ is summarized in table III.

The fact that PIVKAs not adsorb to insoluble barium salts has been reported by several investigators $(4,45-48)$. Fig. 2 shows that PIVKA-X differs from factor $X$ since it does not adsorb to $\mathrm{Al}(\mathrm{OH})_{3}$ up to $2 \mathrm{mg} / \mathrm{ml}$. Adsorption of the factors II, IX, and $X$ and their analog PIVKAs onto $\mathrm{Al}(\mathrm{OH})_{3}$ from oxalated plasma was studied further as is shown in fig. 7. It was found that an $\mathrm{Al}(\mathrm{OH})_{3}$ concentration of $2.5 \mathrm{mg} / \mathrm{ml}$ quantitatively adsorbs factor $X$, while about 20 factor IX activity and 40 factor II activity remains in the supernatant. In comparison with the normal factors, the PIVKAs have a much lower affinity for $\mathrm{Al}(\mathrm{OH})_{3}$ (fig. $\left.7 \mathrm{~B}\right)$. At an $\mathrm{Al}(\mathrm{OH})_{3}$ concentration of $10 \mathrm{mg} / \mathrm{ml}$, PIVKA-X is quantitatively adsorbed, while about $90 \%$ of the factor II and factor IX related antigen remains in the supernatant.

From these results it is obvious that normal factor $x$ activity may be removed from oxalated plasma obtained by phenprocoumon treated cows by adsorption with $1.5 \mathrm{mg} / \mathrm{ml} \mathrm{Al}(\mathrm{OH})_{3}$, without a loss of PIVKA-X. Unlike reported by Gaudernack $(47,48)$, fig. 8 shows the possibility to remove the factor $X$ related antigen from the plasma by adsorption onto $\mathrm{BaSO}_{4}$. Addition of $30 \mathrm{mg} \mathrm{BaSO} / \mathrm{ml}$ plasma results in a quantitative adsorption of PIVKA-X. It is further shown in fig. 8 that PIVKA-II and PIVKA-IX at this $\mathrm{BaSO}_{4}$ concentration are only adsorbed for about $10 \%$. Batchwise adsorption of the plasma, treated with $\mathrm{BaSO}_{4}$, with QAESephadex, equilibrated in $0.02 \mathrm{M} \mathrm{Tris-HCl}$ buffer $\mathrm{pH} 7.4$ containing $0.1 \mathrm{M} \mathrm{NaCl}$ and subsequently elution by a gradient of $0.1 \mathrm{M}$ to $0.4 \mathrm{M} \mathrm{NaCl}$ only revealed PIVKA-II and PIVKA-IX (eluted both at $0.2 \mathrm{M} \mathrm{NaCl})$. No PIVKA-X could be detected in the eluant of the QAESephadex column even after washing the column with $1.0 \mathrm{M} \mathrm{NaCl}$ solution of $\mathrm{pH}$ 7.4. After dilution of the $\mathrm{BaSO}_{4}$ eluant 1:1 with distilled water and adjusted to $\mathrm{pH} 7.1$ with $1 \mathrm{~N} \mathrm{NaOH}$, PIVKA-X was quantitatively adsorbed on DEAE-Sephadex equilibrated in $0.02 \mathrm{M}$ potassium phosphate buffer pH 6.8 containing 0.1 in NaCl. Fig. 9 shows the elution pattern of PIVKA-X from DEAE-Sephadex. PIVKA-X 
Fig. 9 .

Step 3 in PIVKA- $x$ preparation. DEAE-Sephadex chromatography of $\mathrm{BaSO}_{4}$ eluate in potassium phosphate $0.02 \mathrm{H}+\mathrm{NaCl} 0.1 \mathrm{H}$ p 6.8. After washing the colum with $400 \mathrm{~m}$ of buffer, a gradient was applied ranging from $0.1-0.6 \mathrm{H} \mathrm{NaCl}$ in $0.02 \mathrm{~K}$-phosphate buffer pH 6.8. Each gradient chamber contains $250 \mathrm{ml}$ of the gradient solutions. Bed dimensions of the anionexchanger $45 \times 2.5 \mathrm{~cm}$. Flow rate of $40 \mathrm{ml} /$ hour and fraction volume $5 \mathrm{ml}$. Absorbance at $280 \mathrm{nul}(\bullet)$, PivkA-X concentration (o), gradient $(-)$.

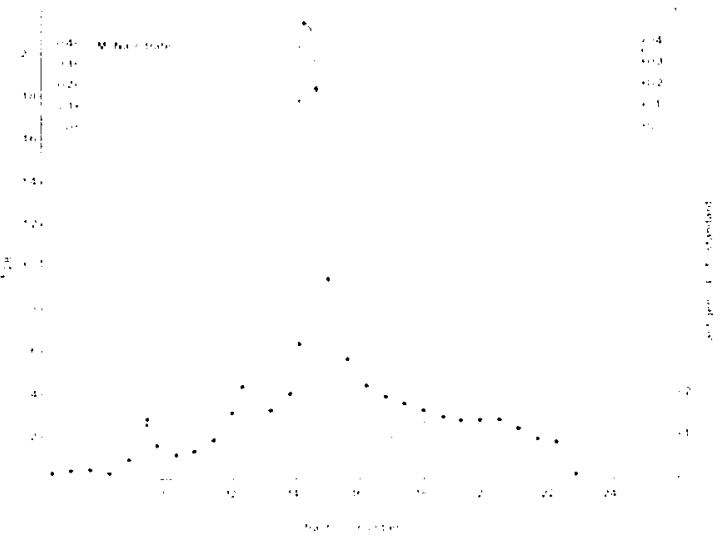

Fig. 10 .

Step 4 in PIVKA-x preparation. QAE-Sephadex chromatography of PIVKA- $x$ containing fractions obtained after OEAE-Sephadex chromatography. $240 \mathrm{ml}$ of prote in solution $(1.0 \mathrm{mg} / \mathrm{ml})$ in 0.05 ii sodium citrate buffer pH 7.U was applied to QAE-Sephadex equilibrated in the same buffer. After washing the column with $600 \mathrm{ml}$ of $0.1 \mathrm{ml}$ trisodium citrate buffer $\mathrm{pH} 7.0$, a gradient $(2 \times 300 \mathrm{ml})$ was applied ranging from $0.1 \mathrm{M}-0.35 \mathrm{M}$ trisodium citrate buffer ph 7.0 . Bed dimensions of anion-exchanger $30 \times 2.5 \mathrm{~cm}$. Flow rate of $10 \mathrm{ml} /$ hour and fraction volume $5 \mathrm{ml}$. hibsorbance at $280 \mathrm{~nm}(\bullet)$, Pl VkA-X concentration $(\mathbf{0})$, gradient $(-)$. 


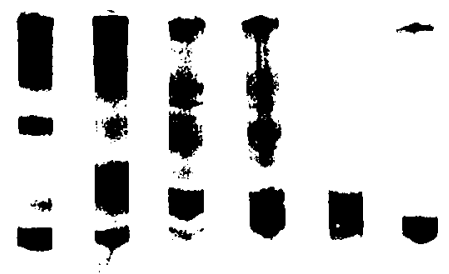

Fig. 11.

Analytical polyacrylamide gel electrophores is of normal bovine plasma and several fractions, obtained during the purification procedures.

1. nomal bovine plasma, $70.9 ; 2 . \mathrm{BaSO}_{4}$-eluate from PIVKA-X purification, $100 . . g$; 3. PIVKA-X after DEAE-Sephadex, 45 ..g; 4. PIVKA-X after QAE-Sephadex, $: 0$ :g; 5. PIVKA- $x$ after preparative polyacrylamide gel electrophores is, $50 \mathrm{ig}$; b. factor $x$ after QAE-Sephadex, 30 .g.

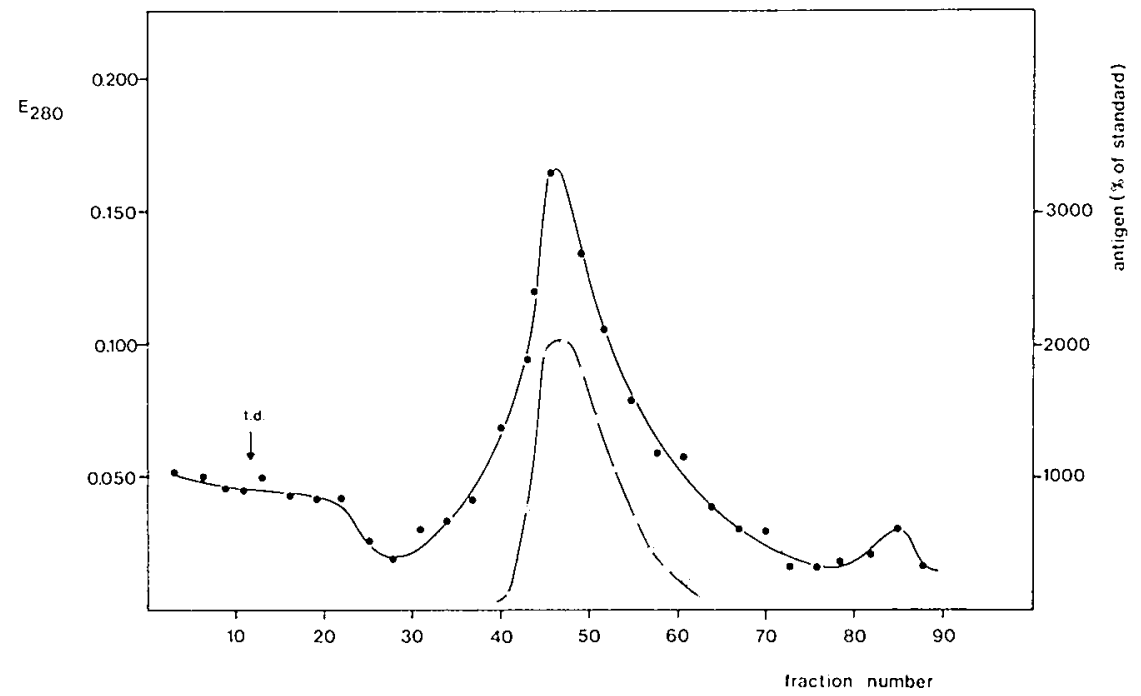

rig. 12.

Purification of PIVKA-X by preparative polyacrylanide gel electrophoresis. $3 \mathrm{ml}$ of PIVKA$X$ containing fractions after OAE-Sephadex $(10 \mathrm{mg} / \mathrm{ml})$ were applied on a ge $(T=7.5$ and $C=3:(35))$ of $10 \mathrm{~cm}$ length. Fraction volume $3.0 \mathrm{ml}$. Absorbance at $280 \mathrm{~mm}(\bullet)$, PlvkA$\therefore$ concentration $(0)$, t.d. = tracking dye. Detailed experimental conditions are described under Methods. 
was eluted as a single peak at 0.3 M NaCl. Fig. 10 shows the elution pattern of PIVKA-X from QAE-Sephadex. Like factor $X$, PIVKA-X is eluted in a double peak at $0.18 \%$ and 0.22 in trisodium citrate. Only in fraction 180 a trace amount of factor $x$ activity $(\cdot 5)$ could be detected.

Polyacrylamide gel electrophoresis shows that the PIVKA-X preparation contains several protein bands after the QAE-Sephadex step, in contrast to the factor $x$ preparation after QAE-Sephadex, which is almost pure (fig. 11). A further purification of PIVKA-X was obtained by preparative polyacrylamide gel electrophoresis. The elution profile is shown in fig. 12. PIVKA-X is eluted in the first major protein peak. Less than 5 factor $x$ activity could be detected in the pooled PIVKA-X fractions. Analytical polyacrylamide gel electrophores is shows that this final PIVKA-X preparation is homogeneous and has the same electrophoretic mobility as factor $X$ (gels 5 and 6 of fig. 11 , respectively).

Like factor $X$, PIVKA-X is highly susceptible to proteolytic enzymes. A proper yield of PIVKA- $x$ could only be obtained by adding benzamidine hydrochloride to all buffers. Omission of benzamidine in the last purification step results in the appearance of three different degradation products of PIVKA-X.

Relative electrophoretic mobility of PIVKA-X and factor $X$. As shown by Stenflo (4) the electrophoretic mobility of normal factor II in agarose gel electrophoresis is lower in a $\mathrm{Ca}^{2+}$ containing buffer than in an EDTA containing buffer, whereas the mobility of PIVKA-II is unaffected by $\mathrm{Ca}^{2+}$ ions. Agarose gel electrophoresis of factor $X$ and PIVKA-X in the presence of $\mathrm{Ca}^{2+}$ ions (fig. 13B) or EDTA (fig. 13A) also demonstrates a difference in affinity to $\mathrm{Ca}^{2+}$ ions for PIVKA-X and factor $X$. It is also shown that PIVKA-X has a somewhat lower electrophoretic mobility than factor $x$ in the presence of EDTA, which indicates a lower net negative charge of PIVKA-X. 


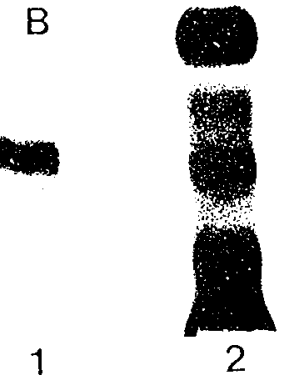

$A$

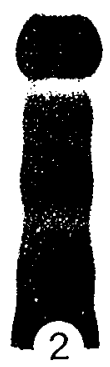


2

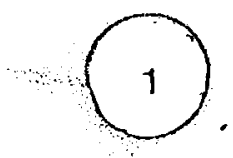

3

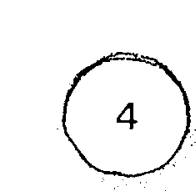

Fig. 15 .

Double immodiffusion. Centre well: anti-factor $x$ antiserum. well 1: coumarin bovine plasma; 2: PIVKA-X; 3 : factor $x ; 4$ : normal bovine plasma.

A

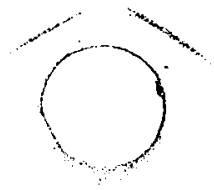


Molecular size of factor $X$ and PIVKA-X. Electrophoresis on polyacrylamide gel in the presence of sodium dodecyl sulfate according to Weber (27) of both factor $X$ and PIVKA-X revealed a major single protein band with a molecular weight around 55,000 (fig. 14). After reduction of the $S-S$ bonds with -mercaptoethanol both proteins show two protein bands with molecular weights of approximately 44,000 and 17,000. The molecular weights of PIVKA-X and factor $X$ estimated by this method, are in good agreement with the molecular weight reported for factor $x(20,21)$.

Immunochemical properties. A double immunodiffusion test of purified factor $X$, PIVKA-X, normal bovine $p l$ asma and phenprocoumon plasma with less than $5 \%$ factor $X$ activity against anti-bovine factor $X$ antiserum shows one precipitation 7 ine. A reaction of complete identity was seen between all samples and the antiserum (fig. 15).

When purified factor $X$ and purified PIVKA-X were analyzed by crossed immunoelectrophores is in calcium containing buffer, single symmetrical arcs were obtained with both proteins (fig. 16A), showing a higher electrophoretic mobility for PIVKA-X. By this technique factor $X$ could not be detected in the PIVKA-X preparation. In the presence of EDTA the precipitation arc of PIVKA-X is at the same position as that found for factor $X$ ( $f$ ig. 16B). The immunoelectrophoretic patterns obtained with the purified proteins were not different from those obtained with unfractionated plasma.

Amino acid analysis. The amino acid composition of PIVKA-X and factor $X_{1,2}$ appeared to be identical (table IV), and is in good agreement with published data $(21,42)$. The composition given is the average of two different preparations of each of the proteins. The number of $y$-carboxyglutamate residues was determined in PIVKA-X, factor $x_{1}$ and factor $x_{2}$ by a modification of the method of Zytkovicz (40) as described in Methods. Less than one $y$-carboxyglutamate residue was detectable in PIVKA-X. No differences were found in the $y$-carboxyglutallate content of factor $x_{1}$ and $x_{2}$ (table $V$ ). These results are in close agreement with the number of $y$-carboxyglutamate residues 
TABLE IV. Amino acid composition of factor $X$ and PIVKA-X.

\begin{tabular}{|l|c|c|c|}
\hline Amino acid & $\begin{array}{c}\text { factor } X \\
\text { mole/50,000 }\end{array}$ & $\begin{array}{c}\text { PIVKA-X } \\
\text { mole/50,000 }\end{array}$ & $\begin{array}{c}\text { factor } X \\
\text { (ref. } 42)^{a} \\
\text { mole/50,000 }\end{array}$ \\
\hline lysine & 20 & 21 & 21 \\
histidine & 11 & 11 & 10 \\
arginine & 25 & 25 & 25 \\
aspartic acid & 40 & 42 & 40 \\
threonine & $28^{b}$ & 28 & 30 \\
serine & $31^{b}$ & 30 & 29 \\
glutanic acid & 61 & 61 & 61 \\
proline & 20 & 18 & 20 \\
glycine & 42 & 37 & 41 \\
alanine & 31 & 29 & 31 \\
half-cystine & 19 & 20 & 24 \\
valine & 20 & 22 & 6 \\
methionine & 6 & 6 & 11 \\
isoleucine & 11 & 13 & 32 \\
leucine & 33 & 29 & 21 \\
tyrosine & 11 & 11 & 9 \\
phenylalanine & 22 & 22 & \\
\hline
\end{tabular}

a: Molecular weights do not include the carbohydrate content (42).

b: Values determined by extrapolation to zero-time hydrolysis.

TABLE $V . \quad Y$-Carboxyglutamate (Gla) content in factor $X_{1}$, factor $x_{2}$, and PIVKA-X

\begin{tabular}{|c|c|c|c|}
\hline & $\begin{array}{l}\text { Factor } X_{1} \\
\text { mole } / 50,000\end{array}$ & $\begin{array}{l}\text { Factor } x_{2} \\
\text { mole } / 50,000\end{array}$ & $\begin{array}{l}\text { PIVKA-X } \\
\text { mole } / 50,000\end{array}$ \\
\hline Gla & $128^{a}$ & $13 \quad 13^{\mathrm{a}}$ & $\therefore 1$ \\
\hline
\end{tabular}

a: Values taken from Neal et al. (43).

ula content was determined by a modified method according to Zytkovicz (40) as described under Methods. 
suggested by several authors from analysis of the $N$-terminal portion of the light chain, prepared from a mixture of factor $x_{1}$ and factor $x_{2}(10,12)$.

Aminoterminal amino acid analysis. Qualitative amino terminal amino acid determination of PIVKA-X and factor $X$ by a method according to Gray (36) showed a single intensive spot and several very weak spots by chromatography on polyamide sheets as described by Weiner et al. (37). In both factor $X$ and PIVKA-X the main spot was identified as DNS-alanine. Fujikawa (21) reported the sequence of the $\mathrm{NH}_{2}$-terminal region of the heavy chain to contain Trp-Ala-lle-His. By the method of Gray (36) tryptophane degrades and therefore cannot be detected.

\section{DISCUSSION}

A protein induced by vitamin $K$ antagonists, analogous to prothrombin (PIVKA-II, as defined in the introduction) has been demonstrated and isolated by many investigators (1-4). The data presented here, clearly demonstrate the existence of an abnormal factor $X$ in plasma of phenprocoumon treated cows (defined as PIVKA-X) which is ineffective in blood coagulation. The following arguments can be brought forward in support of the existence of PIVKA-X besides PIVKA-II. a. The antigen precipitable with monospecific antibodies against factor $X$, found in normal plasma, coumarin plasma, coumarin serum, $\mathrm{Al}(\mathrm{OH})_{3}$-adsorbed coumarin plasma and $\mathrm{Al}(\mathrm{OH})_{3}$-adsorbed coumarin serum shows immunochemically a reaction of complete identity (fig. 2). No precipitable material is found when normal plasma is adsorbed with $\mathrm{Al}(\mathrm{OH})_{3}$ under conditions known to renove all factor $X$ activity. b. Quantitation of antigen reacting with anti-bovine factor $X$ antibodies in the rocket immunoelectrophoresis according to Laurel1 (30) shows that more material is present in coumarin and in $\mathrm{Al}(\mathrm{OH})_{3}$ adsorbed coumarin plasma than can be accounted for by the factor $X$ activity (fig. 4). Horeover, it is shown, that during the phenprocoumon treatment, the concentration of the non-adsorbable factor $x$ related antigen increases while factor $x$ activity decreases. 
c. By a different technique, the crossed immunoelectrophores is in the presence of $\mathrm{Ca}^{2+}(31)$, the appearance of PIVKA-X and parallel disappearance of factor $X$ during the phenprocoumon treatment was al so established (fig. 3 ).

Recent advances in chemical analysis of the differences between prothrombin and PIVKA-II suggest that the vitamin $K$ dependent mechanism serves to modify glutamate residues into $Y$-carboxyglutamate residues $(6,8)$. This fact may cause the differences between prothrombin and PIVKA-II in biological activity, calcium binding and adsorption to insoluble inorganic salts. In addition, our results on PIVKA-IX and PIVKA-X may represent a situation parallel to that found for PIVKA-II. However, our adsorption studies of PIVKA-X on $A 1(O H)_{3}$ and $\mathrm{BaSO}_{4}$ ( $\mathrm{fig} .7$ and fig. 8) appear to be in contradiction with the statement of Nelsestuen et al. (3) that "Ca ${ }^{2+}$ binding sites are responsible for the quantitative and very selective adsorption of prothrombin onto insoluble barium salts". Similar comparison of the electrophoretic mobility of prothrombin and factor $x$ may reveal a larger net negative charge on factor $X(51)$. The more anodical position of PIVKA-X to that of PIVKA-II also indicates the same difference in net negative charge (18). These facts may explain the higher affinity of PIVKA-X towards insoluble barium salts as compared with PIVKA-II.

The isolation procedure for PIVKA-X described in this chapter yields a preparation which is highly pure as judged by several criteria, e.g. gel electrophoresis and amino terminal amino acid analysis. Essentially the same purification procedure as described for factor $X$ could be used for the preparation of PIVKA-X. We performed one minor modification namely the use of a potassium phosphate buffer instead of the citrate-Tris buffer in the DEAE-Sephadex step. It was found that no resolution was obtained between PIVKA-X and the bulk protein using the former buffer in the gradient. The heterogeneity of PIVKA-X as demonstrated in the QAE-Sephadex elution profile is of interest. It is unlikely that this phenomenon is due to the presence of factor $X$, because the factor $x$ activity is far less than the amount of 
precipitable antigen.

It was reported by Neal et al. (43) that factor $x_{1}$ and $x_{2}$ differ in their $y$-carboxyglutamate content (respectively 8 and 13 residues) and that this difference may be accounted for by the different behaviour on anion-exchange chromatography. However, in our hands an equal amount of $;$-carboxyglutamate residues was found in both factor $X_{1}$ and factor $X_{2}$. This result was confirmed by Magnusson (personal communication). Moreover, PIVKA-X which contains less than one residue of $i$-carboxyglutamate also shows heterogeneity on anion-exchange chromatography under certain conditions. Unlike the purification of factor $X$, after the QAE-Sephadex step an additional step was required for PIVKA-X, e.g. polyacrylamide gel electrophoresis. The final purification of factor $X$ is about twice the purification of PIVKA-X. Probably this discrepancy is due to the different methods used in determination of concentration (clotting activity versus an immunochemical assay). As judged by gel electrophoresis techniques both factor $X$ and PIVKA-X preparations are homogeneous.

PIVKA-X is very similar to factor $X$ on the basis of molecular weight, polypeptide chains composition, amino acid composition, amino terminal amino acid, immunochemical reactionand its behaviour on polyacrylanide gel electrophoresis.Furthermore, it is shown that the purified PIVKA-X and the native protein in unfractionated plasma are similar as they have the same immunochemical and electrophoretic properties. Based on amino acid analys is the differences between factor $X$ and PIVKA- $x$ in biological activity and $\mathrm{Ca}^{2+}$ binding may be explained by the difference found in $\gamma$-carboxyglutamate content (table $V$ ). 
1. Halhotra, 0.M. Life Sciences 11 (1972) 455

2. Mal hotra, O.M. and Carter, J.R. J.Biol.Chem. 246 (1971) 2665

3. Nelsestuen, G.L. and Suttie, J.W. J.Biol.Chem. 247 (1972) 8176

4. Stenf1o, J. and Ganrot, P.0. J.Biol.Chem. 247 (1972) 8160

5. Esmon, C.T., Grant, G.A. and Suttie, J.W. Biochem. 14 (1975) 1595

6. Stenflo, J., Fernlund, P., Egan, W. and Roepstorff, P. Proc.Nat7. Acad.Sci.USA 71 (1974) 2730

7. Nelsestuen, G.L. and Suttie, J.W. Proc.Nat1.Acad.Sci.USA 70 (1973) 3366

8. Nelsestuen, G.L., Zytkovicz, T.H. and Howard, J.B. J.Biol.Chem. 249 (1974) 6347

9. Magnusson, S., Sottrup-Jensen, L., Peterson, T.E., Morrison, H.R. and Del1, A. FEBS Letters 44 (1974) 189

10. Howard, J.B. and Nelsestuen, G.L. Proc.Nat7.Acad.Sci. USA 72 (1975) 1281 11. Fryklund, L., Borg, H. and Andersson, L.0. FEBS Letters 65 (1976) 187

12. Enfield, D.L., Ericsson, L.H., Walsh, K.A., Neurath, H. and Titani, K. Proc.Wat1.Acad.Sci. USA 72 (1975) 16

13. Lucher, D., Nebelin, E., Thomsen, J. and Stenflo, J. FEBS Letters 68 (1976) 293

14. Shah, D.V. and Suttie, J.W. Biochem. Biophys.Res.Commun. 60 (1974) 1397

15. Esmon, C.T., Sadowski, J.A. and Suttie, J.H. J.Biol.Chem. 250 (1975) 4744

16. Vermeer, C., Soute, B.A.M., Govers-Riemslag, J. and Hemker, H.C. Biochim.Biophys.Acta 444 (1976) 926

17. Hemker,ii.C., Veltkamp, J.J., Hensen, A. and Loeliger, E.A. ivature 200 (1963) 589

18. Reekers, P.P.M., Lindhout, M.J., Kop-K1aassen, B.H.M. and Hemker, H.C. Biochim. Biophys. Acta 317 (1973) 559

19. Lindhout, H.J., Kop-Klaassen, B.H.M., Reekers, P.P.i. and Hemker, H.C. J.Hol.Hed. 1 (1976) 223

20. Jackson, C.M., Johnson, T.F. and Hanahan, 0.J. Biochem. 7 (1968) 4492 
21. Fujikawa, K., Legaz, M.E. and Davie, E.... Biochem. 11 (1972) 4882 22. Titani, K., Hermodson, M.A., Fujikawa, K., Ericsson, L.H., Walsh, K.A., Weurath, H. and Davie, E.W. Biochem. 11 (1972) 4899

23. Enfield, D.L., Ericsson, L.H., Fujikawa, K., Titani, K., Walsh, K.A. and Neurath, H. FEBS Letters 47 (1974) 132

24. Reekers, P.P.M. and Hemker, H.C. Haemostas is 1 (1972) 2

25. Ornstein, L. Ann.N.Y.Acad.Sci. 121 (1964) 231

26. Davis. B.J. Ann.N.Y.Acad.Sci. 121 (1964) 404

27. Weber, K. and Osborn, i. J.Biol.Chem. 244 (1969) 4406

28. Fairbanks, G. Biochen. 10 (1971) 2606

29. Johansson, B.G. Scand.J.Clin.Lab. Invest. Suppl. 29, 124 (1972) 7

30. Laurel1, C.B. Anal. Biochem. 15 (1966) 45

31. Laure11, C.B. Ana1. Biochem. 10 (1965) 358

32. Ouchterlony, 0. Progr.Al lergy 6 (1962) 30

33. Owren, P.A. and Aas, K. Scand.J.Clin.Lab.Invest. 3 (1951) 201

34. Hemker,H.C., Swart, A.C.W. and Alink, A.M.J. Thrombos.Diathes. haemorrh. 27 (1972) 205

35. Hjerten, S. Arch.Biochem.Biophys. Supp1. 1 (1962) 147

36. Gray, W. Wethods Enzymol. 11 (1967) 139

37. Weiner, A.l., Platt, T. and Weber, K. J.Biol.Chem. 247 (1972) 3242

38. Spackman, D.H., Stein, H.W. and Moore, S. Anal.Chem. 30 (1958) 1190

39. Hamilton, P.B. Anal.Chem. 35 (1963) 2055

40. Zytkovicz, T.H. and Nelsestuen, G.L. J.Biol.Chem. 250 (1975) 2968

41. Howe11, R.M. and Dupe, R.J. Thrombos.Diathes.haemorrh. 28 (1972) 306

42. Jackson, C.M. and Hanahan, D.J. Biochem. 7 (1968) 4506

43. Neal, G.C., Prowse, C.V. and Esnouf, M.P. FEBS Letters 66 (1976) 257

44. Jackson, C.li. Thrombos. Diathes.haemorrh. Supp]. 57 (1974) 197

45. Magnusson, S. (1971) In "The Enzymes" Ed. Boyer, P.D. Acad.Press, New York, 3rd ed. Vol. 2, p. 277

46. Prydz, H. and Gladhaug, A. Thrombos.Diathes.haemorrh. 25 (1971) 157

47. Gaudernack, G., Gladhaug, A., Osterud, B. and Prydz, H. Thrombos. Diathes.haemorrh. 31 (1974) 40

48. Gaudernack, G. and Prydz, H. Thrombos.Diathes.haemorrh. 34 (1975) 455 
49. Kop, J.M.M. and Hemker, H.C. Manuscript in preparation

50. Veltkamp, J.J., Loeliger, E.A. and Drion, E.F. Thrombos.Diathes. haemorrh. 18 (1968) 403

51. Fujikawa, K., Coan, M.H., Enfield, D.L., Titani, K., Ericsson, L.H. and Davie, E.W. Proc.Natr.Acad.Sci. USA 71 (1974) 427. 
THE ROLE OF $Y$-CARBOXYGLUTAMYL RESIDUES IN THE POSITIVE COOPERATIVE BINDING OF $\mathrm{Ca}^{2+}$ TO BLOOD COAGULATION FACTOR $X$

SUMMARY

1. The $\mathrm{Ca}^{2+}$ binding properties of factor $X$ and its analogous decarboxy factor $X$ (PIVKA-X) have been compared with the aid of flow rate dialysis and ultraviolet difference spectroscopy.

2. Factor $x$ binds about 20 moles of $\mathrm{Ca}^{2+}$ per mole of protein. The first four sites exhibit positive cooperativity.

3. Changes in the ultraviolet difference spectrum when $\mathrm{Ca}^{2+}$ ions are bound, suggest a conformational change.

4. In PIVKA-X a very low affinity of $\mathrm{Ca}^{2+}$ and no 1 igand induced conformational change was observed. Both phenomenons lack a cooperative character.

5. It is concluded that the presence of $\gamma$-carboxyglutamyl residues in factor $X$ is a prerequisite for positive cooperative $\mathrm{Ca}^{2+}$ binding. 
INTRODUCTION

The binding of $\mathrm{Ca}^{2+}$ to prothrombin requires the presence of 1 -carboxyglutamyl residues $(1-3)$. Carboxylation of 10 glutamyl residues in the amino-terminal part of prothrombin has been shown to occur by action of vitamin $k$ at a post-ribosomal stage (4-6).

The $\mathrm{Ca}^{2+}$ mediated binding of prothrombin to phospholipid surfaces, a prerequisite of normal thrombin generation is thought to occur via these residues $(7,8)$. It was reported that an abnomal prothrombin isolated from the plasma of cattle treated with vitamin $K$ antagonists and lacking $y$-carboxyglutamyl residues, does not bind to phospholipid vesicles (9).

Calcium binding to prothrombin (3, 10-14) and prothrombin fragment $1(3,13)$ has been investigated in a number of laboratories. It is shown that prothrombin can bind 10-14 moles of $\mathrm{Ca}^{2+}$, of which about four sites with a high affinity.

Factor $X$, another vitamin $K$ dependent clotting factor, shows positive cooperativity until 3-5 of the 20 sites are occupied (3).

However, for both prothrombin and factor $x$, a considerable divergence in form of the binding isotherms was obtained. Positive cooperativity $(2,12,15)$ as well as the presence of two distinct classes of binding sites $(11,13,16)$ were suggested.

In this chapter, we compare $\mathrm{Ca}^{2+}$ binding to factor $X$ and to decarboxy factor $X(P I V K A-X)$ that is obtained from plasma of cattle under phenprocoumon treatment. In this way it will be possible to demonstrate that $\gamma$-carboxyglutamate residues are necessary for cooperative $\mathrm{Ca}^{2+}$ binding. The increased affinity for binding of successive $\mathrm{Ca}^{2+}$ ions implies that a protein conformational change must be associated with $\mathrm{Ca}^{2+}$ binding. This was investigated with ultraviolet difference spectroscopy. 


\section{MATERIALS AND METHODS}

Factor $X$ and PIVKA-X were purified according to the methods described in chapter II. All chemicals were analytical grade and obtained from Merck. ${ }^{45} \mathrm{Ca}^{2+}$ was obtained from the Radiochemical Centre, Amersham. Extinction coefficient ( $E_{1 \mathrm{~cm}}^{1 "}$ at $280 \mathrm{~nm}$ ) and molecular weights used for calculation of the protein concentrations were respectively 12.4 and 55,000 for both factor $X$ and PIVKA-X (17). Standard $\mathrm{CaCl}_{2}$ solutions in $0.05 \mathrm{M}$ Tris-HCl buffer, $\mathrm{pH} \mathrm{7.5}$, containing $0.1 \mathrm{M} \mathrm{NaCl}$ and $0.02 \% \mathrm{Na}$-azide were prepared from reagent grade $\mathrm{CaCl}_{2} \cdot 2 \mathrm{H}_{2} \mathrm{O}$. The $\mathrm{Ca}^{2+}$ concentration in these solutions was determined by titration (18).

Flow rate dialysis. The $\mathrm{Ca}^{2+}$ binding properties of factor $X$ and PIVKA- $X$ were studied by the flow rate dialysis technique according to Colowick (19). The method is based on measuring the rate of dialysis of ${ }^{45} \mathrm{Ca}^{2+}$ from a protein- $\mathrm{Ca}^{2+}$ equilibrium mixture across a membrane.

The upper chamber of the dialysis cell containing the protein solution and ${ }^{45} \mathrm{Ca}^{2+}$ was separated by a Visking dialysis membrane from the lower chamber. Both chambers have a volume of $2.5 \mathrm{ml}$. A buffer solution, identical to the solvent for the protein was pumped through the lower chamber. Under the conditions used, the withdrawal of ligand from the upper chamber is a negligible fraction of the total 1 igand. When a steady state is reached, i.e. the rates of ligand entering and leaving the lower chamber are equal, the concentration in the effluent becomes a measure of the concentration of free ligand in the upper chamber.

With this method a series of equilibrium measurement can be performed at increasing ligand concentrations in the same protein solution. The volume of buffer that has to be passed to reach a steady state is given by:

$$
\frac{d N}{d t}=S_{1} D-N \cdot \frac{f}{\nabla}
$$


where: $N=$ number of ligand molecules in the lower chamber $S_{1}=$ initial concentration of 1 igand $\left({ }^{45} \mathrm{Ca}^{2+}\right)$ in the upper chamber

$D=$ diffusion constant (dependent on properties of the dialysis apparatus and the nature of the diffusion ligand)

$V=$ volume of lower chamber

$f=$ volume of buffer passing through the lower chamber per unit of time.

In the steady state:

$$
\frac{N}{V}=\frac{S_{1} D}{f}
$$

The time required to reach a steady state concentration of $\mathrm{Ca}^{2+}$ in the lower chamber can be calculated from the integrated form of equation (1):

$$
\frac{N_{t}}{V}=\frac{S_{1} D}{f}\left(1-e^{-(f t / V)}\right)+\frac{N_{t=0}}{V} e^{-(f t / v)}
$$

When the volume flowing through the lower chamber, ft, is more than four times the volume of the lower chamber, $V$, the exponential term is negligible and therefore the concentration of ligand in the lower chamber, $N_{t} / V$, becomes constant $\left(>98^{\circ}\right.$ of the steady state volume). Subsequent addition of ligand to the upper chamber alters the concentration of free ligand from $S_{1}$ to $S_{2}$. Then, equation (3) becomes:

$$
\frac{N_{t}}{V}=\frac{S_{2} D}{f}\left(1-e^{-(f t / V)}\right)+\frac{S_{1} D}{f} \cdot e^{-(f t / V)}
$$

Again the additional flow required to reach the new steady state concentration $S_{2} D$ is the same as that to reach the first steady state. 
In a represencative experiment the upper chamber was filled with $2 \mathrm{ml}$ of a solution containing about $1.5 \mathrm{mg}$ protein in $0.1 \mathrm{M} \mathrm{NaCl}$, U.05 M Tris-HCl, pH 7.5. $10 ; 17$ of ${ }^{45} \mathrm{Ca}^{2+}$ solution (specific activity $8: \mathrm{Ci} / \mathrm{g}$ ) was added to the upper chamber (final concentration $12: \mathrm{M}$ ). The steady state was established after $12 \mathrm{ml}$ of $0.05 \mathrm{M} \mathrm{Tris-HCl}$ buffer, pH 7.5, containing $0.1 \mathrm{M} \mathrm{NaCl}$ and $0.02: \mathrm{Na}$-azide passed through the lower chamber at a flow rate of $4 \mathrm{ml} / \mathrm{min}$. After the steady state is reached, small volumes (5 - $15: 11$ ) of a nonradioactive $\mathrm{Ca}^{2+}$ were added to the upper chamber to increase the total $\mathrm{Ca}^{2+}$ concentration stepwise.

Fractions of $3 \mathrm{ml}$ were collected and a $0.5 \mathrm{ml}$ al iquot was mixed with $5 \mathrm{ml}$ of a gelling scintillation solution (Aquasol, New England Nuclear) and counted in a Packard Tricarb liquid scintillation spectrometer. All experiments were performed at room temperature.

In an identical experiment, the steady state concentration of ${ }^{45} \mathrm{Ca}^{2+}$ was determined in the absence of protein. This control value will be a measure of the concentration of 100 free $\mathrm{Ca}^{2+}$ in the upper chamber (designated the $100 \% \mathrm{~F}$ value).

The steady state concentration of ${ }^{45} \mathrm{Ca}^{2+}$ in the effluent is always proportional to the free ${ }^{45} \mathrm{Ca}^{2+}$ concentration in the upper chamber. Therefore, the steady state concentration of ${ }^{45} \mathrm{Ca}^{2+}$ in the presence of protein devided by the $100 \% \mathrm{~F}$ value represents the fraction of the total $\mathrm{Ca}^{2+}$ concentration that is in the free state. The total $\mathrm{Ca}^{2+}$ concentration in the upper chamber is known, so that the concentration of the free and bound $\mathrm{Ca}^{2+}$ can be calculated. However, the $100 ; F$ value will decrease during the time course of the experiment as a result of dilution after each addition of $\mathrm{Ca}^{2+}$ and loss of radioactivity. in the effluent. The effect of dilution can be determined in a control experiment. The effect of cpm loss on the $100 \% \mathrm{~F}$ value must be calculated. For each step the 100. F value was corrected in the following way: 
corrected control value $=\frac{\text { actual cpm in upper chamber }}{\text { initial cpm in upper chamber }} \times 100 \mathrm{~F}$

The actual counts in upper chamber arecalculated by subtracting the total amount of counts of the effluent collected at any moment from the total counts in the upper chamber present at the start of the experiment.

The $\mathrm{Ca}^{2+}$ binding properties of factor $X$ and PIVKA-X were evaluated by plotting $\bar{v}$ (mole $\mathrm{Ca}^{2+}$ bound / mole protein) versus $\bar{v} /$ free $\mathrm{Ca}^{2+}$ concentration (F), according to the method of Scatchard (20).

The ligand binding properties were also expressed by the equation given originally by Hill (21):

$$
\bar{v}=K[F]^{n_{H}} /\left(1+K[F]^{n_{H}}\right)
$$

in which $\bar{v} / N$ is the fraction of the total number of binding sites occupied by ligand, $[F]$ is the free ligand concentration and $K$ and $n_{H}$ are constants. Equation (1) can be written as:

$\log \frac{\bar{v}}{N-\nabla}=\log K+n_{H} \log [F]$

giving a straight line when $\log \nabla /(N-\bar{v})$ is plotted versus $\log [F]$, which is known as the Hill plot.

Although the Hill equation is known to be an oversimplification(22), the slope ( $n_{H}$, Hill coefficient) indicates the presence of any site-site interaction. That is, binding is cooperative $\left(n_{H} \neq 1\right)$ or non-cooperative $\left(n_{H}=1\right)$.

An alternative method with which the contributions of site-site interactions in multiple ligand binding can be assessed, is given by De Meyts and Roth (23). They attempted to overcome the problems caused by the unknown stoichiometry of the binding process, i.e. unknown number of sites of different affinities or sites of 
changing affinity, by taking an average affinity $(\bar{K})$ at each level of occupancy $(\bar{Y})$. The assumption is that when binding sites are not occupied, they are all in the same conformation and an identical affinity for the ligand is expected. Due to sitesite interaction, the affinity will vary as a function of occupancy, as can be shown by plotting $\bar{K}$ versus $\bar{Y}$. The average affinity $(\bar{K})$ is given by the negative slope of a line joining $\bar{v} / F$ at a particular $\bar{v}$ to the number of total sites occupied $(N)$. The fractional occupancy, $\bar{Y}$, is given by $\bar{v} / N$. Ultraviolet difference spectroscopy. Ultraviolet difference spectra were measured on an Aminco DW-2 double beam spectrophotometer equipped with a thermostated cell holder maintained at $25^{\circ} \mathrm{C}$. A set of matched, rectangular quartz cells (Hellma 104 QS) with light path of $1.0 \mathrm{~cm}$ were used. To study the protein-Ca ${ }^{2+}$ interaction, a $\mathrm{Ca}^{2+}$ solution was added in the sample cell and an equal volume of buffer in the reference cell, using Hamilton microsyringes. Both cells contain about $1.5 \mathrm{mg}$ factor $X$ or PIVKA-X, in $0.1 \mathrm{M} \mathrm{NaCl}, 0.01 \mathrm{M} \mathrm{Tris-HCl}$ at $\mathrm{pH}$ 7.5. Difference spectra were recorded from $240 \mathrm{~nm}$ to $340 \mathrm{~nm}$ on a full scale of 0.05 absorbance unit.

\section{RESULTS AND DISCUSSION}

Flow rate dialysis

Evaluation of the flow rate dialysis technique. In order to obtain a correct interpretation of the data obtained, some control experiments had to be carried out in order to evaluate the influence of several factors on the experimental system. The following requirements have to be met:

1. The steady state has to be reached after an amount of buffer corresponding to 4 times the volume of the lower chamber was pumped through.

2. The steady state concentration of ${ }^{45} \mathrm{Ca}^{2+}$ in the effluent has to be directly proportional to the concentration of free ${ }^{45} \mathrm{Ca}^{2+}$ in the upper chamber. 


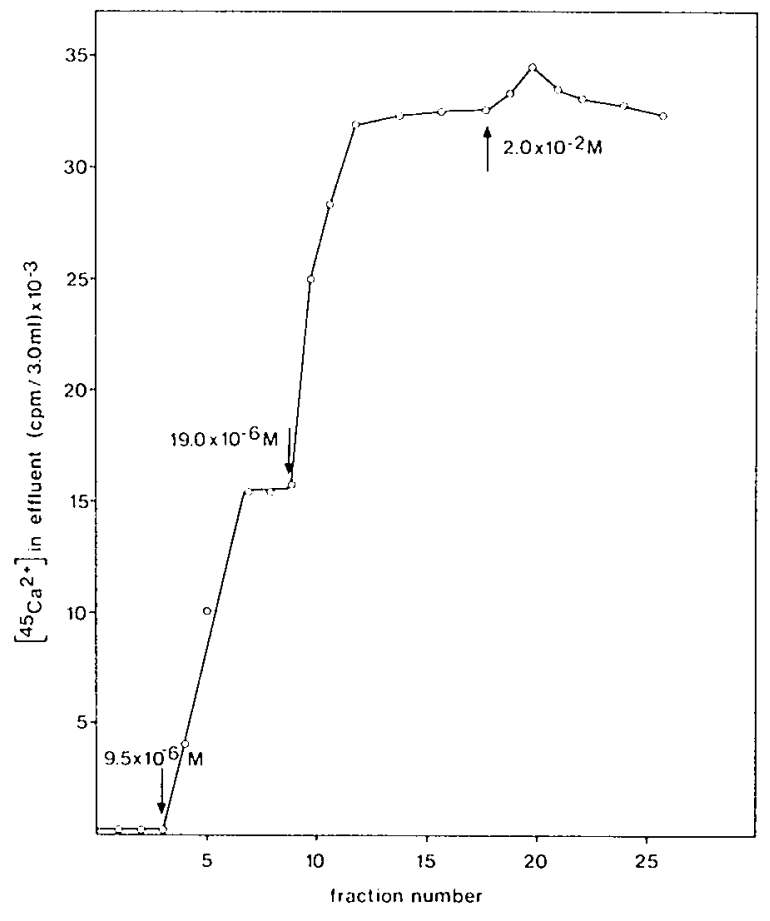

Fig. 1 .

Flow dialysis profile of ${ }^{45} \mathrm{Ca}^{2+}$. At the first two arrows ${ }^{45} \mathrm{Ca}^{2+}$ was introduced into the upper chamber containing $2.0 \mathrm{ml}$ of $0.05 \mathrm{~m}$ Tris-icl, 0.1 in : Hacl pH 7.5. int the third arrow non-radioactive $\mathrm{Ca}^{2+}$ was added at a concentracion of 20 min. For further experimental details see materials and methods.

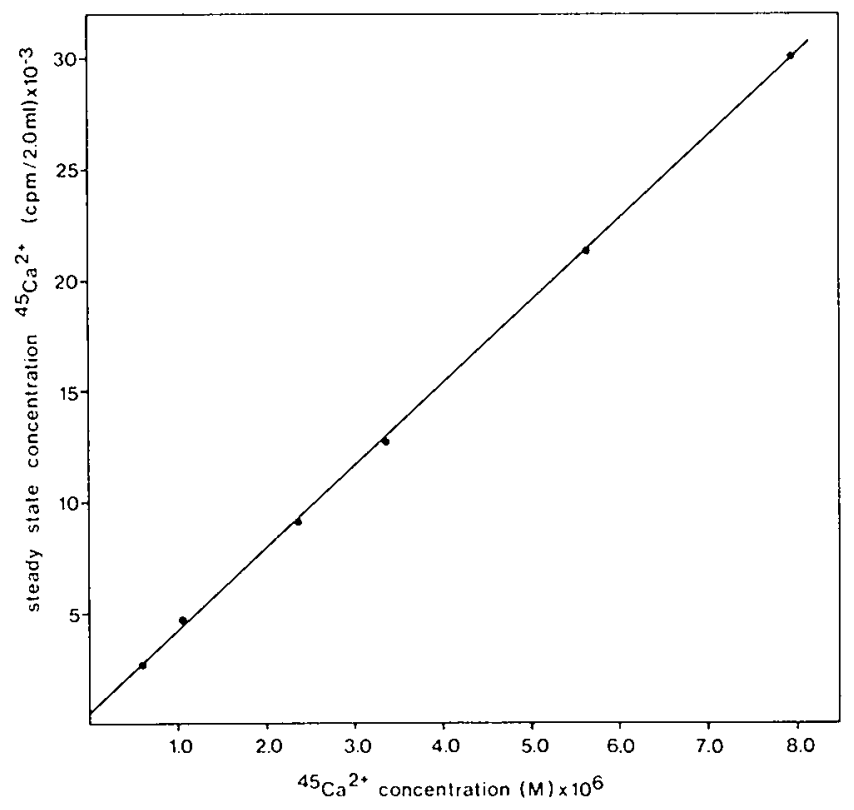

Fig. 2 .

Steady state concentration of ${ }^{45} \mathrm{Ca}^{2+}$ in the effluent as a function of the ${ }^{45} \mathrm{Ca}^{2+}$ concentration in the upper chamber. Six subsequent additions of ${ }^{45} \mathrm{Ca}^{2+}$ were made to the upper chamber which contained $2.0 \mathrm{ml}$ of $0.05 \mathrm{HT}$ Tris- $\mathrm{HCl}, 0.1 \mathrm{H} \mathrm{NaCl}$ $\mathrm{pH}$ 7.5. Experimental conditions as described under liaterials and Hethods. 
3. The time required for the binding reaction to equilibrate must be much faster than the time required to reach a steady state concentration of ${ }^{45} \mathrm{Ca}^{2+}$ in the effluent.

4. Non-specific $\mathrm{Ca}^{2+}$ binding must be absent, e.g.: $\mathrm{Ca}^{2+}$ binding to the dialysis membrane and other parts of the apparatus.

As demonstrated in fig. 1 the steady state at any step was reached after collection of about $12 \mathrm{ml}$ of effluent, which is 5 times the volume of the lower chamber.

Al iquots of ${ }^{45} \mathrm{Ca}^{2+}$ solution $\left(5.7 \times 10^{-4} \mathrm{M}\right)$ were added in succession to the upper chamber containing $2 \mathrm{ml}$ of $0.05 \mathrm{M} \mathrm{Tris-HCl}, 0.1 \mathrm{M}$ $\mathrm{NaCl}$ buffer $\mathrm{pH} 7.5$.

Fig. 2 shows a linear relationship between the steady state concentration of ${ }^{45} \mathrm{Ca}^{2+}$ in the effluent and the concentration of free ${ }^{45} \mathrm{Ca}^{2+}$ in the upper chamber. It is concluded that these results fit the theoretical model described under Materials and Methods.

Indication that no errors are introduced by a possible slow approach to equilibrium of the binding reaction was obtained from the following experiment. An al iquot $(2.0 \mathrm{ml})$ of factor $x$ preincubated for $30 \mathrm{~min}$. with $0.5 \mathrm{mM} \mathrm{Ca}^{2+}$ was added to the upper chamber, immediately followed by the addition of 10,11 ${ }^{45} \mathrm{Ca}^{2+}$ which makes the final $\mathrm{Ca}^{2+}$ concentration $0.512 \mathrm{mM}$. The time required to reach the steady state was the same as in an experiment where non-radioactive $\mathrm{Ca}^{2+}$ and ${ }^{45} \mathrm{Ca}^{2+}$ were added simultaneously to the upper chamber containing the factor $x$ solution.

Binding of $\mathrm{Ca}^{2+}$ to the membrane may cause a considerable error in the estimation of the amount $\mathrm{Ca}^{2+}$ bound to the protein (24). However, the flow dialysis profile of ${ }^{45} \mathrm{Ca}^{2+}$ in the absence of protein (fig. 1) shows that after addition of high excess of $\mathrm{Ca}^{2+}$ to the upper chamber to a final concentration of $20 \mathrm{mM}$, the steady state concentration in the effluent shows only a small spike. This shows that the amount of ${ }^{45} \mathrm{Ca}^{2+}$ bound to 

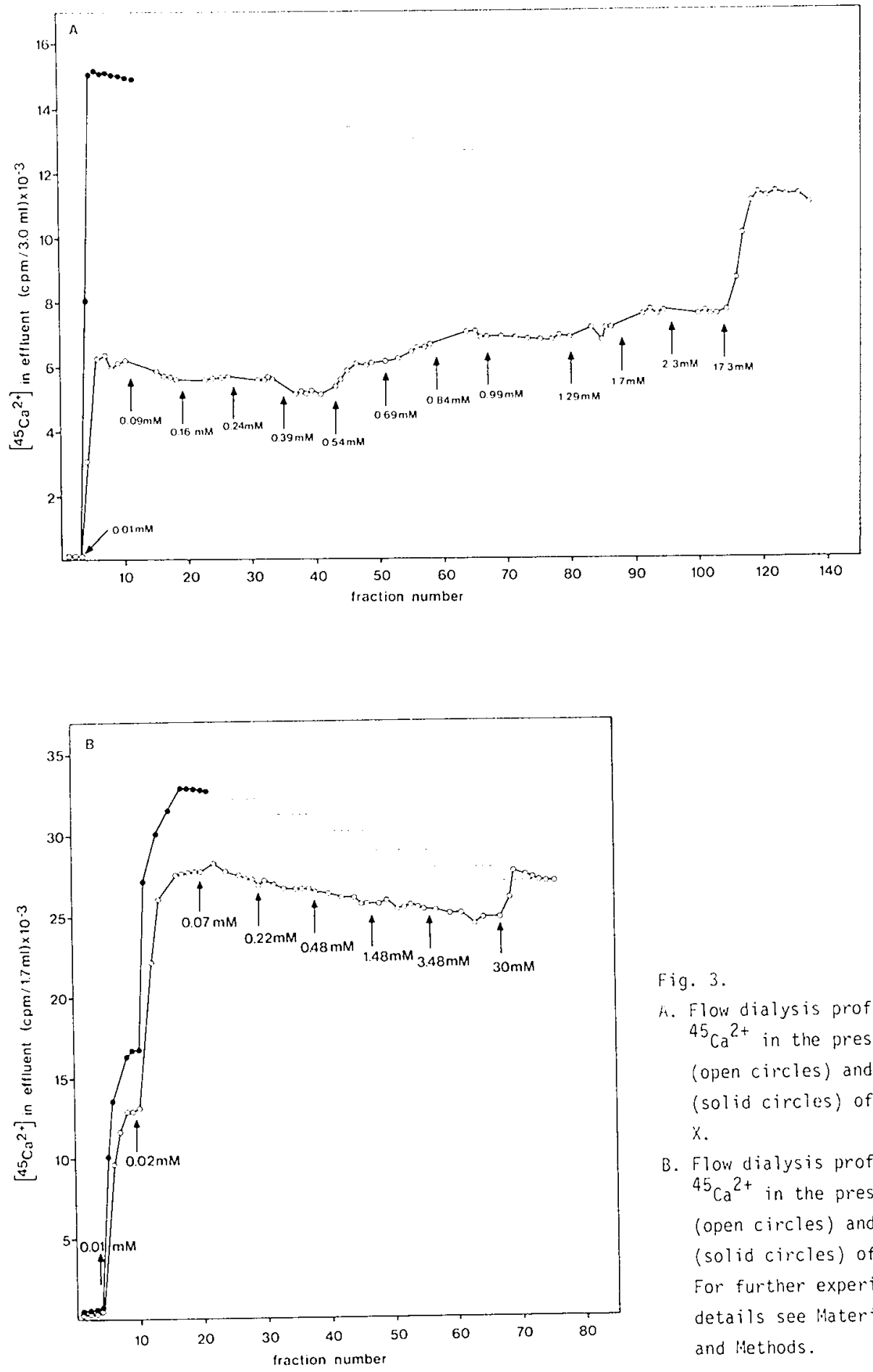

Fig. 3.

A. Flow dialysis profiles of ${ }^{45} \mathrm{Ca}^{2+}$ in the presence (open circles) and absence (solid circies) of factor $x$.

B. Flow dialysis profiles of ${ }^{45} \mathrm{Ca}^{2+}$ in the presence (open circles) and absence (solid circles) of PIVKA-X. For further experimental details see Materials and Wethods. 
the membrane can be neglected.

The final conclusion of these control experiments may be that several factors which can induce errors in the binding experinents can be neglected.

$\mathrm{Ca}^{2+}$ binding by factor $X$ and PIVKA-X. The flow dialysis profiles of ${ }^{45} \mathrm{Ca}^{2+}$ in the presence and absence of factor $x$ are shown in fig. $3 A$. The initial addition of ${ }^{45} \mathrm{Ca}^{2+}$ to the factor $x$ solution ( $0.036 \mathrm{mil}$ ) in the upper chamber resulted in a final $\mathrm{Ca}^{2+}$ concentration of $0.012 \mathrm{mM}$. Subsequent additions of non-radioactive $\mathrm{Ca}^{2+}$ are indicated by the arrows. The concentration of $\mathrm{Ca}^{2+}$ shown represents the final $\mathrm{Ca}^{2+}$ concentration in the upper chamber. Up to sample no. 10 the control curve (solid circles) represents experimental values. The dotted part of the curve is the calculated control curve compensated for dilution and cpm loss as described under Materials and Methods. Addition of excess $\mathrm{Ca}^{2+}(17 \mathrm{~min})$ resulted in a rise of the steady state, concentration of ${ }^{45} \mathrm{Ca}^{2+}$ to the level of the corrected control value. The radioactivity in the effluent, therefore is indeed a measure for the free $\mathrm{Ca}^{2+}$ concentration. It also indicates that the steady state concentration in the effluent does not depend on the total $\mathrm{Ca}^{2+}$ concentration in the upper chamber.

The binding curve for factor $X$ (solid circles) obtained by plotting $\overline{\mathrm{v}} / \mathrm{Ca}^{2+}$ versus $\overline{\mathrm{v}}$ according to scatchard (20) is shown in fig. 4. The Scatchard plot shows a positive slope between 0 and 3-4 mole $\mathrm{Ca}^{2+}$ bound per mole factor $x$, which indicates positive cooperative $\mathrm{Ca}^{2+}$ binding. Extrapolation of the curve to the $\bar{v}$ axis shows the presence of $20 \mathrm{Ca}^{2+}$ binding sites per mole of factor $x$.

The flow dialysis profiles of ${ }^{45} \mathrm{Ca}^{2+}$ in the presence and absence of PIVKA-X are shown in fig. 3B. The first additions of ${ }^{45} \mathrm{Ca}^{2+}$ resulted in final concentrations of 0.012 and 0.024 M respectively. Subsequently, non-radioactive $\mathrm{Ca}^{2+}$ was added to final concentrations as indicated in the figure. At a final concentration of $30 \mathrm{mll}$ $\mathrm{Ca}^{2+}$ in the upper chamber all ${ }^{45} \mathrm{Ca}^{2+}$ bound to PIVKA-X is exchanged 


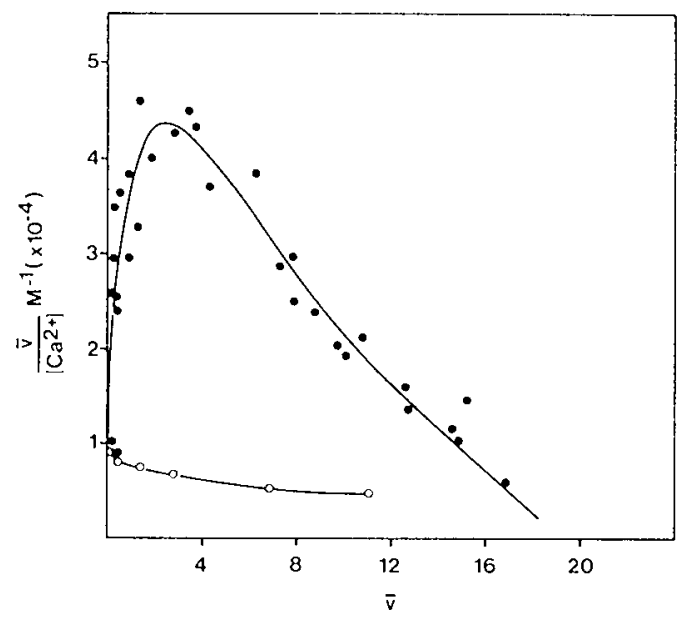

Fig. 4.

Scatchard plot of $\mathrm{Ca}^{2+}$ binding by factor $X$ (solid circles) and PIVKA- $X$ (open circles). Proteins are dissolved in 0.05 i. Tris-HCl, $0.1 \mathrm{M} \mathrm{CaCl}_{2}$ buffer pii 7.5.

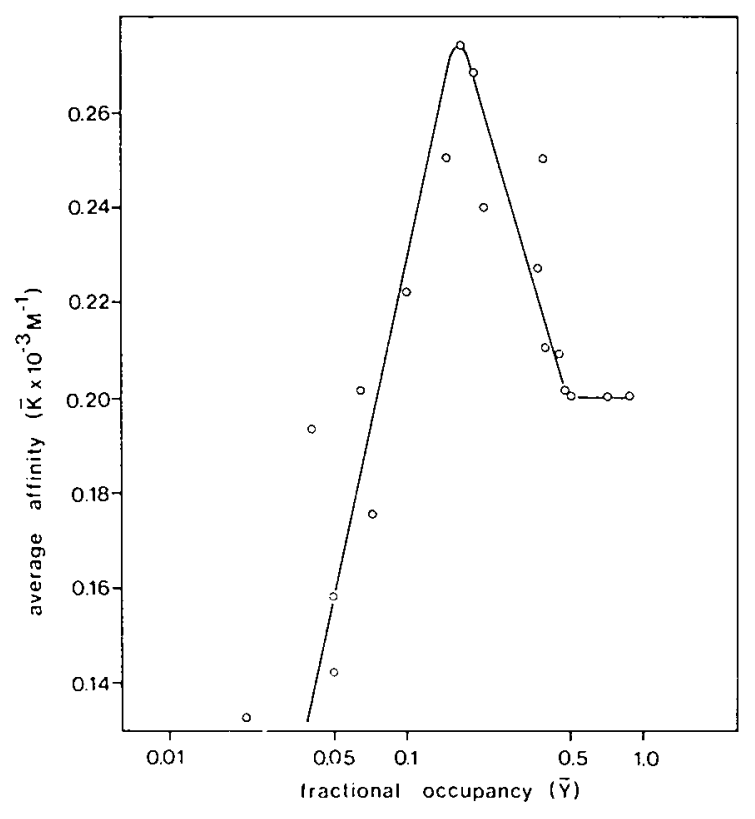

Fig. 5.

The "average affinity" profile of the factor $\mathrm{X} \mathrm{Ca}^{2+}$ binding. Data are those calculated from fig. 4 as described under Haterials and Methods. 
since the steady state concentration in the binding experiment reaches the corrected control value. The results of this experiment were used to construct a Scatchard plot (open circles, fig. 4).

PIVKA- $X$ as compared to factor $X$ gives a different Scatchard plot. Only low affinity binding sites were detected. Because of the very low affinity of PIVKA-X for $\mathrm{Ca}^{2+}$, the total number of binding sites and binding constant cannot be determined.

The complexity of the factor $x$ binding curve due to site-site interaction does not allow to calculate the binding constants from the slopes of the Scatchard plot.

In order to describe the site-site interaction in a different way, we plotted the average affinity of a $\mathrm{Ca}^{2+}$ binding site, $\bar{K}$, versus the fractional occupancy, $\bar{Y}$, according to the method of De Meyts et al. (23). Such a plot for the $\mathrm{Ca}^{2+}$ binding sites in factor $X$ is shown in fig. 5. It clearly demonstrates that when the sites are empty a very low affinity is observed. When occupancy increases, the $\bar{K}$ values also increase until about $20 \%$ of the sites are occupied, i.e. when $4.0 \mathrm{Ca}^{2+}$ per mole factor $X$ are bound. The plot also suggests the presence of negative cooperativity, i.e. decrease of $\bar{K}$ with increase of $\bar{Y}$. However, the scattering of the data points in that region and the uncertainty in determining the number of total binding sites $(N)$, prevent definite conclusions.

Evidence for cooperative $\mathrm{Ca}^{2+}$ binding to factor $X$ was also obtained from the Hill plot shown in fig. 6. Assuming $20 \mathrm{Ca}^{2+}$ binding sites, the binding data of fig. 4 gave two $n_{H}$ values: 1.5 for the binding of the first four moles of $\mathrm{Ca}^{2+}$ and 0.90 for the subsequent ones. From these results we conclude that there are at least two different classes of binding sites, e.g.: positive cooperativity in the binding of the first 3-4 $\mathrm{Ca}^{2+}$ ions and about 16 sites showing non site-site interaction. 


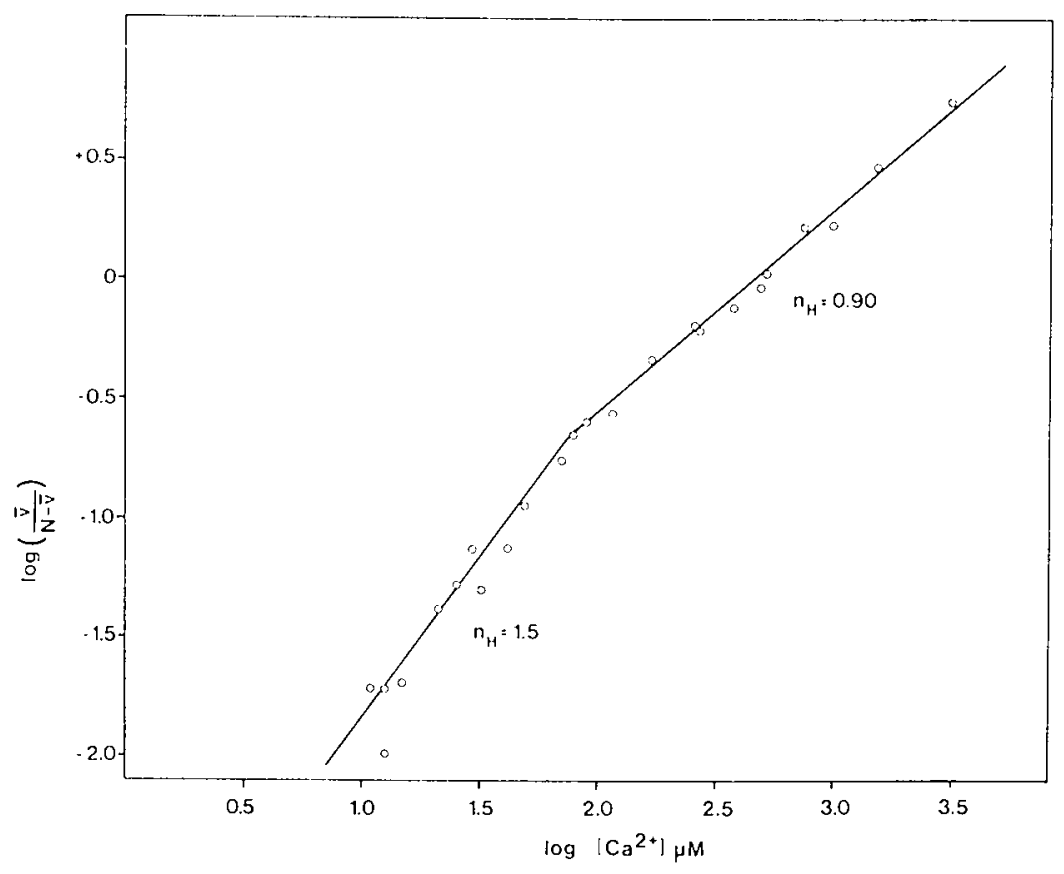

Fig. 0 .

Hill plot of the factor $\times \mathrm{Ca}^{2+}$ binding data. Uata are those of fig. A which were obtained with factor $x$. 
U1traviolet different spectroscopy. Interaction of $\mathrm{Ca}^{2+}$ with factor $X$ changes the ultraviolet difference spectra as is shown in fig. 7. The two absorption peaks at $286 \mathrm{~nm}$ and $293 \mathrm{~nm}$ indicate a significant environmental change for tryptophanyl and possibly tyrosyl chromophores during $\mathrm{Ca}^{2+}$ binding. The changes are not observed in a similar experiment with PIVKA-X. This fact confirms that interaction of $\mathrm{Ca}^{2+}$ with ${ }^{2}$-carboxyglutamate residues perturbs the tryptophane surrounding. The ultraviolet difference spectrum obtained upon binding of $\mathrm{Ca}^{2+}$ to the $y_{\text {-carboxyglutamate residues }}$ indicates a polar perturbation of the tryptophane residues, because such changes are reported to induce a red shift of the ${ }^{1} L_{a}$ band, resulting in a difference spectrum extending into the $300 \mathrm{~nm}$ region and a broad negative band around $260 \mathrm{~nm}(30)$.

As can be seen in fig. 8 , the height of the absorption peak at $293 \mathrm{~nm}$ increases with $\mathrm{Ca}^{2+}$ concentration. Of interest is the curvature of the plot at low $\mathrm{Ca}^{2+}$ concentration. It implies the positive cooperative character of the $\mathrm{Ca}^{2+}$ binding. We conclude that the results obtained by the ultraviolet difference spectroscopy are qualitatively comparable with that obtained by the flow rate dialysis technique. The maximal height of the absorption peak at $293 \mathrm{~nm}$ was obtained at a $\mathrm{Ca}^{2+}$ concentration above $2 \mathrm{~mm}$. It was calculated from the data presented in fig. 4 , that at this concentration the fractional occupancy is about 0.5 . This result suggests that there is no relationship between the number of sites showing cooperativity and the number of binding sites involved in the ultraviolet difference spectrum change.

\section{CONCLUDING REMARKS}

The results of our $\mathrm{Ca}^{2+}$ binding studies indicate that $\mathrm{Ca}^{2+}$ binds positively cooperatively to factor $x$. They are in good agreement with those reported by Henriksen and Jackson (3). PIVKA-X, which is identical to factor $X$ but for the $\gamma$-carboxyglutamate residues, does not show positive cooperativity. We therefore conclude that 


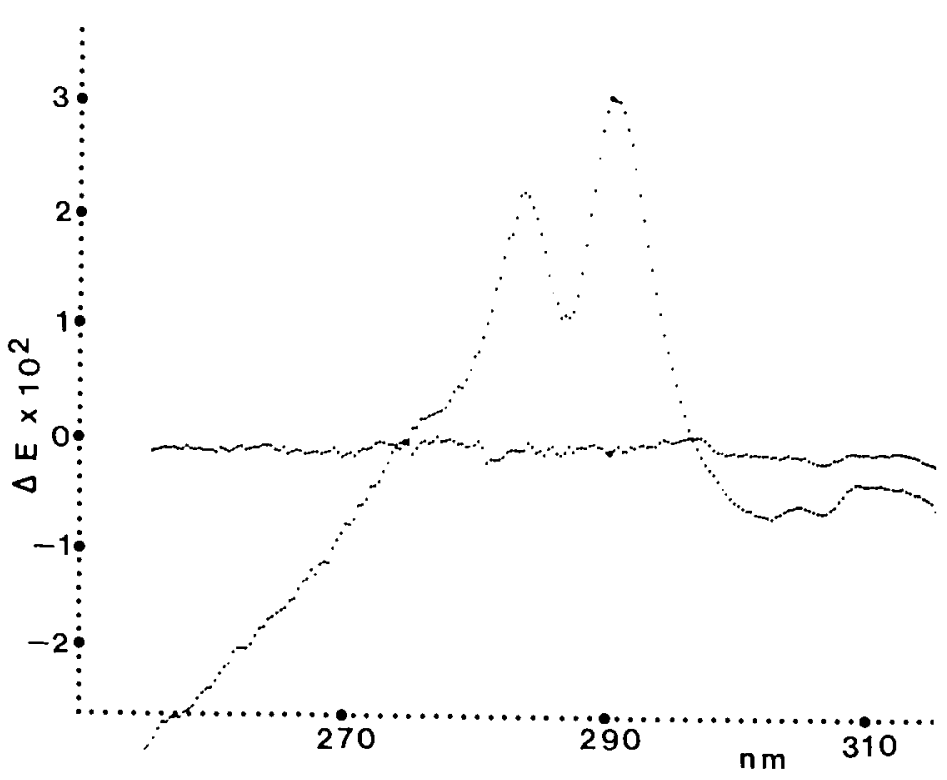

Fig. 7 .

Ultraviolet difference spectrum produced by the interaction of factor $x$ with $\mathrm{Ca}^{2+}$.

Experimental conditions: $1.5 \mathrm{mg}$ factor $X$ dissolved in $0.01 \mathrm{~A} \mathrm{Tris-HCl,} 0.1 \mathrm{M} \mathrm{NaCl}$ buffer $\mathrm{pH}$ 7.5. Finai $\mathrm{Ca}^{2+}$ concentration in the sample cuvette: $5 \mathrm{mM}$.

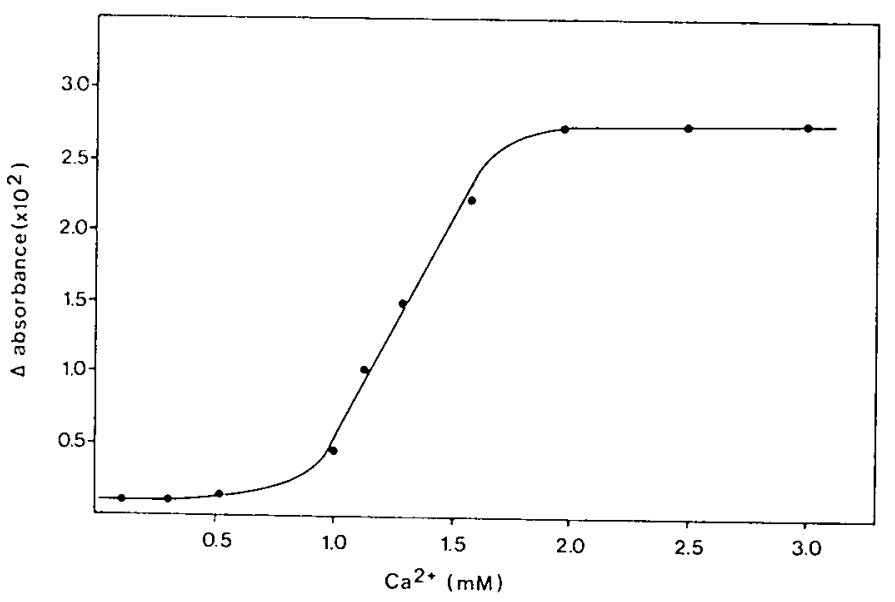

Fig. 8 .

Increase in absorption maximum at $293 \mathrm{~nm}$ produced upon interaction of factor $X(1.5 \mathrm{mg} / \mathrm{mil})$

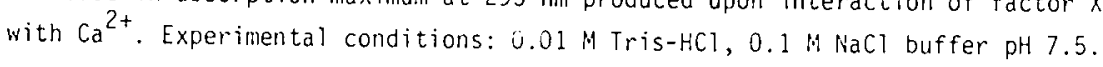


$r$-carboxyglutamate residues are involved in this binding. This is strongly supported by the results obtained with the ultraviolet difference spectroscopy experiments with factor $X$ and PIVKA- $X$. Indeed, only in case of factor $x$ evidence for a conformational change on binding of $\mathrm{Ca}^{2+}$ is obtained. It is further shown that this $\mathrm{Ca}^{2+}$ induced conformational change exhibits cooperativity.

Although several models for the geometry of the $\mathrm{Ca}^{2+}$ binding to $\gamma$-carboxyglutamic acid are proposed (25-27), no conclusion can be put forward about the relationship between the different sets of sites (positive cooperative and non-cooperative) and the number of $\gamma$-carboxyglutamate residues involved in $\mathrm{Ca}^{2+}$ binding.

From recent studies $(28,29)$ on metal ion induced transitions of prothrombin fragment 1 , it appears that prothrombin fragment 1 has two classes of metal binding sites. One set of sites (about 4) apparently non-selective with respect to the metal ion bound, probably triggers a conformational transition, which leads to unmasking of a subsequent set of sites. This second set of sites must be filled in order to permit binding of fragment 1 to phospholipids and to obtain $\mathrm{Ca}^{2+}$ mediated self-association of prothrombin fragment 1 .

The question arises, whether the phenomenon of self-association causes the changes in the ultraviolet difference spectrum. If there is any effect, a reasonable explanation can be given for the observed difference between the number of sites showing positive cooperativity $\left(3-4 \mathrm{Ca}^{2+}\right.$ bound per mole factor $\left.x\right)$ and the number of sites which have to be filled in order to obtain a maximal change in the ultraviolet spectrum (about 10). Perturbation of the tryptophanyl residues caused by self-association may be superimposed on the perturbation due to site-site interaction of the initial binding sites. 


\section{REFERENCES}

1. Stenflo, J., Fernlund, P., Egan, W. and Roepstorff, P. Proc.Nat1.Acad.Sci.USA 71 (1974) 2730

2. Nelsestuen, G.L., Zytkovicz, T.H. and Howard, J.B. J.Biol. Chem. 249 (1974) 6347

3. Henriksen, R.A. and Jackson, C.M. Arch.Biochem.Biophys. 170 (1975) 149

4. Shah, D.V. and Suttie, J.W. Biochem. Biophys.Res.Commun. 60 (1974) 1397

5. Sadowski, J.A., Esmon, C.T. and Suttie, J.W. J.Biol.Chem. 251 (1976) 2770

6. Vermeer, C., Soute, B.A.M., Govers-Riemslag, J. and Henker, H.C. Biochim.Biophys. Acta 444 (1976) 926

7. Gite1, S.N., Owen, W.G., Esmon, C.T. and Jackson, C.M. Proc. Nat1.Acad.Sci.USA 70 (1973) 1344

8. Esmon, C.T., Owen, W.G. and Jackson, C.M. J.Biol.Chem. 249 (1974) 7798

9. Esmon, C.T., Suttie, J.W. and Jackson, C.M. J.Biol.Chem. 250 (1975) 4095

10. Nelsestuen, G.L. and Suttie, J.W. Biochem. 11 (1972) 4961

11. Benson, B.J., Kisiel, W. and Hanahan, D.J. Biochim.Biophys. Acta 329 (1973) 81

12. Stenflo, J. and Ganrot, P.0. Biochem.Biophys.Acta 329 (1973) 81

13. Benson, B.J. and Hanahan, D.J. Biochem. 14 (1975) 3265

14. Bajaj, S.P., Butkowski, R.J. and Mann, K.G. J.Biol.Chem. $250(1975) 2150$

15. Mann, K. G., Bajaj, S.P., Heldebrant, C.M., Butkowski, R.J. and Fass, D.D. Ser. Haemat. 6 (1973) 479

16. Yue, R.H., Starr, T. and Gertler, M.H. Fed.Proc. 31 (1972) 241 (Abstract)

17. Jackson, C.M. Biochem. 11 (1972) 4873

18. Vogel, A.I. (1972) A textbook of quantiative inorganic analys is Longman, London, p. 415 
19. Colowick, S.P. and Womack, F.C. J.Biol.Chem. 244 (1969) 774

20. Scatchard, G. Ann.H.Y.Acad.Sci. 51 (1949) 660

21. Hil1, A.V. J.Physiol. (London) 40 (1910) IV

22. Cornish-Bowden, A. and Koshland, D.E. J.Hol.Biol. 95 (1975) 201

23. De Meyts, P. and Roth, J. Biochem. Biophys.Res.Commun. 66 (1975) 1118

24. Reed, K.U. Biochem. Biophys.Res.Commun. 50 (1973) 1136

25. Howard, J.B. and Nelsestuen, G.L. Proc.Nat1.Acad.Sci.USA 72 (1975) 1281

26. Enfield, D.L., Ericsson, L.H., Walsh, K.A., Neurath, H. and Titani, K. Proc.lvatl.Acad.Sci.USA 72 (1975) 16

27. Jackson, C.M., Dombrose, F.A. and Peng, C.W. Thrombos. Haemostas. 38 (1977) 129 (Abstract)

28. Nelsestuen, G.L. J.Biol.Chem. 251 (1976) 5648

29. Prendergast, F.G. and Mann, K.G. J.Biol.Chem. 252 (1977) 840.

30. Strickland,E.H., Billups, C. and Kay,E. Biochem. 11 (1972) 3657 

ACTIVATION OF DECARBOXY FACTOR X (PIVKA-X) BY A PROTEIN FROM RUSSELL'S VIPER VENOM (RVV-X)

Purification and partially characterization of activated PIVKA-X

SUMMARY

1. Incubation of PIVKA-X with the factor $X$ activating enzyme from Russell's Viper venom revealed the generation of amidase activity towards Bz-ITe-Glu-Gly-Arg-pNA but not of activity in blood coagulation.

2. The rate of activation of both factor $X$ and PIVKA-X depends on the ability of the zymogens to bind $\mathrm{Ca}^{2+}$. The relationship between $\mathrm{Ca}^{2+}$ concentration and velocity of the activation reaction is sigmoid in case of factor $X$ but hyperbolic with PIVKA-X.

3. Activated PIVKA-X was purified by powder column electrophoresis.

4. Identical changes of primary structure accompanied the activation of factor $X$ and PIVKA-X. Identical molecular weight and common antigenic determinants were found in factor $X_{a}$ and PIVKA- $X_{a}$. The amino acid composition was identical except for 10 glutamic acid residues in PIVKA-X $X_{a}$ that are $\gamma$-carboxyglutamic acid residues in factor $x_{a}$.

5. Unlike factor $X$, activated factor $X$ remains in the same position in the presence of calcium at $\mathrm{pH} 8.6$. This is probably due to self-association of factor $x_{a}$ under the influence of $\mathrm{Ca}^{2+}$. The electrophoretic mobility of activated PIVKA-X is only slightly decreased compared to PIVKA-X in the presence of $\mathrm{Ca}^{2+}$. 


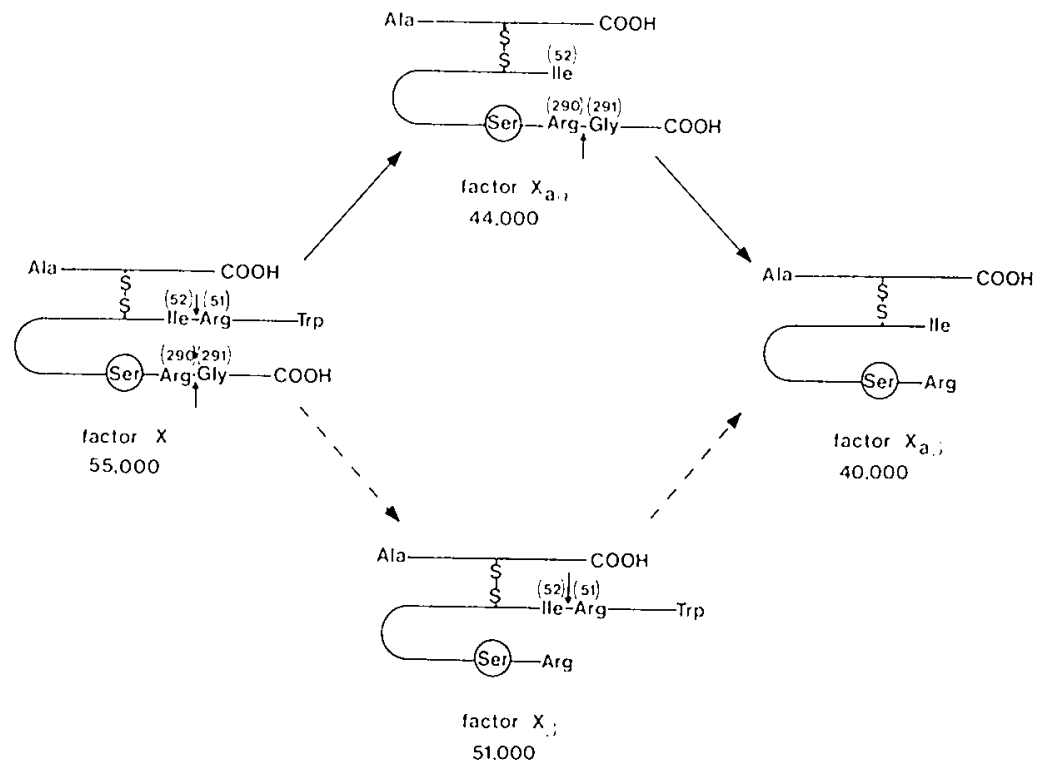

Fig. i.

The mechanism of activation for bovine factor $x$ (14). The solid arrow refers to the major pathway. The active centre serine is circled. 


\section{INTRODUCTION}

Two alternative modes of activation of factor $x$ exist in the physiological blood coagulation process: the extrinsic and the intrinsic system. The principal intrinsic pathway requires tissue thromboplastin and factor VII (1-17). Via the intrinsic pathway factor $X$ is activated by a product of activated factor IX, factor VIII, phospholipids and $\mathrm{Ca}^{2+}$ ions (18-30).

Several non-physiological modes of activation of factor $X$ have also been described, utilizing Russell's Viper venom (RVV) $(15,28,31-41)$, trypsin $(13,42,43)$ and various other reagents (44). It is generally agreed that the activation products obtained with each of these systems exhibit functional similarity in that they rapidly convert prothrombin to thrombin in the presence of factor $V$, phospholipids and $\mathrm{Ca}^{2+}$ ions. Conflicting results are reported concerning physical and chemical properties of the activation products. Seegers and coworkers give evidence which favors different molecular forms of factor $x_{a}$ as obtained by different conditions of activation $(36,45,46)$. Bajaj and Mann (47) showed that trypsin activation of factor $x$ resulted in an eight fold higher yield of factor $x_{a}$ than obtained with the venom. Whether this is due to the formation of a different species of factor $x_{a}$ is unknown.

Radcliff and coworkers concluded that the different ways of activation yield essentially the same product (13). Recent studies $(14,34,35)$ showed that the conversion of factor $X$ (M.W. 55,000) to factor $x_{a}$ by factor IX ${ }_{a}$ and factor VIII, factor VII and tissue factor, a protease from Russell's Viper venom or pancreatic trypsin is due to cleavage of an activation peptide from the $\mathrm{NH}_{2}$-terminal region of the heavy chain. This cleavage occurs between Arg-51 and Ile-52, giving rise to factor $X_{a c i}$ (M.W. 45.000) and an activation peptide (M.W. 9,500). Factor $X_{a c i}$ is converted into factor $x_{a, z}(M . W .42,600)$ by hydrolysis of a second peptide bond between Arg-290 and G1y-291 at the $\mathrm{C}$-terminal region 
of the heavy chain. Jesty et al. noted that the conversion of factor $x_{a \alpha}$ to factor $x_{a \beta}$ could be catalyzed by factor $x_{a \alpha}$ in the presence of $\mathrm{Ca}^{2+}$ and phospholipids $(16,48)$.

A minor pathway involving the cleavage of more than one peptide bond has also been reported. In a slow reaction, factor $X$ is converted into factor $X_{B}$ (M.W. 51,000) by intrinsic activators, factor VII and tissue thromboplastin or trypsin by cleavage of the peptide bond between Arg-290 and Gly-291. Factor $X_{\beta}$ has no enzymatic activity. It can be further hydrolyzed into factor $x_{a \beta}$. The mechanism of activation for factor $x$ is summarized in figure 1 (from Fujikawa et al. ref. 14).

Factor $X$ activated by one of the agents described above is the protein that contributes the active site to prothrombinase, the physiological activator of prothrombin consisting of factor $V$, phospholipids and $\mathrm{Ca}^{2+}(49)$. Factor $\mathrm{X}_{a}$ alone has a small prothrombinase activity. Unlike factor $x$, PIVKA-X lacks the ability to bind $\mathrm{Ca}^{2+}$, and does not function normally in blood coagulation. Whether this is because PIVKA-X cannot be split by factor $X$ activation agents or because "activated" PIVKA-X is still inactive in prothrombinase was as yet unknown.

This chapter describes the activation mechanism of PIVKA-X by Russel1's Viper venom. The role of $\mathrm{Ca}^{2+}$ in the activation process is studied, and the purification and partially characterization of activated factor $X$ and PIVKA-X are described.

MATERIALS AND METHODS

All chemicals were analytical grade and obtained from Merck. Factor $X$ and PIVKA-X were obtained according to the purification procedures described in chapter II. Russell's Viper venom was obtained from Sigma Chemical Co., St. Louis, USA and the factor $X$ activator (RVV-X) was purified with the method according to Schiffman (50). The chromogenic substrate Bz-Ile-Glu-Gly-Arg-pNA (S-2222) was a kind gift of Dr.G.Claeson, A.B. Bofors Nobel Division, Peptide Research, Mölndal, Sweden. p-Nitrophenyl- 
guanidino-benzoate (NPGB) was purchased by Biochemical Nutrition Comp.

Amino acid and $\mathrm{NH}_{2}$-terminal amino acid analysis. The amino acid composition was determined by means of the method according to Spackman (51). Amino terminal amino acid analysis was performed according to Gray (52), y-carboxyglutamic acid was determined with the modified method of Zytkovicz (53). More details about the analysis are described in chapter II.

Protein concentration determination. Concentration of total protein in solutions was determined with absorbance at $280 \mathrm{~nm}$, assuming $E_{1 \%}^{1 \%}$ for factor $X=12.4(54)$. The same value could be used for determination of PIVKA-X concentration because the molecular weight and amino acid composition for factor $X$ and PIVKA-X are equivalent. An $E_{280}^{1 \%} \mathrm{~nm}$ of 10.0 was employed for the venon coagulation protein (39) and $E_{280 \mathrm{~nm}}^{1 \%}$ of 12.2 for factor $X_{a}$ (RVV) and PIVKA-X $X_{a}$ (RVV)

Gel electrophoresis. Analytical polyacrylamide gel electrophoresis, disc-gel electrophoresis in the presence of sodium dodecyl sulphate and agarose gel electrophoresis were performed as described in chapter II.

Immunochemical methods. The one-dimensional crossed immunoelectrophoresis, employed for PIVKA-X determination using monospecific anti-bovine factor $X$ antiserum, was performed with the method of Laurell (55) as described in more detail in chapter II. Double immunodiffusion was performed according to Ouchterlony (56).

Factor $X$ assay. Factor $X$ was activated in suitable mixtures as described under Methods. At intervals, 10,11 aliquots were removed from the activation mixtures and diluted with $1.0 \mathrm{ml}$ Michaelis buffer containing $10 \mathrm{mM}$ EDTA. The samples were further diluted with Michael is buffer depending on the degree of activation. 
Subsequently, an aliquot $(0.1 \mathrm{ml})$ of the final dilution was incubated at $37^{\circ} \mathrm{C}$ for $30 \mathrm{sec}$ with $0.1 \mathrm{ml}$ cephal in prepared with the method of Bell (57) from bovine brain and $0.1 \mathrm{ml}$ factor $X$ deficient bovine plasma. Clotting was initiated by adding $0.1 \mathrm{ml}$ of $33 \mathrm{mM} \mathrm{CaCl} 2$ solution to the incubation mixture. The clotting times were converted into units obtained by a reference curve of the logarithm of clotting time against the logarithm of dilutions of activated factor $x$. One unit factor $x_{a}$ activity per $\mathrm{ml}$ was defined as the activity of 10 ig factor $x_{a}$ per $\mathrm{ml}$, i.e. about the amount that can be generated in $1 \mathrm{ml}$ normal plasma.

Active site titration. Titration of factor $X_{a}$ and PIVKA-X with p-NPGB was performed according to Smith (58). In a typical titration the sample cuvette contains $0.3 \mathrm{mg}$ per $\mathrm{ml}$ of factor $x_{a}$ or PIVKA- $x_{a}$ in $0.1 \mathrm{M}$ sodium barbital pH 8.3 with a final volume of $300 \mathrm{kl}$. The reference cuvette contains the same volume of buffer solution alone. To each cuvette $10 \mu l$ of a 0.01 M solution of $p$-NPGB in dimethylformamide-acetonitrile $(1: 3 \mathrm{v} / \mathrm{v})$ was simultaneously added.

The reaction was followed at $410 \mathrm{~nm}$ in an Aminco DW-2 spectrophotometer at $25^{\circ} \mathrm{C}$. The concentration of $p$-nitrophenol released during the reaction was calculated from the zero time intercept of the extrapolated steady state absorbance. In the Aminco DW-2 spectrophotometer $\varepsilon_{410}$ for p-nitrophenol at $\mathrm{pH} 8.3$ was calculated as 17,500 .

Amidase activity assay. The amidase activity of activated factor $X$ and activated PIVKA- $X$ was measured according to svendsen et a 1 . (59). At intervals, 10,1 al iquots were removed from the incubation mixture and diluted with 90,11 of $0.05 \mathrm{M} \mathrm{Tris-HCl}$ $0.05 \mathrm{M}$ imidazole buffer ( $\mathrm{pH} 8.3$ ) containing $0.1 \mathrm{M} \mathrm{NaCl}$ and $10 \mathrm{mM}$ EDTA. To obtain a final volume of $350,1 ! 1,320 \quad 0.05 \mathrm{M}$ Tris-HCl, $0.05 \mathrm{M}$ imidazole buffer ( $\mathrm{pH} 8.3$ ) containing $0.1 \mathrm{M} \mathrm{NaCl}$, 25 ul solution of Bz-Ile-Glu-Gly-Arg-pNA (S-2222) in water (2 mM) and 5,11 of the diluted sample were mixed. 
The initial rate of hydrolysis was measured in an Aminco DW-2 spectrophotometer, operating in the dual wavelength mode. Analysis was conducted at $37^{\circ} \mathrm{C}$ and amidase activity is expressed as $\mathrm{AA}_{391-344} / \mathrm{min}$

Rate of conversion of factor $X$ and PIVKA-X. The following incubation procedure was used when factor $X$ and PIVKA-X were activated by RVV $X$. Buffer solution of 0.05 M Tris-HCl 0.05 M imidazole ( $\mathrm{pH} \mathrm{8.3),}$ containing $0.1 \mathrm{M} \mathrm{NaCl}, \mathrm{RVV}-\mathrm{X}, \mathrm{S}-2222$ and factor $X$ or PIVKA-X was added to a microcuvet (Helma, type 105 os with 10 mm lightpath). The final concentrations of the reaction components are given in the legend to figure 4 . The endogenous rate of hydrolys is of S-2222 was measured before the reaction was initiated by addition of $\mathrm{Ca}^{2+}$.

A11 assays were performed in an Aninco DW-2 spectrophotometer operating in the dual wavelength mode. The hydrolysis of S-2222 was measured at $391 \mathrm{~nm}$ with $344 \mathrm{~nm}$ as the reference wavelength. The determination was carried out at $37^{\circ} \mathrm{C}$ and amidase activity was expressed as $\triangle \mathrm{A}_{391-344^{/ m i n} \text {. }}$

Preparation of factor $X_{a}$. A solution containing $48 \mathrm{mg}$ of factor

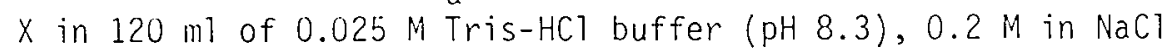
was made $5 \mathrm{mM}$ with respect to $\mathrm{CaCl}_{2}$ and incubated at $37^{\circ} \mathrm{C}$ for $30 \mathrm{~min}$. with $0.8 \mathrm{mg}$ of the factor $X$ converting protein from Russell's Viper venom. Complete activation of factor $X$ was achieved as judged by factor $X_{a}$ activity assay of the incubation mixture. The reaction mixture was then diluted two times with $0.05 \mathrm{M}$ Tris-HCl (pH 7.1) containing 0.06 M trisodium citrate and dialyzed overnight against the same buffer. Then the incubation mixture was applied to a column $(30 \times 1.5 \mathrm{~cm})$ of DEAE-Sephadex equilibrated in the dialysis buffer. Factor $X_{a}$ was eluted by a linear NaCl gradient $(0-0.6 \mathrm{M})$ in $0.05 \mathrm{M} \mathrm{Tris-HCl}$ buffer $\mathrm{pH}, 8.0$ containing $0.1 \mathrm{M}$ trisodium citrate. 

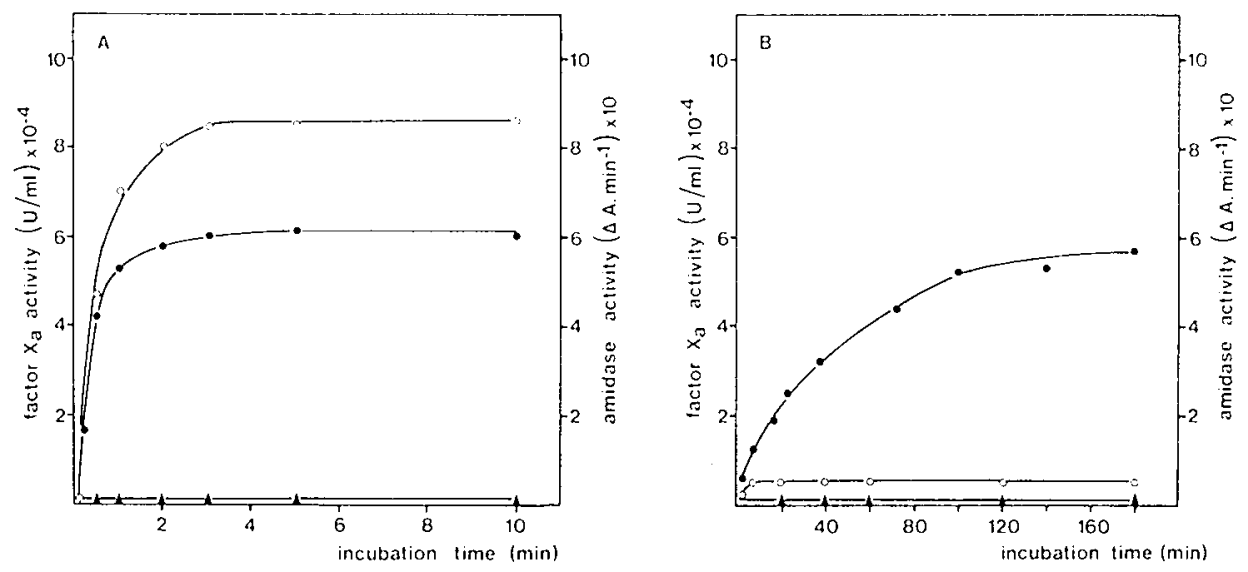

Fig. 2.

Activation of factor $X$ and PIVKA-X by RVV-X.

A. Factor $\ddot{x}(0.8 \mathrm{mg} / \mathrm{ml})$ was incubated with RVV- $x(10 \mathrm{gg} / \mathrm{ml})$ and $\mathrm{Ca}^{2+}, 10 \mathrm{~mm}$ final concentration.

B. PIVKA-X $(1.0 \mathrm{mg} / \mathrm{ml})$ was incubated with RVV-X $(25 \mathrm{gg} / \mathrm{ml})$ and $\mathrm{Ca}^{2+}, 10 \mathrm{mil}$ final concentration.

- - factor $x_{a}$ activity as determined by bioassay.

- amidase activity towards Bz-11e-Glu-Giy-Arg-piNA.

- - anidase activity. Activation carried out in the presence of $10 \mathrm{~m}$ EDTA.

A

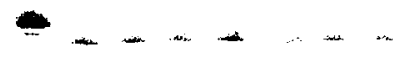

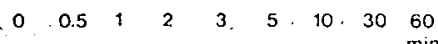
$\min$
B

$\begin{array}{lllllllllll}0 & 0.5 & 1 & 2 & 3 & 5 & 10 & 30 & 60 & 90 \\ \min \end{array}$

Fig. 3 .

Time courses of activation of factor $X$ and PIVKA-X by RWV.

A. Factor $x, 0.7 \mathrm{mg} / \mathrm{ml}$ in 0.025 H Tris-HCl buffer $\mathrm{pH} 7.4-0.2 \mathrm{H} \mathrm{ilaCl}$, was incubated with RWV-X, $7 . \mathrm{g} / \mathrm{ml}$, in the presence of $10 \mathrm{~m}$ i $\mathrm{Ca}^{2+}$. At several time intervals, samples, 50.1 , were removed and added to $50:: 1$ of 5 . sodium dodecyl sulfate, followed by heating to $100^{\circ} \mathrm{C}$ for 2 min. before electrophoresis.

B. PIVKA-X, $1.0 \mathrm{mg} / \mathrm{ml}$ in $0.025 \mathrm{H}$ Tris-HCl buffer $\mathrm{pH} 7.4-0.2 \mathrm{H} \mathrm{iaCl}$, was incubated with RWV-x, $10 \mathrm{~g} / \mathrm{ml}$, in the presence of $10 \mathrm{~m}^{\mathrm{C}} \mathrm{Ca}^{2+}$. Samples, $50: .1$, were removed at the times shown and treated as described for factor $x$. 
Preparation of activated PIVKA-X. Semi-purified PIVKA-X obtained after QAE-Sephadex chromatography (fig. 10, chapter II) was dialyzed against $0.025 \mathrm{M}$ Tris-HCl buffer pH 7.4 contairing $0.1 \mathrm{M}$ $\mathrm{NaCl}$.

PIVKA-X, $40 \mathrm{mg}$ in $25 \mathrm{ml}$ of dialysis buffer was incubated with $1 \mathrm{mg}$ RVV $-X$ in the presence of $10 \mathrm{mM} \mathrm{Ca}{ }^{2+}$ at $37^{\circ} \mathrm{C}$ for $100 \mathrm{~min}$. The reaction was stopped by the addition of EDTA to a final concentration of $10 \mathrm{mM}$. Then the reaction mixture was dialyzed against $2 \mathrm{mM}$ Trisglycine buffer $\mathrm{pH} 8.3$ containing 1 mM EDTA. Activated PIVKA-X was isolated by powder column electrophoresis according to Rosenbaum (60). All buffers contained $5 \mathrm{mM}$ calcium lactate, in order to obtain a separation between PIVKA-X $X_{a}$ and residual amounts of factor $X_{a}$. The column of the LKB 7900 Uniphor apparatus was packed with a slurry of Biogel P-300 (100-200 mesh) in 0.025 M Tris-glycine buffer $\mathrm{pH} 8.3$. A volume of $25 \mathrm{ml}$ of $0.025 \mathrm{M} \mathrm{Tris-HCl}$ buffer, pH 8.2 was allowed to flow into the column and then the sample, $30 \mathrm{mg}$ protein dissolved in $25 \mathrm{ml}$ Tris-HCl buffer was allowed to flow into the column. After the sample had entered the column, Tris-glycine buffer pH 8.3 was placed on the top of the column. A potential difference of $600 \mathrm{~V}$ was applied and the power was maintained at $16 \mathrm{~W}$ throughout the course of the separation. The sample was eluted from the bottom of the column with Trisglycine buffer $\mathrm{pH} 8.3$ at a flow rate of $30 \mathrm{ml}$ per hour. Fractions of $3 \mathrm{ml}$ were collected. PIVKA-X $x_{a}$ was determined by amidase assay as described el sewhere.

\section{RESULTS}

Activation of bovine factor $X$ and PIVKA-X by RVV-X. Activation of factor $X$ and PIVKA- $X$ by the purified protease from Russell's Viper venom (RVV-X) was followed in time. Fig. $2 A$ shows the curves for factor $X_{a}$ activity (open circles) and amidase activity (solid circles) upon action of RVV-X. The weight ratio of RVV-X to factor $X$ in this experiment was $80: 1$. The results show a good 
agreement between formation of factor $x_{a}$ activity and amidase activity. The reaction is essentially complete within 3 min.

It is also demonstrated that EDTA completely inhibits the activation reaction (solid triangles).

Fig. $2 B$ shows the time course for PIVKA-X activation by RVV-X as measured for factor $X_{a}$ activity (open circles) and amidase activity (solid circles). For the activation of PIVKA-X the weight ratio of PIVKA-X to $R V V-X$ was $50: 1$. In contrast with an almost negligible formation of factor $x_{a}$ activity within 2 min., a progressively increase in amidase activity is demonstrated. The small factor $X_{a}$ activity generated by RVV-X from PIVKA-X is most likely to be due to a contamination of factor $X(<5 \%)$. Under the conditions used, PIVKA-X is almost completely activated within $150 \mathrm{~min}$. As in the activation of factor $X$, EDTA inhibits the reaction completely. The final yield of amidase activity per mole of zymogen with PIVKA- $X$ is about $90 \%$ of that obtained with factor $x$.

Wolecular weight changes in factor $X$ and PIVKA-X upon activation were also monitored. At intervals aliquots were removed from the activation mixture and analyzed by SDS gel electrophoresis (fig. 3). Fig. $3 \mathrm{~A}$ gives the result of factor $X$ activation with RVV-X. The large protein band at zero time decreases in intensity during the first minutes of activation. Parallel with the disappearance of this band a new faster moving protein band appears. Appearance of this band coincides with the generation of factor $x_{a}$ and amidase activity (fig. 2), and can be assigned to as factor $x_{a}$ (14) At longer incubation time a slightly faster moving protein band was also observed, this will be referred to as factor $x_{a \beta}$ (14). Because the $x_{a}$ activity and amidase activity remain unchanged, factor $x_{a w}$ and $x_{a, 3}$ have the same specific activity.

Qualitative the same molecular changes, as described for factor $X$ were observed in PIVKA-X upon incubation with RVV-X (fig. 3B). 

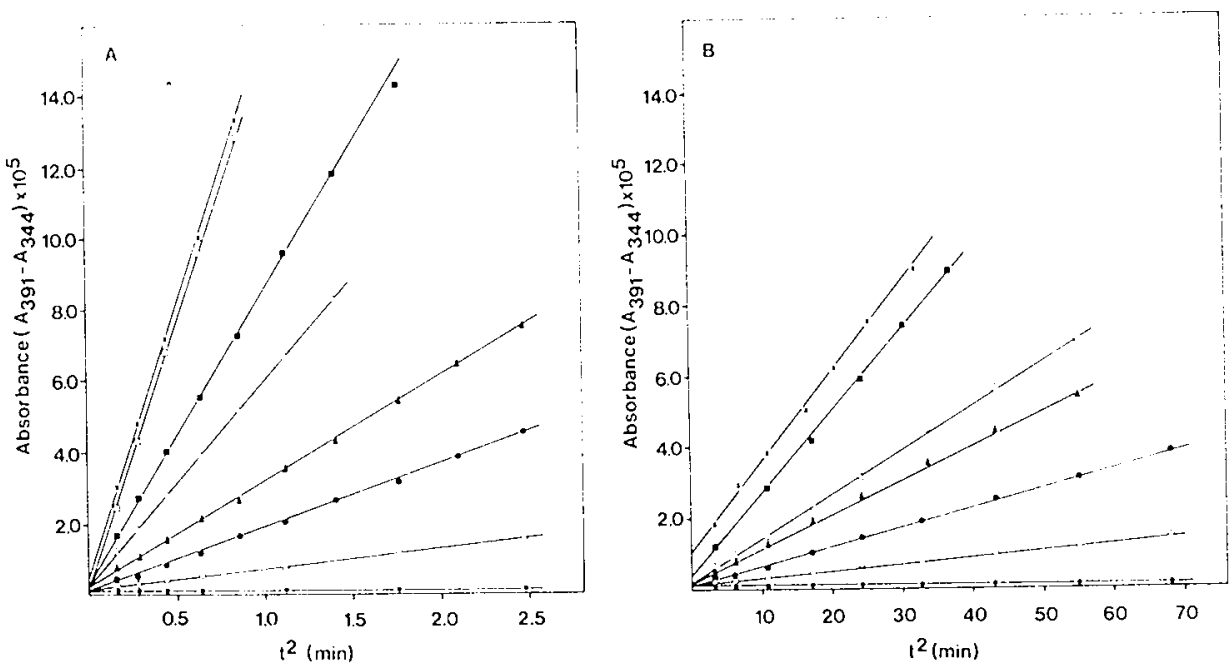

Fig. 4.

The effect of $\mathrm{Ca}^{2+}$ on factor $X$ and PIVKA-X activation by RVV-X.

$A$. The time courses of activation of factor $X$. Factor $X, 13 \mathrm{jg} / \mathrm{ml}$, was incubated with RVV-X, $0.12, . \mathrm{g} / \mathrm{ml}$ in the presence of $B z-[1 \mathrm{l}-G] \mathrm{G}-G 1 \mathrm{y}$-Arg-pNA $\left(1.1 \times 10^{-4} \mathrm{~m}\right)$. The final concentration of $\mathrm{Ca}^{2+}$ in the activation mixture was:

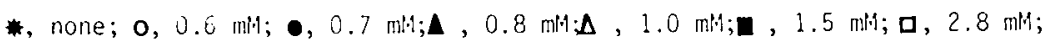
$x, 5.6 \mathrm{~m}$.

$B$. The time courses of activation of PIVKA-X. PIVKA-X, $13: .9 / \mathrm{ml}$, was incubated with RVV-X, $0.12: \mathrm{g} / \mathrm{ml}$, in the presence of Bz-Ile-Glu-Gly-Arg-pNA $\left(1.1 \times 10^{-4} \mathrm{M}\right)$. The final concentration of $\mathrm{Ca}^{2+}$ in the activation mixture was:

*, none; $0,0.3 \mathrm{~min} ; \bullet, 0.6 \mathrm{mir} ; \mathbf{\Delta}, 1.0 \mathrm{mir} ; \Delta, 1.5 \mathrm{mH} ; \mathbf{m}, 3.0 \mathrm{~min} ; \mathbf{x}, 6.0 \mathrm{~min}$. Experimental conditions as described under Methods. 
The appearance of a new faster moving protein band coincided with the generation of anidase activity. Both occurred at a slower rate with PIVKA-X than with factor $X$.

Influence of $\mathrm{Ca}^{2+}$ on rate of activation of factor $X$ and PIVKA-X by RVV-X. The rate of factor $X$ and PIVKA-X activation by RVV-X was measured by a continuous spectrophotometric assay as described under Methods. In case of a linear rate of factor $x_{a}$ or PIVKA-X formation, the increase of amidase activity towards Bz-Ile-GluGly-Arg-pNA will be parabolic in time. A plot of absorbance versus $t^{2}$ yields a straight line the slope of which indicates the initial velocity of the activation reaction (28). The linear relationship between absorbance and $t^{2}$ obtained from activation experiments at variable $\mathrm{Ca}^{2+}$ concentrations is shown in fig. 4 . The effect of $\mathrm{Ca}^{2+}$ on the initial rate of the activation of factor $X$ and PIVKA-X by RVV-X is shown in fig. 5 . It is shown that under optimal conditions the initial rate of factor $X_{a}$ formation is about 60 times higher than the initial rate of PIVKA-X formation. Of particular interest in these studies were the differences in nature of the $\mathrm{Ca}^{2+}$ dependence: sigmoid and hyperbolic in case of factor $X$ and PIVKA-X activation, respectively (fig. 5). The Hill plot (fig. 6) of the data presented in fig. $5 \mathrm{~A}$ and $5 \mathrm{~B}$ suggests cooperativity and non-cooperativity in the $\mathrm{Ca}^{2+}$ dependent activation of respectively factor $X$ and PIVKA-X.

Preparation of activated factor $x$. Factor $x_{a}$ was separated from the activation mixture described under Methods by a single step of DEAE-Sephadex chromatography. To prevent a further conversion of factor $x_{a:}$ into factor $x_{a \beta}$ (14) the activation was stopped by addition of trisodium citrate instead of EDTA. The latter was found to precipitate factor $x_{a}$ with considerable loss of activity. Precipitation of protein material during the incubation was observed when factor $X$ concentrations greater than $500: ! g$ per $\mathrm{ml}$ were used in the activation mixture. This is probably due to the $\mathrm{Ca}^{2+}$ mediated aggregation of factor $X_{a}$. 

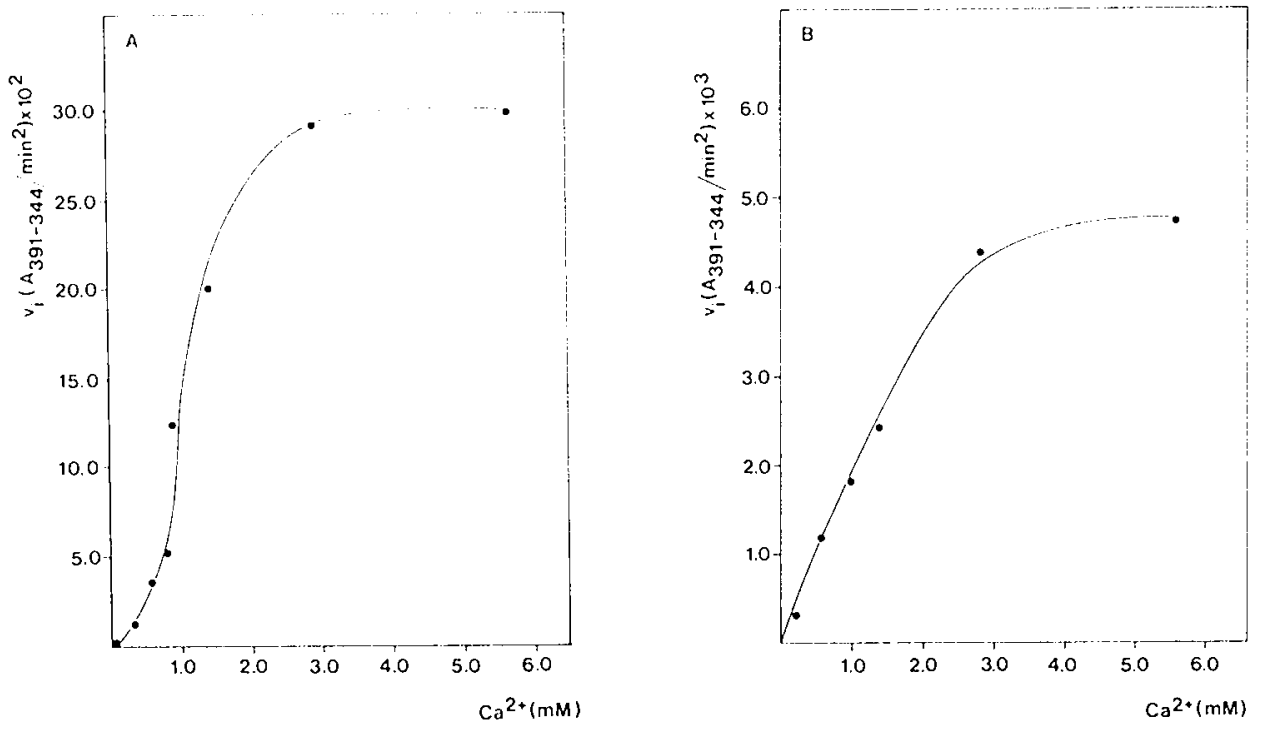

iig. 5 .

Rate of generation of amidase activity from factor $X$ (panel $A$ ) and PIVKA-X (panel B) by RVV-X at various $\mathrm{Ca}^{2+}$ concentrations, as determined from fig. 4.

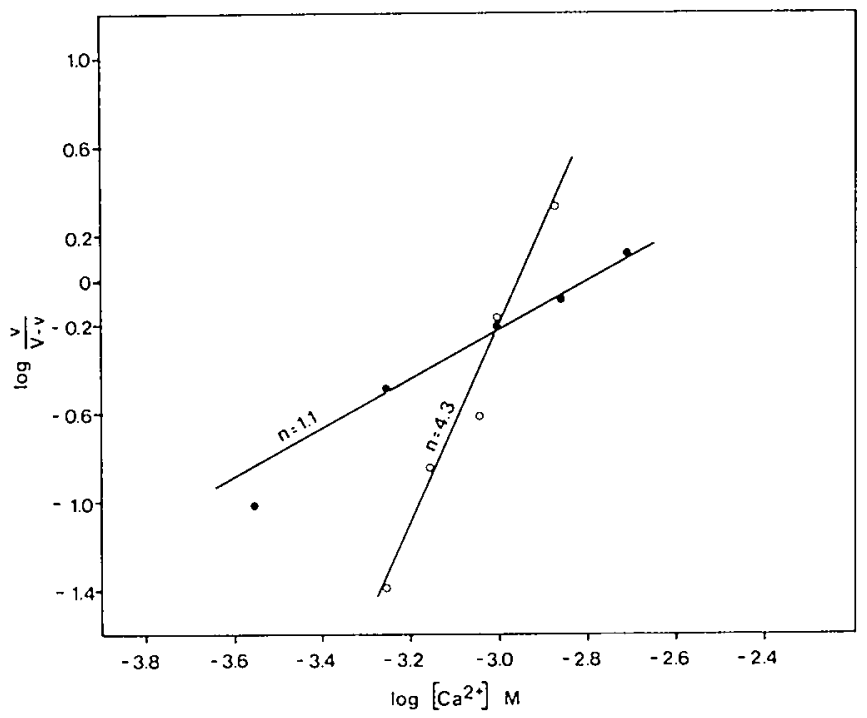

Fig. 6 .

Hill plot of the data presented in fig. $5 A$ and $B$., where $v=$ initial velocity at any $\mathrm{Ca}^{2+}$ concentration, $y=$ initial velocity at optimal $\mathrm{Ca}^{2+}$ concentration, -o-, factor $X$; - , PIVKA-X. 


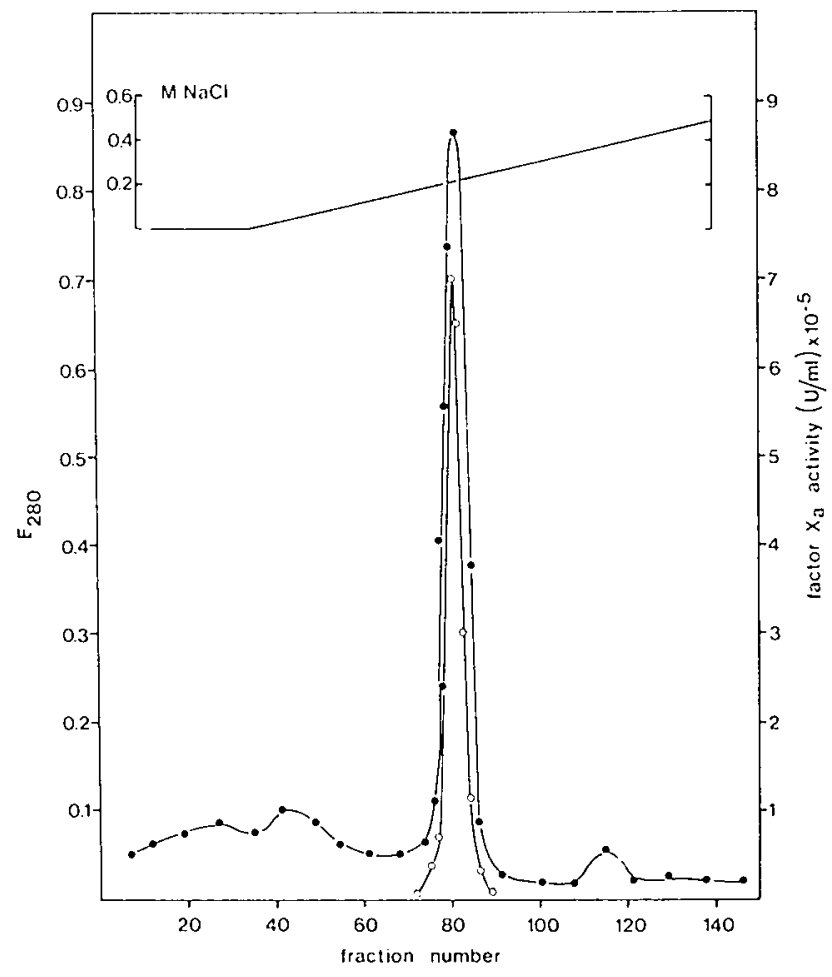

Fig. 7 .

Purification of factor $x_{a}$.

Factor $X, 48 \mathrm{mg}$ in $120 \mathrm{ml}$ of a reaction mixture containing 0.025 " Tris-HCl buffer, $\mathrm{pH}$. $3.0-0.2 \mathrm{M} \mathrm{NaCl}$ and $5 \mathrm{mill}^{2+}$ was activated by RVV-X, $0.2 \mathrm{mg}$, for $30 \mathrm{~min}$. at $37^{\circ} \mathrm{C}$. After dialysis against $0.05 \mathrm{M}$ Tris-HCl buffer, $0.06 \mathrm{li}$ trisodium citrate, $\mathrm{pH} 7.1$, the solution was appiied to a DEAE-Sephadex column $(30 \times 1.3 \mathrm{~cm})$, equilibrated with the dialysis buffer. The column was eluted with a linear gradient, $250 \mathrm{ml}$ per gradient chamber, from $0-0.6 \mathrm{M} \mathrm{NaCl}$ in $0.05 \mathrm{MTris}-\mathrm{HCl}$ buffer, 0.1 iil trisodium citrate $\mathrm{pH} 8.0$, at $30 \mathrm{ml}$ per hour. Fractions of $4.5 \mathrm{ml}$ were collected. - - , protein $\left(E_{280 \mathrm{~nm}}\right)$; $-0-$, factor $x_{a}$ activity; -., iracl gradient. 
Factor $x_{a}$ was eluted from the DEAE-Sephadex column at a $\mathrm{NaCl}$ concentration of $0.24 \mathrm{M}$ in a single peak (fig. 7). The factor $\mathrm{x}_{a}$ prepared by this method is homogeneous as is shown by disc gel electrophoresis. It is further shown that factor $x_{a}$ has a higher electrophoretic mobility than factor $x$ (fig. 8 ). The specific activity of the preparation as determined by bioassay was found to be $3.0 \times 10^{5} \mathrm{U} / \mathrm{mg}$ protein. The functional enzyme concentration as determined by NPGB titration was about $90 \%$ of the actual protein concentration $\left(5.5 \times 10^{-6} \mathrm{M}\right)$.

Preparation of activated PIVKA-X. The activation procedure of PIVKA- $X$ was performed as described under Methods. After maximal amidase activity was formed, activated PIVKA-X was purified from the activation mixture by powder column electrophores is with continuous elution. $\mathrm{Ca}^{2+}$ was present in the electrophoresis buffer in order to decrease the electrophoretic mobility of factor $x_{a}$ which may be present as a contamination in the activation mixture.

The relevant part of the elution profile of the electrophoresis is shown in fig. 9. The first large protein peak contained amidase activity and was found to crossreact with monospecific anti-bovine factor $X$ antiserum. The PIVKA-X containing fractions were pooled and concentrated to about $5 \mathrm{ml}$ (Amicon PM-10 membrane).

The final yield is about $30 \%$, as calculated from protein recovery. The specific activity as determined by bioassay for factor $x_{a}$ activity was approximately $6 \times 10^{2} \mathrm{U} / \mathrm{mg}$ protein. This is less than $1 \%$ of the specific activity general determined for purified factor $x_{a}$. The functional PIVKA-X concentration as assayed by NPGB titration was about $75 \%$ of the calculated protein concentration.

The PIVKA-X $X_{a}$ prepared with this method was homogeneous in polyacrylamide gel electrophoresis and has in absence of $\mathrm{Ca}^{2+}$ an electrophoretic mobility equal to factor $x_{a}$ (fig. 8). 


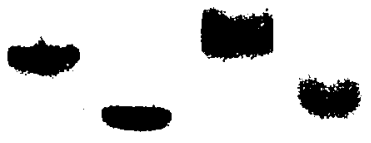

Fig. 8.

Polyacrylamide disc gel electrophoresis of purified factor $x_{(a)}$ and PIVKA-X $(a)$.

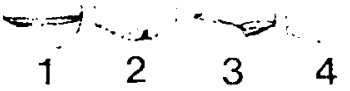
Gel 1: factor $X, 50 . . g$; gel 2: factor $X_{a}, 50 . .9$; gel 3: PIVKA-X, $50 \mathrm{ig}$; gel 4: PIVKA-Xa $, 30:$.

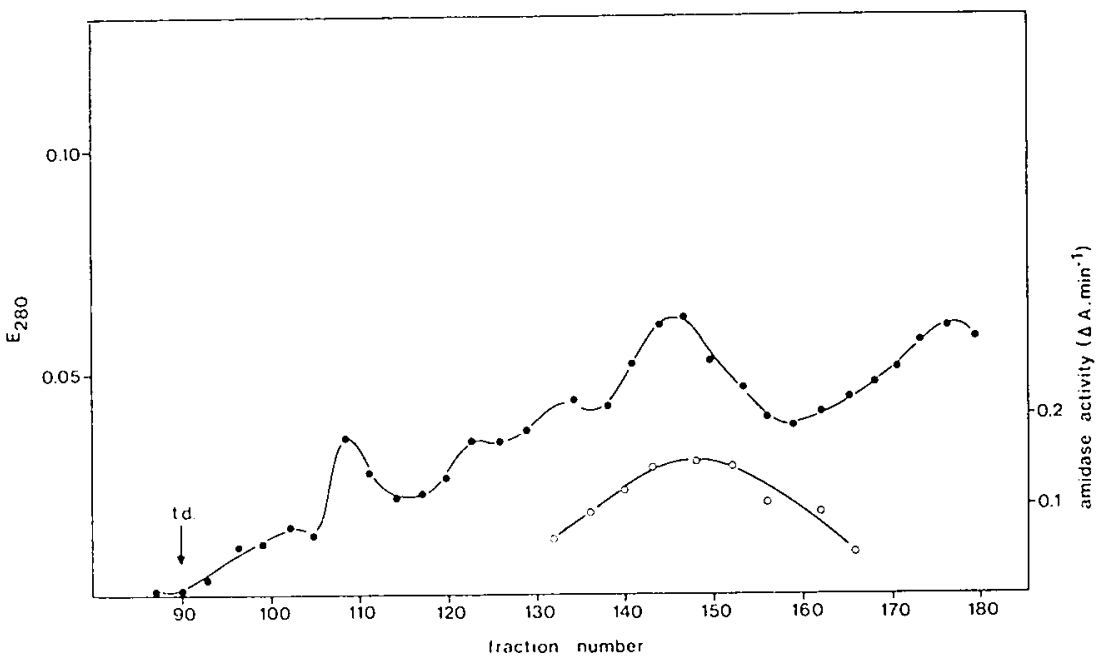

Fig. 9 .

Purification of activated PIVKA-X by preparative powder column electrophoresis. Experinental conditions as described under Hethods. $-\bullet$, protein $\left(E_{280} \mathrm{~nm}\right) ;-\mathbf{0}^{-}$, amidase activity towards Bz-Ile-Glu-Gly-Âg-pNA, t.d., tracking dye (bromophenol blue). 
Zone electrophoresis of factor $x_{-a}$ and PIVKA-X $x_{a}$. In order to study the electrophoretic mobility of factor $x_{a}$ and PIVKA-X $x_{a}$ in the presence of EDTA or $\mathrm{Ca}^{2+}$ we performed an electrophoresis in agarose gel at pH 8.6 as described in chapter II. Fig. 10 (left) shows the electrophoretic mobility in the presence of EDTA. It is demonstrated that factor $x_{a}$ and PIVKA- $x_{a}$ have identical electrophoretic mobilities, that are somewhat lower than that of factor $x$. In the presence of $\mathrm{Ca}^{2+}$ factor $\mathrm{x}_{a}$ has lost its electrophoretic mobility and even tends to migrate to the cathode. It is also shown that the electrophoretic mobility of PIVKA-X $x_{a}$ is retarded in the presence of $\mathrm{Ca}^{2+}$ (fig. 10 , right panel).

Immunodiffusion. In double immunodiffusion experiments according to Ouchterlony (56) single precipitation 1 ines were observed for anti-factor $X$ against activated factor $X$ and activated PIVKA-X. Reactions of partial identity were observed. The results indicate that the two proteins have antigenic determinants in common (fig. 11).

Polyacrylanide gel e? ectrophores is in the presence of sodium dodecyl sulphate. Electrophoresis of purified factor $x_{a}$ and PIVKA- $X_{a}$ on polyacrylamide in the presence of sodium dodecyl sulphate according to Weber and Osborn (61) shows that both enzymes have an identical molecular weight of about 48,000 (fig. 12, gels 1 and 3). Electrophoresis after disulfide reduction demonstrates that the proteins consist of two polypeptide chains with molecular weights around 33,000 and 17,000 (fig. 12 gels 2 and 4$)$. A comparison with reduced factor $X$ or reduced PIVKA-X indicates that the molecular change by activation with RVV-X occurs by splitting off a peptide from the heavy chain. The molecular weight of the light chain remains unchanged in the activation process.

Amino-terminal amino acid analysis. Amino-terminal amino acid analys is was performed with the method according to Gray (52). For both factor $x_{a}$ and PIVKA-X $x_{a}$ alanine and isoleucine were found as the amino-terminal amino acids. In chapter II alanine 
was reported as the amino-terminal amino acid of the light chain while tryptophane was probably found as the amino-terminal amino acid of the heavy chain of PIVKA-X. It is obvious that after activation of PIVKA-X isoleucine becomes the new aminoterminal amino acid of the heavy chain, as in the case with factor $x(34)$.

Amino acid analysis. The amino acid compositions for factor $x_{a}$ and PIVKA- $x_{a}$ are summarized in table $I$. No significant differences in amino acid composition were observed. These amino acid analyses are in good agreement with the data published by Fujikawa (34). Y-Carboxyglutamate residues were determined by a modified method according to Zytkovicz (53) as described in chapter II. The number of $y$-carboxyglutamate residues detected in factor $x_{a}$ was about the same as in factor $X$, indicating that no $Y$-carboxyglutamate residues were lost during the activation and subsequent purification of factor $X_{a}$. Less than one residue of $Y$-carboxyglutamate was found in PIVKA-X $x_{a}$. The presence of $y$-carboxyglutamate in the PIVKA- $x_{a}$ preparation might be due to a contanination with factor $x_{a}$ or to a partial carboxylation of glutamic acid residues in PIVKA-X $X_{a}$.

\section{DISCUSSION}

In this chapter experiments are described by which we demonstrate the conversion of PIVKA-X into an active enzyme analogous to factor $x_{a}$. Preliminary communications of this phenomenon were made by us earlier $(62,63)$.

The aim of the experiments was to find out whether the inability of PIVKA-X to participate in blood coagulation is due to an impaired activation mechanism and/or impaired enzymatic function in prothrombinase.

The synthetic chromogenic substrate, Bz-Ile-Glu-Gly-Arg-pNA has been shown to be a useful tool in studying the reactions involved in activation of factor $X(64,66)$. It also appeared 
TABLE I. Amino acid composition of factor $x_{a}$ and PIVKA-X $a$

\begin{tabular}{|c|c|c|c|}
\hline Amino acid & $\begin{array}{r}\text { factor } x_{a} \\
\text { mole/48,000 }\end{array}$ & $\begin{array}{l}\text { PIVKA-Xa } \\
\text { mote/48,000 }\end{array}$ & $\begin{array}{l}\text { factor } x_{a}(\text { ref.14) } \\
\text { mole } 45,000\end{array}$ \\
\hline lysine & 21 & 16 & 20 \\
\hline histidine & 8 & 8 & 8 \\
\hline arginine & 22 & 23 & 23 \\
\hline aspartic acid & 38 & 41 & 33 \\
\hline threonine ${ }^{a}$ & 25 & 23 & 26 \\
\hline serine ${ }^{a}$ & 35 & 27 & 24 \\
\hline glutamic acid & 63 & 58 & 58 \\
\hline proline & 12 & 11 & 15 \\
\hline glycine & 44 & 38 & 38 \\
\hline alanine & 28 & 25 & 26 \\
\hline half-cystine & 17 & 15 & 24 \\
\hline val ine & 18 & 17 & 26 \\
\hline methionine & 6 & 6 & 5 \\
\hline isoleucine & 9 & 11 & 11 \\
\hline leucine & 26 & 26 & 23 \\
\hline tyrosine & 8 & 8 & 9 \\
\hline phenylalanine & 21 & 21 & 21 \\
\hline
\end{tabular}

a: Values determined by extrapolation to zero time hydrolysis.

Acid hydrolysate after reduction with $\left[{ }^{3} H\right]$-diborane

\begin{tabular}{|l|c|c|}
\hline Amino acid & factor $x_{a}$ & PIVKA-X \\
\hline i-carboxyglutamic acid & 10 & $<1$ \\
\hline
\end{tabular}


suitable for studying the activation of PIVKA-X.

The factor $X$ activating protein from Russell's Viper venom (RVV-X) was suitable as an activator of PIVKA-X, because of its well documented reaction mechanism $(14,16)$ and the inability of RVV-X to bind $\mathrm{Ca}^{2+}(41)$. The latter is important since any $\mathrm{Ca}^{2+}$ effect on activation will primarily be due to interaction of $\mathrm{Ca}^{2+}$ with factor $X$ or PIVKA-X.

In contrast to activation by the physiological activators, factor $V_{I I}$ and factor IX $X_{a}$, the activation of factor $X$ with RVV-X does not require phospholipids (14). However, the mechanism of activation of factor $X$ by physiological and non-physiological activators has been shown to be identical (14).

Under the conditions used, factor $X$ was completely activated within 3 minutes and clotting and amidase activity increased in parallel (fig. $2 A$ ). Under the same conditions the complete activation of PIVKA-X as measured by amidase activity requires about $180 \mathrm{~min}$ (fig. $2 B$ ).

After that time about the same amidase activity as in the factor $X$ activation was reached. The possibility to convert PIVKA- $X$ in an enzyme analogous to factor $x_{a}$ was also confirmed by the comparable time course of generation of amidase activity and limited proteolysis, as visualized by SDS-gel electrophoresis. The time course of generation of clotting activity is qualitatively and quantitatively quite different. Therefore, it is concluded that no clotting activity can be generated from PIVKA-X. The factor $x_{a}$ activity, which is generated, must be due to a contamination with factor $X$.

To our surprise the activation of PIVKA-X depends on the presence of $\mathrm{Ca}^{2+}$. This $\mathrm{Ca}^{2+}$ requirement is unexpected because it is known that RVV-X binds no $\mathrm{Ca}^{2+}(41)$ and PIVKA-X has a very low affinity for $\mathrm{Ca}^{2+}$, due to the absence of $\gamma$-carboxyglutamate residues (this thesis). It appeared that the maximal rate of factor $X$ activation is about 60 times higher than that of PIVKA-X, 
whereas the velocity of activation of factor $X$ is dependent upon $\mathrm{Ca}^{2+}$ concentration in a sigmoidal fashion, that of PIVKA-X is hyperbolic.

A Hill plot of the data obtained, indicates that only in case of factor $x$ the increase in $\mathrm{Ca}^{2+}$ concentration has an allosteric effect on the reaction velocity $\left(n_{H}=4.3\right)$.

We conclude that the substrate for RVV-X is the protein complexed with $\mathrm{Ca}^{2+}$ and $\mathrm{Ca}^{2+}$ binding to $\gamma$-carboxyglutamate residues is essential for a rapid conversion to factor $x_{a}$.

In view of the Hill coefficient obtained it is tempting to speculate that a $\mathrm{Ca}^{2+}$ induced conformational change in factor $x$ is important for the activation reaction. Evidence for a $\mathrm{Ca}^{2+}$ dependent conformation in factor $X$ was obtained by $u 1$ traviolet difference spectroscopy analysis (chapter III). The fact that addition of $\mathrm{Ca}^{2+}$ to PIVKA-X has no effect on the spectra of the aromatic amino acids and the low rate of activation of PIVKA- $X$ clearly demonstrates the importance of a $\mathrm{Ca}^{2+}$ dependent conformational change in the substrate for a rapid activation.

From the $\mathrm{Ca}^{2+}$ binding experiments it is assumed that cooperativity in the $\mathrm{Ca}^{2+}$ dependent activation of factor $X$ is caused by $a$ positive cooperative binding of the first four $\mathrm{Ca}^{2+}$ ions to factor $x$ (chapter III). However, the concentration of $\mathrm{Ca}^{2+}, 2 \mathrm{mll}$, required for a maximal rate of activation of factor $x$, suggests that in addition to the occupancy of the $\mathrm{Ca}^{2+}$ binding sites mentioned above, a second set of sites must be filled. This interpretation is consistent with the observation of Prendergast and Mann (65), who showed that the maximal rate of activation of prothrombin is found at a $\mathrm{Ca}^{2+}$ concentration that greatly exceeds that required to fill the $\mathrm{Ca}^{2+}$ binding sites which exhibit positive cooperativity.

Recently, kosow (66) reported studies on the role of $\mathrm{Ca}^{2+}$ in the activation of human factor $X$ by $R V V-X$. Based on a sigmoidal re- 
lationship between $\mathrm{Ca}^{2+}$ concentration and initial reaction velocity, he proposed that there are at least three cooperative binding sites for $\mathrm{Ca}^{2+}$.

Separation of activated factor $X$ from the activation mixture could be achieved by DEAE-Sephadex chromatography as described by Jesty (48). Using this procedure we did not succeed to separate activated PIVKA-X from its activation mixture. Using powder column electrophoresis, a homogeneous preparation as judged by polyacrylamide electrophoresis was obtained. Addition of $\mathrm{Ca}^{2+}$ to the electrophoresis buffer was carried out in order to obtain a separation between PIVKA-X $X_{a}$ and contaminating factor $X_{a}$. In spite of this, a residual factor $x_{a}$ activity (about $6 \times 10^{2} \mathrm{U} / \mathrm{mg}$ protein) can be detected in the purified PIVKA-X $a$ preparation. The presence of factor $x_{a}$ activity in the purified product may be due to a persistant contamination or to an intrinsic activity of PIVKA-X $x_{a}$, like in the case of PIVKA-II (67). Differentiation will only be possible when high yields of PIVKA-X enable us to carry out rigorous tests for purity of this product.

As measured by sodium dodecyl sulfate gel electrophoresis, factor $x_{a}$ and PIVKA- $x_{a}$ have equal molecular weights. In fig. 12 it is shown that two forms of the enzymes may exist, with molecular weights of approximately 48,000 and 44,000 daltons. Upon reduction, prior to electrophoresis it was shown that the heterogeneity is due to a difference in molecular weight of the heavy chain. Because the only amino-terminal amino acids found were isoleucine and alanine, the difference must be caused by splitting off a peptide at the carboxy-terminal end of the heavy chain. These results are consistent with the two forms of factor $x_{a}$ reported by Fujikawa (35) and Jesty (68).

Further proof for the conversion of PIVKA-X into an active enzyme analogous to factor $X_{a}$ was obtained with an immunological technique and amino acid analysis. It has been shown that PIVKA-X $X_{a}$ and factor $x_{a}$ have common antigenic determinants (fig. 11). Differences in 
amino acid composition were only found with respect to $i$-carboxyglutaliate content (table I). Moreover, the i-carboxyglutanate content of factor $x_{a}$ is unaltered as compared with factor $x$. This result indicates that al $1 \quad Y$-carboxyglutamate residues are conserved after activation with RVV-X. A striking difference of electrophoretic mobility of factor $x_{a}$ and factor $X$ was found in the presence of $\mathrm{Ca}^{2+}$. The most likely explanation for this phenomenon might be the tendency of factor $x_{a}$ to aggregate in the presence of $\mathrm{Ca}^{2+}(48)$. Also the electrophoretic mobility of PIVKA-X $x_{a}$ in the presence of $\mathrm{Ca}^{2+}$ is somewhat decreased. Whether this can be due to aggregation is not yet clear. 


\section{REFERENCES}

1. Flynn, J.E. and Roon, R.W. Amer.J.Physiol. 175 (1953) 289

2. Hjort, P.F. Scand.J.Clin.Lab.Invest. 9 (1957) Suppl. 27

3. Hougie, C. Proc.Soc.Exp.Biol.Med. 101 (1959) 132

4. Straub, W. and Duckert, F. Thrombos. Diathes.haemorrh. 5 (1961) 402

5. Deutsch, E., Irsignler, K. and Lonoschitz, H. Thrombos.Diathes. haemorrh. 12 (1964) 12

6. Nemerson, Y. and Spaet, T.H. Blood 23 (1964) 657

7. Williams, W.J. J.Biol.Chem. 239 (1964) 933

8. Williams, W.J. J.Biol.Chem. 241 (1966) 1840

9. Williams, W.J. and Norris, D.G. J.Biol.Chem. 241 (1966) 1847

10. ivemerson, Y.Biochem. 5 (1966) 601

11. Nemerson, Y. and Pitlich, F.A. Biochem. 9 (1970) 5100

12. Pitlick, F.A., Nemerson, Y., Gottlieb, A.J., Gordon, R.G. and Williams, W.J. Biochem. 10 (1971) 2650

13. Radcliff, R.D. and Barton, P.G. J.Biol.Chem. 248 (1973) 6788 14. Fujikawa, K., Coan, M.H., Legaz, M.E. and Davie, E.H. Biochem. 13 (1974) 5290

15. Esmon, C.T. and Jackson, C.H. J.Biol.Chem. 249 (1974) 7782

16. Jesty, J. and Nemerson, Y. J.Biol.Chem. 249 (1974) 509

17. Engel, A.i.l, Alexander, B. and Parts, A. Thrombos.Res. 1 (1972) 581

18. Bergsagel, D.E. and Hougie, C. Brit.J.Haematol. 2 (1956) 113

19. Hougie, C., Barrow, E.M. and Graham, J.B. J.Cl in. Invest. 36 (1957) 485

20. Spaet, T.H. and Cintron, J. Blood 21 (1963) 745

21. Lundblad, R.L. and Davie, E.H. Biochem. 3 (1964) 1720

22. Biggs, R. and Macfarlane, R.G. Thrombos.Diathes.haemorrh. Supp1. 17 (1965) 23

23. Hougie, C., Denson, K.W.E. and Biggs, R. Thrombos.Diathes. haemorrh. Suppl. 18 (1967) 211 
24. Osterud, B. and Rapaport, S. I. Biochen. 9 (1970) 1854

25. Hemker, H.C. and Kahn, M.J.P. Nature 215 (1967) 1201

26. Barton, P.G. Nature 215 (1967) 1508

27. Chuang, T.F., Sargeant, R.B. and Hougie, C. Biochim.Biophys. Acta 237 (1972) 287

28. Kosow, D.P., Furie, B. and Forastieri, H. Thrombos.Res. 4 (1974) 219

29. Varadi, K. and Hemker, H.C. Thrombos.Res. 8 (1976) 303

30. Irwin, J.F., Seegers, W.H., Andary, T.J., Fekete, L.F. and Noron, E. Thrombos.Res. 6 (1975) 431

31. Macfarlane, R.G. Brit.J.Haematol. 7 (1964) 496

32. Williams, W.J. and Esnouf, M.P. Biochem.J. 84 (1962) 52

33. Papahadjopoulos, D. and Hanahan, D.J. Biochim.Biophys. Acta 90 (1964) 436

34. Fujikawa, K., Legaz, M.E. and Davie, E.W. Biochen. 11 (1972) 4892

35. Fujikawa, K., Titani, K. and Davie, E.W. Proc. Hat.Acad.Sci.USA $72(1975) 3359$

36. Dombrose, F.A. and Seegers, W.H. Thrombos.Res. 3 (1974) 737

37. Radcliff, R.D. and Barton, P.G. J.Biol.Chem. 247 (1972) 7735

38. Jackson, C.P., Gordon, J.G. and Hanahan, D.J. Biochim.Biophys. Acta 252 (1971) 255

39. Kisiel, W., Hermodson, M.A. and Davie, E.W. Biochem. 15 (1976) 4901

40. Furukawa, Y., Matsunaga, Y. and Hayaski, K. Biochim. Biophys. Acta $453(1976) 48$

41. Furie, B. and Furie, B.C. J.Biol.Chem. 250 (1975) 601

42. Rimon, A., Alexander, B. and Katchalski, E. Biochem. 5 (1966) 792

43. Yin, E.T. Thrombos.Diathes.haemorrh. 12 (1964) 307

44. Barton, P.G. (1969) In "Structural and Functional Aspects of Lipoproteins in Living Systems" Tria, E. and Scana, A.M. eds. p. 465-515 Acad.Press, New York

45. Seegers, W.H., i.lc.Coy, L.E., Renterby, J., Sakuragawa, N., Mureno, G. and Agrawal, B.B.L. Thrombos.Res. 1 (1972) 209 
46. Harmison, C.R., Schröer, H. and Seegers, H.H. Thrombos.Diathes. haemorrh. 13 (1965) 587

47. Bajaj, S.P. and Mann, K.G. J.Biol.Chem. 248 (1973) 7729

48. Jesty, J. and Esnouf, H.P. Biochen. J. 131 (1973) 791

49. Esmon, C.T., Owen, W.G., Jackson, C.H. J.Biol.Chem. 249 (1974) 8045

50. Schiffman, S., Theodor, I. and Rapaport, S.I. Biochem. 8 (1969) 1397

51. Spackman, U.H., Stein, H.W. and Moore, S. Anal.Chen. 30 (1958) 1190

52. Gray, W. Wethods Enzymol. 11 (1967) 139

53. Zytkovicz, T.H. and Nelsestuen, G.L. J.Biol.Chem. 250 (1975) 2968

54. Esnouf, M.P., Lloyd, P.H. and Jesty, J. Biochem.J. 131 (1973) 781

55. Laurel1, C.B. Ana 1.Biochem. 15 (1966) 45

56. Ouchterlony, 0. Progr.All ergy 6 (1962) 30

57. Bell, W.N. and Alton, H.G. Nature 174 (1954) 880

58. Smith, R.L. J.Biol.Chem. 248 (1973) 2418

59. Svendsen, L., Blombäck, B., Blombäck, M. and 01son, P.I. Thrombos.Res. 1 (1972) 267

60. Rosenbaum, T., Ph.D. Thesis, MC.Gill University, Montreal, Quebec (1970)

61. Weber, K. and Osborn, H. J.Biol.Chem. 244 (1969) 4406

62. Lindhout, M.J. and Kop-Klaassen, B.H.M. Vth Congress of the Int.Soc. on Thrombosis and Haemostasis, Paris 1975

63. Lindhout, M.J., Kop-Klaassen, B.H.M. and Hemker, H.C.

Thrombos.Haemostas. 38 (1977) 179

64. Suomela, H., Blombäck, M. and Blombäck, B. Thrombos.Res. 10 (1977) 267

65. Prendergast, F.G. and Mann, K.G. J.Biol.Chem. 252 (1977) 840 66. Kosow, D.P. Thrombos.Res. 9 (1976) 565

67. Vermeer, C., Govers-Riemslag, J.W.P., Soute, B.A.M., Lindhout, H.J., Kop, J.M.M. and Henker, H.C. Submitted for publication

68. Jesty, J.,Spencer,A.K. and Nemerson, Y. J.Biol.Chem.249 (1974) 5614. 

CHAPTER $V$

THE EFFECT OF Y-CARBOXYGLUTAMYL RESIDUES ON THE ENZYMATIC PROPERTIES OF THE ACTIVATED BLOOD CLOTTING FACTOR $X$

A comparison of the normal and the decarboxy enzyme

\section{SUMMARY}

The esterolytic and amidolytic properties of activated blood coagulation factor $x$ (factor $x_{a}$ ) and the analogous decarboxy enzyme were compared in order to find out if the $\gamma$-carboxyglutamyl residues influence the function of the active centre. It was found that the two proteins

1. Showed similar kinetic parameters when titrated with p-NPGB.

2. Had a similar $k_{i 1}$ and $k_{\text {cat }}$ for various synthetic chromogenic substrates.

3. Were inhibited in the same way by benzamidine.

Further it was observed that:

4. $\mathrm{Ca}^{2+}$ inactivates factor $X_{a}$, presumably by inducing the formation of a dimer, but has no influence on PIVKA-X ${ }_{a}$.

5. Factor $V$ prevents $\mathrm{Ca}^{2+}$ induced inactivation of factor $X_{a}$ but does not influence the amidase activity of both factor $x_{a}$ and PIVKA- $x_{a}$. 0 . The prothrombin activation in the absence of $C a^{2+}$ by factor $x_{a}$ and PIVKA-X $X_{a}$ is similar. Identical distribution of activation products is observed. Evidence is obtained that the conversion of prothrombin by both factor $x_{a}$ and PIVKA-X $x_{a}$ is enhanced by $\mathrm{Ca}^{2+}$, but that this effect is markedly greater with factor $x_{a}$.

We conclude that the interaction of the $Y$-carboxyglutamic residues with $\mathrm{Ca}^{2+}$ in factor $x_{a}$ has no measurable influence on the properties of the active centre. 


\section{INTRODUCTION}

Factor $x_{a}$ is a protease belonging to the chymotryps in family. With thrombin, plasmin, trypsin, and chymotrypsin it shares many structural and functional features. It can be safely assumed that a similar catalytic mechanism, involving the "charge relay system" Asp-His-Ser and common features in the three dimensional structures are shared by these mammalian serine proteases (1-4). Amino acid sequences in the region surrounding the reactive serines in the heavy chain of factor $x_{a}$ are found to be homologous with the same regions of trypsin, chymotrypsin-A, elastase and thrombin (4-9). Like trypsin, activated factor $X$ is inhibited by soybean trypsin inhibitor $(10,11)$, diisopropylphosphofluoridate $(11,12)$ and synthetic aromatic amidine and guanidino inhibitors (13). Factor $x_{a}$ catalyzes the hydrolys is of various synthetic substrates such as $\mathrm{N}$-c-benzoyl-L-arginine ethylester (14), $\mathrm{N}-\mathrm{a}-\mathrm{p}$ toluene sulfonyl-L-arginine methylester $(11,15)$, p-nitrophenyl$p^{\prime}$-guanidinobenzoate (16) and benzoxy-isoleucyl-glutamyl-glycylarginyl-p-nitroanilide (17). Contrary to other serine proteases (with the exception of clotting factor $I X_{a}$ ) factor $X_{a}$ has an unique structural feature in that it possesses several couples of $\gamma$ carboxyglutamic acid residues in the $N$-terminal part of its smaller chain. Activated factor $X$ also can be considered a protease with trypsin-like specificity in that it selectively attacks amido bonds adjacent to arginine. Unlike trypsin, the $N$ - acylaliino acid esters containing lysine are less readily hydrolyzed by factor $x_{a}$ than the arginine containing esters (14).

When acting on its natural substrate (prothrombin) factor $x_{a}$ cleaves only two peptide bonds adjacent to arginine, the Arg-Thr and A2 3324 - 34 bonds $(18-21)$, whereas there are 75 bonds that in principle must be considered susceptible.

The highly restricted substrate specificity of factor $x_{a}$ is an interesting but hardly investigated feature. Experiments comparing 
factor $x_{a}$ to trypsin with respect to their inhibition by various amidines and guanidines made Johnson et al. (13) suggest that factor $x_{a}$ contains a primary substrate binding site equal to that of trypsin in potential binding energy and a secondary substrate binding site responsible for the specificity of factor $x_{a}$.

It can be safely assumed that apart from the active site, vulnerable site interaction in a protease and its protein substrate "subsite" interactions are largely responsible for highly specific interactions like these of factor $x_{a}$ and prothrombin (22-25).

Studies employing small molecule substrates and peptide substrates in determining kinetic behaviour indicate that the specificity of thrombin, chymotryps in and tryps in towards these substrates is reflected in the rate determining acylation step rather than in the enzyme-substrate complex formation (26-33).

As was mentioned above, in its physiological function factor $x_{a}$ is a highly specific protease which activates prothrombin to thrombin $(19,34-40)$. The activation of prothrombin by factor $x_{a}$ alone or the complexed enzyme containing factor $x_{a}, v_{a}$, phospholipid and $\mathrm{Ca}^{2+}$ ions in vitro occurs in several steps. Data from numerous studies focussed upon the activation mechanism in vitro suggest an activation pathway as shown in fig. $1(19,21,34,43-50)$. Factor $x_{a}$ cleaves peptide bonds 2 and 3 . In addition to the two factor $x_{a}$ catalyzed cleavages, thrombin rapidly cleaves prothrombin and fraglient 1.2. The data now available give evidence that the main, if not only, pathway for prothrombin activation by the complex enzyme can be summarized by the following equations (42, 51-53):

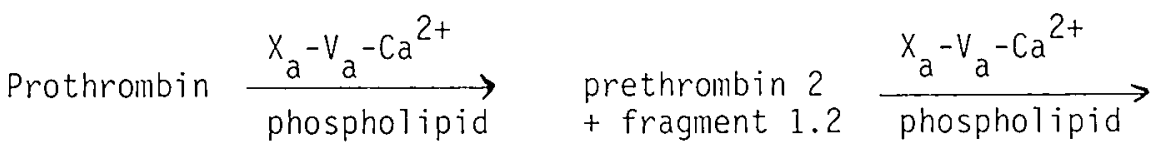

thrombin + fragment 1.2 
$\leftarrow$ prothrombin

fragment 1 prethrombin-1
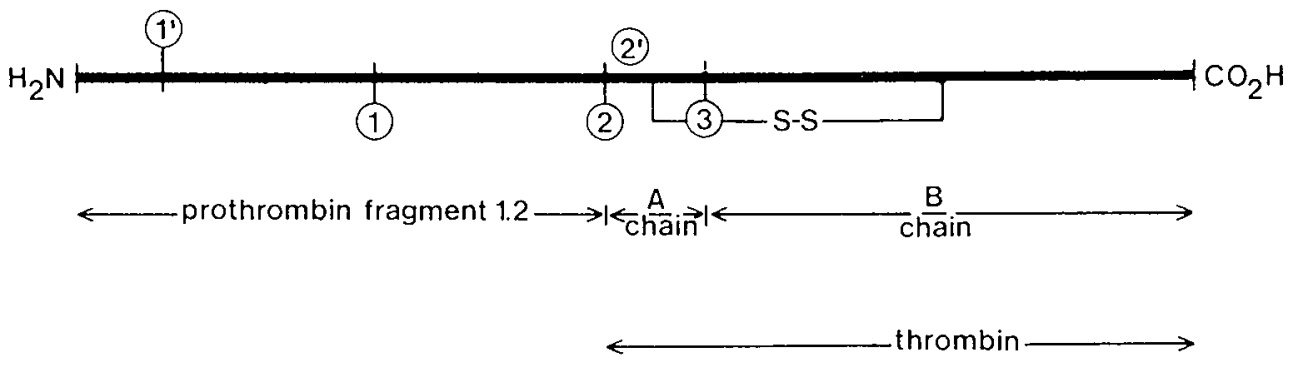

Fig. 1 .

Schematic structure for prothroibin. The three peptide bonds that are cleaved in bovine prothromin auring or as a result of prothrombin activation are designated by (1) , (2), and (3). Another bond, (1), can be cleaved in both bovine and human prothrombins; however, neither the precise location nor the agent has been determined. The nomenclature system for prothrombin proteolysis products, proposed by a Task Force of the International Committee on Thrombos is and Haemostasis is designated as follows: if bond (1) is cleaved in prothrombin, two products are formed: prothrombin fragment 1 and prethrombin 1. Buvine prothrombin 1 consists of the region from the amino terminus to bond (1) (Arg 156 - Ser 157): prethrombin 1 is the polypeptide from bond (1) to the carbonyl terminus of prothrombin. By convention, prethrombin implies that the amino acid sequence ultimately giving rise to thrombin is contained in the polypeptide: fragment implies that the amino acid sequence of the polypeptide is not finally associated with thrombin. cleavage of bond (2) (Arg 274 - Thr 275) gives rise to prothromb in fragment 1.2 and prethrombin 2. Cleavage of bond (1) in prothrombin fragment 1.2 yields prothrombin fragment 1 and prothrombin fragnent 2. Cleavage of bond (3) (Arg 323 - Ile 324) in prethrombin 2 yields thrombin, a disulfide-linked, two-chain enzyme in which the polypeptide chain between bonds (2) and (3) is designated the chain $A$ and the polypeptide chain betweer. bond (3) and the carboxyl terminus is designated the $B$ chain. In human prothrombin an additional bond (3) is cleaved wich results in the formation of an A chain of bovine thrombin that is 13 residues shorter than the $A$ chain of bovine thrombin. 
fragment $1.2 \stackrel{\text { thrombin }}{\longrightarrow}$ fragment $1+$ fragment 2

The direct formation of prethrombin 2 from prothrombin was not recognized in the earlier investigations due to the complicating feature of thrombin catalyzed proteolysis of prothrombin as well as fragment $1.2(19,34,43,49,50)$.

During slow prothrombin activation thrombin catalyzed proteolys is exceeds the factor $x_{a}$ catalyzed prothrombin activation, resulting in the appearance of large quantities of prethrombin 1:

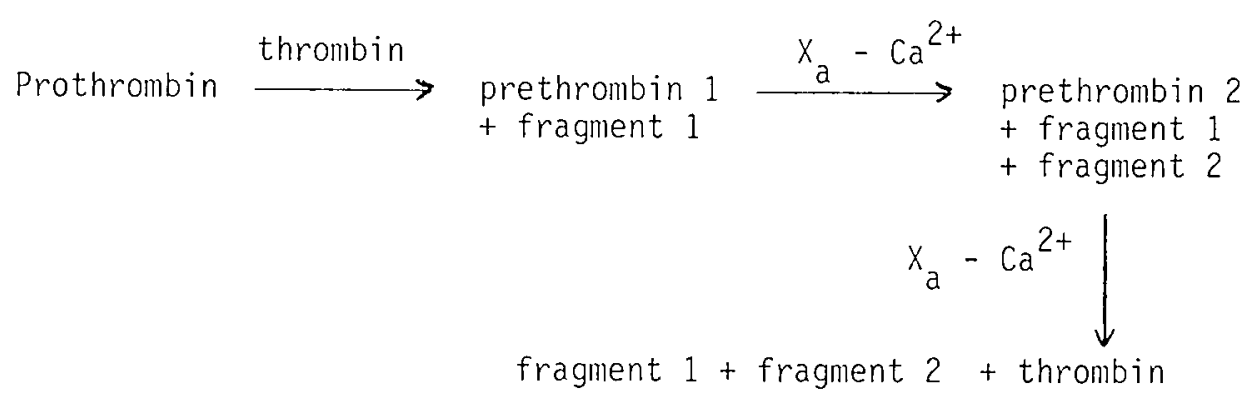

The rate of thrombin generation by factor $x_{a}$ alone is less than $0.1 \%$ of that obtained with the complex prothrombinase $(41,42)$. Factor $V_{a}$ alone does not catalyze peptide bond cleavage or activation in either prothrombin or the prethrombins $(19,54)$. A particularly interesting feature of the prothrombin activation is the release of a large activation fragment (i.e. fragment 1.2) $(21,43)$. Esmon et al. (52) have clearly shown that in the pure aqueous phase reaction (factor $x_{a}$ alone) neither fragment 1 or fragment 2 alone or together effects the reaction rate. Addition of factor $V_{a}$ and phospholipids to factor $x_{a}$ and $\mathrm{Ca}^{2+}$ results in an increased rate of prothrombin activation. This is almost completely dependent on the presence of fragment 1 and fragment 2 as sites for respectively the $\mathrm{Ca}^{2+}$ mediated binding of prothrombin to phospholipids and non-covalent protein interaction with factor $V_{a}(51,53)$. 
It is the purpose of the experiments described in this chapter to elucidate a possible role of y-carboxyglutamate residues in the catalytic activity of factor $x_{a}$ by comparing it with the activity of decarboxy factor $X_{a_{2}}\left(P I V K A-X_{a}\right)$. Experiments are described concerning the role of $\mathrm{Ca}^{2+}$ in the activation of prothrombin by both enzymes.

\section{MATERIALS AND METHODS}

Materials and methods, except for those described below, are reported in the preceding chapters.

Chemicals. p-Nitrophenyl-p'-guanidinobenzoate hydrochloride (NPGB) was purchased from Nutritional Biochemicals Corp. Benzoxy-phenylalanylvalyl-arginyl-p-nitroanilide (Bz-Phe-Val-Arg-pNA) and benzoxyisoleucyl-glutamyl-glycyl-arginyl-p-nitroanalide (Bz-Ile-Glu-GlyArg-pNA) were products of A.B. Bofors, Nobel Pharma, Sweden. Sulfopropyl (SP)-Sephadex was obtained from Pharmacia Phine Chemicals.

Proteins. Prothrombin was prepared according to the method of Owen et al. (19). Snall amounts of thrombin possibly formed during purification procedures and other proteolytic enzymes were removed by passing the prothrombin preparation through a column $(0.9 \times 20 \mathrm{~cm})$ of SP-Sephadex and soybean trypsin inhibitor-Sepharose (55). Soybean trypsin inhibitor was coupled to Sepharose $4 \mathrm{~B}$ with the method of Cuatrecasas (56). Factor $V_{a}$ prepared with the nethod of Smith et a1. (57) was a kind gift of Dr.J.Rosing. Activated factor $X$ and activated PIVKA- $X$ were prepared with the method described in chapter IV.

\section{ACTIVE SITE TITRATION}

Theory of titration. The general reaction scheme for the interactions of serine proteases with substrates is:

$E+S \stackrel{K_{S}}{\longrightarrow} E S \stackrel{k_{2}}{\longrightarrow} P_{1}+E S^{\prime} \stackrel{k_{3}}{\longrightarrow} E+P_{2}$ 
where in the case of NPGB as the substrate (S), $E$ is the enzyme, ES is the enzyme-substrate complex, ES' is the guanidinobenzoyl enzyme, $P_{1}$ is the product of the acylation reaction ( $p$-nitrophenol) and $P_{2}$ is the product of the deacylation reaction ( $p$ guanidinobenzoate).

As shown by Bender et al. (58) the expression for the formation of p-nitrophenol is:

$P_{1}=\frac{k_{c a t}\left[E_{0}\right]\left[S_{0}\right] t}{\left[S_{0}\right]+k_{M}}+\left[E_{0}\right]\left[\frac{k_{c a t} / k_{3}}{1+k_{M} /\left[S_{0}\right]}\right]^{2} \cdot\left(1-e^{-b t}\right)$

Here, $k_{c a t}=\frac{k_{2} \cdot k_{3}}{k_{2}+k_{3}} ; k_{M}=\frac{k_{s} \cdot k_{3}}{k_{2}+k_{3}} ; b=k_{3}+\frac{k_{2}}{1+k_{s} /\left[s_{0}\right]}$

This equation holds under the assumption $\left[S_{0}\right] \gg\left[E_{0}\right]$

We put in equation (1):

$A=\frac{k_{\operatorname{cat}}\left[E_{0}\right]\left[S_{0}\right]}{\left[S_{0}\right]+k_{M}}$

$\pi=E_{0}\left[\frac{k_{\mathrm{Cat} / \mathrm{k}_{3}}}{\left.1+\mathrm{K}_{M} / \mathrm{S}_{0}\right]}\right]^{2}$

then $P_{1}=A t+n\left(1-e^{-b t}\right)$

When the transient phase is over, $e^{-b t}$ approaches zero, so that in the steady state $P_{1}$ is given by

$P_{1}^{*}=A t+\cdots$

From this equation it can be seen that the line of steady state 
production of $P_{1}$ will intercept the ordinate in When $k_{2}>k_{3}$ and $S_{0}>K_{M}, \frac{k_{c a t} / k_{3}}{1+k_{M} / E_{0} j}$ will approach unity and If only the first assumption holds ii must be determined at several substrate concentrations. A plot of $1 / 1 ;$ versus $1 /\left[\mathrm{S}_{0}\right]$ will intercept the ordinate at $\left.1 / / \mathrm{S}_{0}\right]$ as can be seen from a rearrangement of equation (4).

Determination of $k_{s}$ and $k_{2}$. Rearrangement of equation (5) and substitution of $(6)$ gives

$P_{1}-P_{1}^{*}=-i e^{-b t}+i i$

A plot of $\ln \left(P_{1}^{*}-P_{1}\right)$ versus $t$ thus provides $b$ from its slope. As $b=k_{3}+\frac{k_{2}}{1+k_{s} / s_{0}}$

under the assumption that $k_{2}>k_{3}$ may be arranged to

$1 / b=1 / k_{2}+k_{s} / k_{2} \cdot s_{0}$

a plot of $1 /$ b versus $1 / S_{0}$ will provide $k_{s}$ and $k_{2}$.

Determination of $k_{3}$ and $K_{M}$. The rate constant of deacylation can be determined by isolation of the acylenzyme by gelfiltration, incubation under the conditions of titration and rate assay of the recovered enzymatic activity.

$E S^{\prime} \stackrel{k_{3}}{\longrightarrow} E+P_{2}$

A plot of $\ln \frac{\left[E S^{\prime}\right]}{\left[E_{0}\right]}$ versus $t$ provides $k_{3}$ from the slope. 
$k_{\text {in }}$ arises from the substitution of known values of $k_{2}, k_{3}$, and $k_{s}$ in the expression

$k_{m}=\frac{k_{5} \cdot k_{3}}{k_{2}+k_{3}}$

Determination of $K_{\mathrm{pb}}$. A second factor involved in the postburst p-nitrophenol production may be the nonspecific nitrophenol production, presumably by the imidazole and amino groups of the protein (59).

A plot of NPGB concentration versus the rate constant of the postburst $p-n i t r o p h e n o l$ production, $k_{p b}$, provides the first order rate constant for deacylation $\left(k_{3}\right)$ from the intercept and the second order rate constant of the nonspecific nitrophenol production from the slope.

Titration of factor $x_{a}$ and PIVKA-X ${ }_{2}$. Titration of activated factor $X$ and activated PIVKA- $x$ was performed according to Smith (16). In a typical titration the sample cuvette contains $150 \mathrm{~g}$ of factor $x_{a}$ or $180: 9$ of PIVKA-X in 300 :1 of 0.1 M sodium barbital buffer pH 8.3. The reference cuvette contains the same volume of buffer solution alone. To each cuvette 3 : 1 of a 0.01 M solution of $\mathrm{p}$-ivPGB in dimethyl formamide-acetonitrile $(1: 3 \mathrm{v} / \mathrm{v})$ were simultaneously added. The reaction was followed at $410 \mathrm{~nm}$ in an Aminco DW-2 spectrophotometer at $25^{\circ} \mathrm{C}$. The concentration of $p-$ nitrophenol released during the reaction was calculated from the zero time intercept of the extrapolated steady state 7 ine. In the Aminco DW-2 spectrophotometer, 410 for p-nitrophenol at $\mathrm{pH} 8.3$ was calculated to be 17,500 .

Determination of kinetic constants $k_{5}$ and $k_{2}$. The presteady state reaction of factor $x_{a}$ and PIVKA- $x_{a}$ with $p$-NPGB occurs slowly enough to follow the reaction by continuous recording, therefore $\left(P_{1}^{*}-P_{1}\right)$ values at various intervals of the presteady state reaction can easily be determined. 
Enzyme concentrations were $3.2 \times 10^{-6}$ if factor $x_{a}$ and $2.2 \times 10^{-6} \mathrm{~m}$ PIVKA-X $x_{a}$. The NPGB concentrations ranged from $3.3 \times 10^{-5} \mathrm{M}$ to $13.3 \times 10^{-5}$ i. The operational first order rate constant for the presteady state reaction, $b$, was determined as described above, at each concentration of $\mathrm{p}$-NPGB by 1 inear regression analys is. $1 / k_{2}$ and $k_{s} / k_{2}$ were determined from the intercept and slope of a plot of $1 /$ b versus $1 /$ [p-liPGB].

Determination of $k_{2}$ and $k_{p b}$. Acylation of factor $x_{a}$ and PIVKA-X was performed by addition of 10.7 of $0.01 \mathrm{M} \mathrm{p}-\mathrm{NPGB}$ to $1.2 \mathrm{ml}$ of a solution of factor $X_{a}$ or PIVKA-X $x_{a}$ in 0.1 M sodium barbital buffer $\mathrm{pH}$ 8.3. The final concentration of $\mathrm{p}-\mathrm{NPGB}$ was $8.3 \times 10^{-5} \mathrm{M}$. The final enzyme concentrations were $3.2 \times 10^{-6} \mathrm{M}$ factor $x_{a}$ and $2.2 \times 10^{-6}$ M PIVKA-X $a$.

The acylenzyme solutions with excess $p-N P G B$ were applied to a column $(0.9 \times 30 \mathrm{~cm})$ of Sephadex G-25 equilibrated with $0.1 \mathrm{M}$ sodium barbital buffer pH 8.3. Enzyme containing fractions were collected and incubated at $25^{\circ} \mathrm{C}$. At several intervals a) iquots were removed from the incubation mixture and assayed for anidase activity with $\mathrm{S}-2222$. The time which the acylenzyme had sunk into the column was taken as zero time. The deacylation rate constant $k_{3}$ was determined from the slope of In $\frac{\left[E_{0}\right.}{E_{0}-E_{t}}$ versus time, where $\left[E_{0}\right]$ is the concentration acylenzyme at zero time and $i E_{t}$. the concentration deacylated enzyme at time t. Airidase activity is determined as described under liethods.

The rate constant for the postburst p-llitrophenol production is determined at $1.6 \times 10^{-4}$ in $p$-NPGB from the slope of the steady state 1 ine and enzyme concentration.

Amidase activity of factor $x_{a}$ and PIVKA-X

Introduction. The many properties that factor $x_{a}$ shares with 
i-chymotrypsin permit us to assume that qualitatively the mechanism of amidolysis will be identical in both enzymes. As shown by Gutfreund and Sturtevant $(60,61)$, the chymotrypsin catalyzed amidoiysis proceeds according to the following reaction pathway.

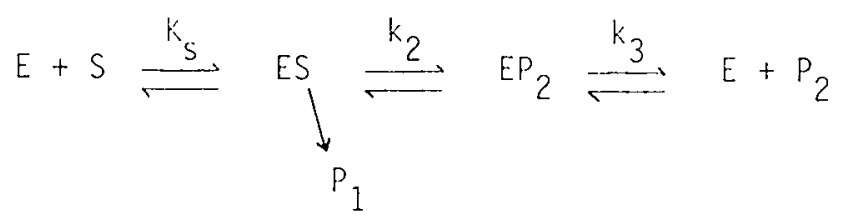

When the substrate $S$ is Bz-Phe-Val-Arg-pNA, the first product $P_{1}$ is $p$-nitro-aniline ( $P N A$ ) and the second product $P_{2}$ is Bz-PheVal-Arg-COOH. ES is the reversible enzyme-substrate complex and $K_{s}$ the dissociation constant of this complex. $E P_{2}$ is the acylenzyme, $k_{2}$ and $k_{3}$ are the rate constants pertaining to the 1 iberation of $P_{1}$ and $P_{2}$, respectively. When $\left[S_{0}\right] \gg\left[E_{0}\right]$, the Michaelis-Menten rate equation holds:

$v=\frac{v_{\max }[S]}{k_{M}+[S]}$, where $k_{M}=k_{S} \frac{k_{3}}{k_{2}+k_{3}}$ and $\frac{v_{\max }}{\left[E_{0}\right]}=\frac{k_{2} k_{3}}{k_{2}+k_{3}}$

A plot of $v$ (the velocity of the catalyzed hydrolysis of the substrate) versus [S] provides the determination of two steady state parameters: $V_{\max }$ (the velocity of the reaction at complete saturation of enzyme with substrate) and the Michaelis-Menten constant $K_{M}$.

In the chymotrypsin catalyzed hydrolysis of amides the acylation rate constant $\left(k_{2}\right) \cdots$ deacylation rate constant $\left(k_{3}\right)(62,63)$. When the formation of the acylenzyme is rate 7 imiting, the steady state kinetic parameters become $k_{c a t}=k_{2}$ and $k_{m}=k_{s}$.

Amidase activity assay. The initial rates of hydrolysis of the amides $\mathrm{N}$-benzoyl-L-phenylalanyl-L-valyl-L-argirine-paranitroanilide-HCl and N-benzoyl-L-isoleucyl-L-glutamyl-glycyl-L-arginine-paranitroanilide-HCl by factor $X_{a}$ and PIVKA-X $x_{a}$ were measured in 
TABLE I. Titration of factor $x_{a}$ and PIVKA-X with $p-: P G B$ : independence of $i$ and $P$-NPGB concentration.

\begin{tabular}{|l|l|c|c|c|}
\hline $\begin{array}{l}\text { Final p-NPGB } \\
\text { concentration } \\
\text { in cuvette (M) }\end{array}$ & \multicolumn{2}{|l|}{$\begin{array}{l}\text { Presteady state production } \\
p-n i t r o p h e n o l\end{array}$} & \multicolumn{2}{|c|}{$\begin{array}{l}\text { Functional enzyme } \\
\text { concentration (i.M) }\end{array}$} \\
\hline factor $X_{a}$ & PIVKA-X & factor $X_{a}$ & PIVKA-X \\
\hline $3.3 \times 10^{-5}$ & $5.30 \times 10^{-2}$ & $3.64 \times 10^{-2}$ & 3.03 & 2.08 \\
$6.6 \times 10^{-5}$ & $5.68 \times 10^{-2}$ & $4.06 \times 10^{-2}$ & 3.25 & 2.32 \\
$9.9 \times 10^{-5}$ & $5.53 \times 10^{-2}$ & $3.85 \times 10^{-2}$ & 3.16 & 2.20 \\
$13.2 \times 10^{-5}$ & $5.28 \times 10^{-2}$ & $3.94 \times 10^{-2}$ & 3.02 & 2.25 \\
\hline
\end{tabular}

TABLE II. Kinetic constants of reaction of factor $x_{a}$ and PIVKA-X with p-NPGB.

\begin{tabular}{|c|c|c|}
\hline Constant & Factor $x_{a}$ & PIVKA-X \\
\hline $\begin{array}{l}k_{s} \\
k_{2} \\
k_{3} \\
k_{2} / k_{3} \\
k_{M} \\
k_{p b}\end{array}$ & $\begin{array}{l}4.2 \times 10^{-4} \mathrm{M} \\
0.19 \mathrm{sec}^{-1} \\
4.2 \times 10^{-5} \mathrm{sec}^{-1} \\
4.5 \times 10^{3} \\
9.3 \times 10^{-8} \mathrm{M} \\
8.0 \times 10^{-5} \mathrm{M}\end{array}$ & $\begin{array}{l}4.0 \times 10^{-4} \mathrm{M} \\
0.15 \mathrm{sec}^{-1} \\
3.0 \times 10^{-5} \mathrm{sec}^{-1} \\
5.0 \times 10^{3} \\
8.0 \times 10^{-8} \mathrm{M} \\
7.0 \times 10^{-5} \mathrm{M}\end{array}$ \\
\hline
\end{tabular}


Tris-imidazole buffer of $\mathrm{pH} \mathrm{8.2,} \mathrm{and} \mathrm{ionic} \mathrm{strength} \mathrm{of} 0.15$ at $37^{\circ} \mathrm{C}$ by determining the increase of p-nitroaniline absorbance in the Aminco DW-2 spectrophotometer operating in the dual wavelength mode with ${ }_{r}=344 \mathrm{~nm}$ and $s=391 \mathrm{~nm}$ at $37^{\circ} \mathrm{C}$. The $391-344 \mathrm{~nm}$ of p-nitroaniline in the buffer solution of $\mathrm{pH} 8.2$ was determined as 11,400 00/mol.

Activation of prothrombin and prethrombin 1 . The conversion of prothrombin and prethrombin 1 by factor $x_{a}$ and PIVKA-X $x_{a}$ were studied in the 1 iquid phase activation process. The activations were performed in $0.02 \mathrm{M} \mathrm{Tris-HCl} 0.1 \mathrm{M} \mathrm{NaCl}$ buffer, $\mathrm{pH} 7.5 \mathrm{at}$ $37^{\circ} \mathrm{C}$. The final concentrations for the activation components in the activation mixture are given in the figure legends. The functional enzyme concentrations of factor $x_{a}$ and PIVKA- $x_{a}$ were determined by active site titration as described under Methods.

At several time intervals aliquots were removed from the activation mixture and added to a microcuvette containing $5.7 \times 10^{-5}$ $M$ of Bz-Phe-Val-Arg-pNA in a final volume of $350 ; 1$ of $0.025 \mathrm{M}$ Tris-imidazole, $0.1 \mathrm{M} \mathrm{NaCl}$ buffer, $\mathrm{pH} \mathrm{8.2.} \mathrm{The} \mathrm{rate} \mathrm{of} \mathrm{p-nitro-}$ aniline formation, proportional to the amount of thrombin activity was measured as described above. Aliquots of the reaction mixture were heated at $100^{\circ} \mathrm{C}$ for $2 \mathrm{~min}$ in $5 \mathrm{~mm}$ sodium phosphate buffer pH 7.0 containing 1.5\% sodium dodecyl sulfate and 50 glycerol, followed by an incubation during 60 min at $37^{\circ} \mathrm{C}$ in the presence of -mercaptoethanol. Sodium dodecylsulfate gel electrophoresis of these prepared aliquots was performed by the method of Weber and Osborn (64). The gels were stained with the method of Fairbanks (65).

RESULTS

Titration of factor $X_{a-}$ and PIVKA-X

Functional enzyme concentration. Factor $x_{a}$ and PIVKA-X were 


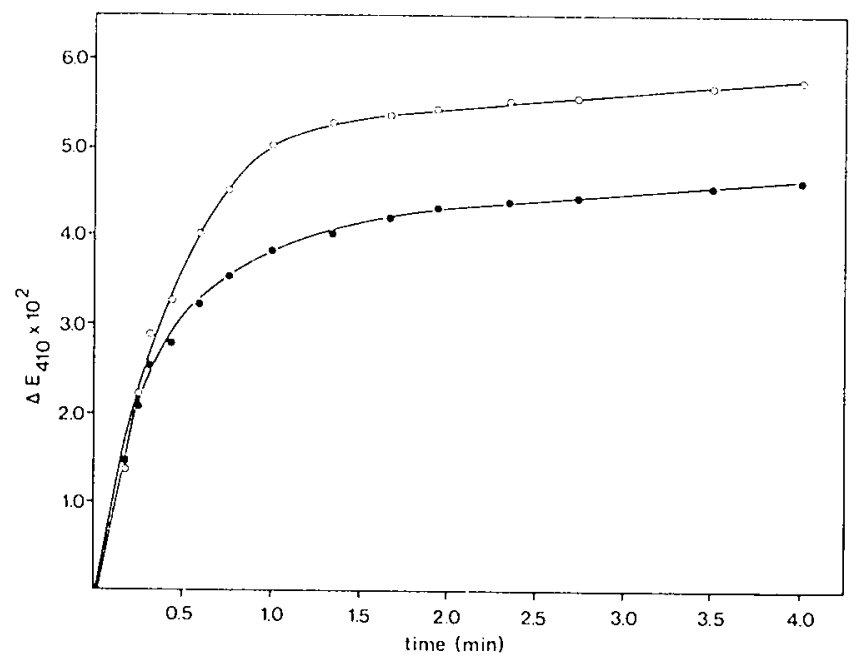

Fig. 2.

Time courses of the reaction between $p^{\prime}$-nitrophenyl-pguanidino-benzoate and factor $x_{a}$ (open circles) and PIVKA$\therefore$ a (solid circles). Procedure is as described under Methods. The actual protein concentration is $3.6 \times 10^{-6} \mathrm{M}$ and $3.1 \times 10^{-6}$ ii for respectively factor $x_{a}$ and PIVKA- $x_{a}$. The $p-N P G B$ concentration is $9.9 \times 10^{-5}$ ir.
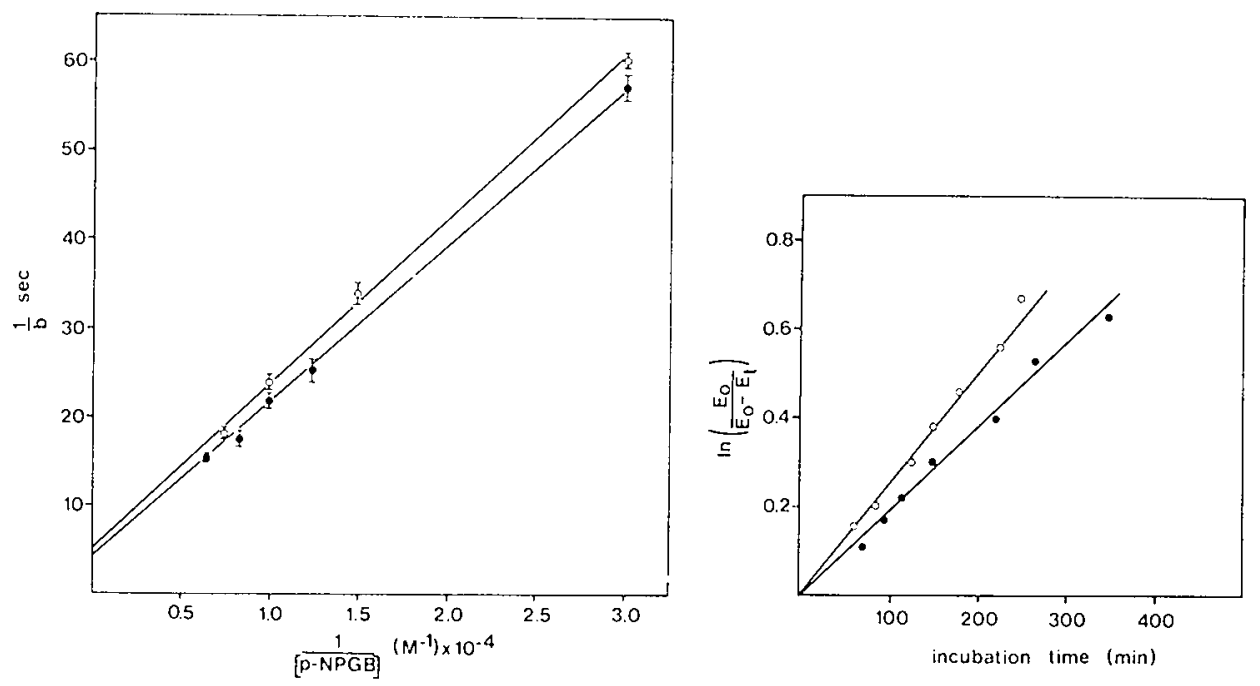

Fig. 3.

Plot of the first order rate constant of the presteady state reaction of factor $X_{a}$ (open circles) and PIVKA-X $x_{a}$ (solid circles) versus the reciprocal p-i.PGB concentration.

Fig. 4.

Deacylation of guanidinobenzoyl-factor $x_{a}$ (open circles) and guanidinobenzoylPIVKA-X ${ }_{a}$ (solid circles). Experimental conditions are described under Methods. 
titrated with p-NPGB as described under Methods. As shown in fig. 2 , the presteady state $p$-nitrophenol production was complete after about 2 minutes for both factor $X_{a}$ and PIVKA-X $X_{a}$ and is followed by a very low linear postburst production of p-nitrophenol. Fron this type of curves it was determined as described under Methods. As can be seen from table I, ii does not vary significantly with the NPGB concentration. This fact, and the low postburst production of p-nitrophenol indicate that $S_{0}>K_{M}$ and $k_{2}>k_{3}$. Therefore $\left[E_{0}\right] \approx$ and the molarity of the enzyme solutionscan be calculated as $(3.1 \pm 0.1) 10^{-5} \mathrm{M}$ and $(2.1 \pm 0.1) 10^{-5} \mathrm{M}$ for factor $x_{a}$ and PIVKA-X $x_{a}$, respectively. veterinination of kinetic constants. The kinetic constants of the hydrolysis of $p$ - NPGB catalyzed by factor $x_{a}$ and PIVKA- $x_{a}$ are summarized in table $I 1$. The linear relationship between $1 / \mathrm{b}$ versus $1 /$ p-NPGB (fig. 3) and in $\left[\frac{E_{0}}{E S^{\prime}}\right]$ versus time (fig. 4) shows that the kinetics of both factor $X_{a}$ and PIVKA- $x_{a}$ reacting with $\mathrm{p}-\mathrm{NPGB}$ are adequately described by the theory as summarized under Methods. The rate constant for the postburst $p$-nitrophenol production, $K_{p b}$, determined at a NPGB concentration of $1.6 \times 10^{-4} \mathrm{M}$ was about two times the deacylation constant $k_{3}$ for both factor $x_{a}$ and PIVKA- $x_{a}$. However, the ratio $k_{2} / k_{3}$ is very large:

therefore the postburst $p$-nitrophenol production has no serious effect on the accuracy of the factor $x_{a}$ and PIVKA- $x_{a}$ titration under the conditions used.

Amidase activity of factor $X_{a}$ and PIVKA-X

Determination of the kinetic constants. The Lineweaver-Burk plots (66) for factor $X_{a}$ and PIVKA-X with Bz-Phe-Val-Arg-pNA and Bz-Ile-Glu-Gly-Arg-pNA are shown in fig. 5A-5D. The kinetic constants are summarized in table III and were determined from slope and intercept by regression analysis of each set of data. The functional enzyme concentrations determined by NPGB titration, instead of the enzyme concentration based on protein concentration, were used for calculation of 

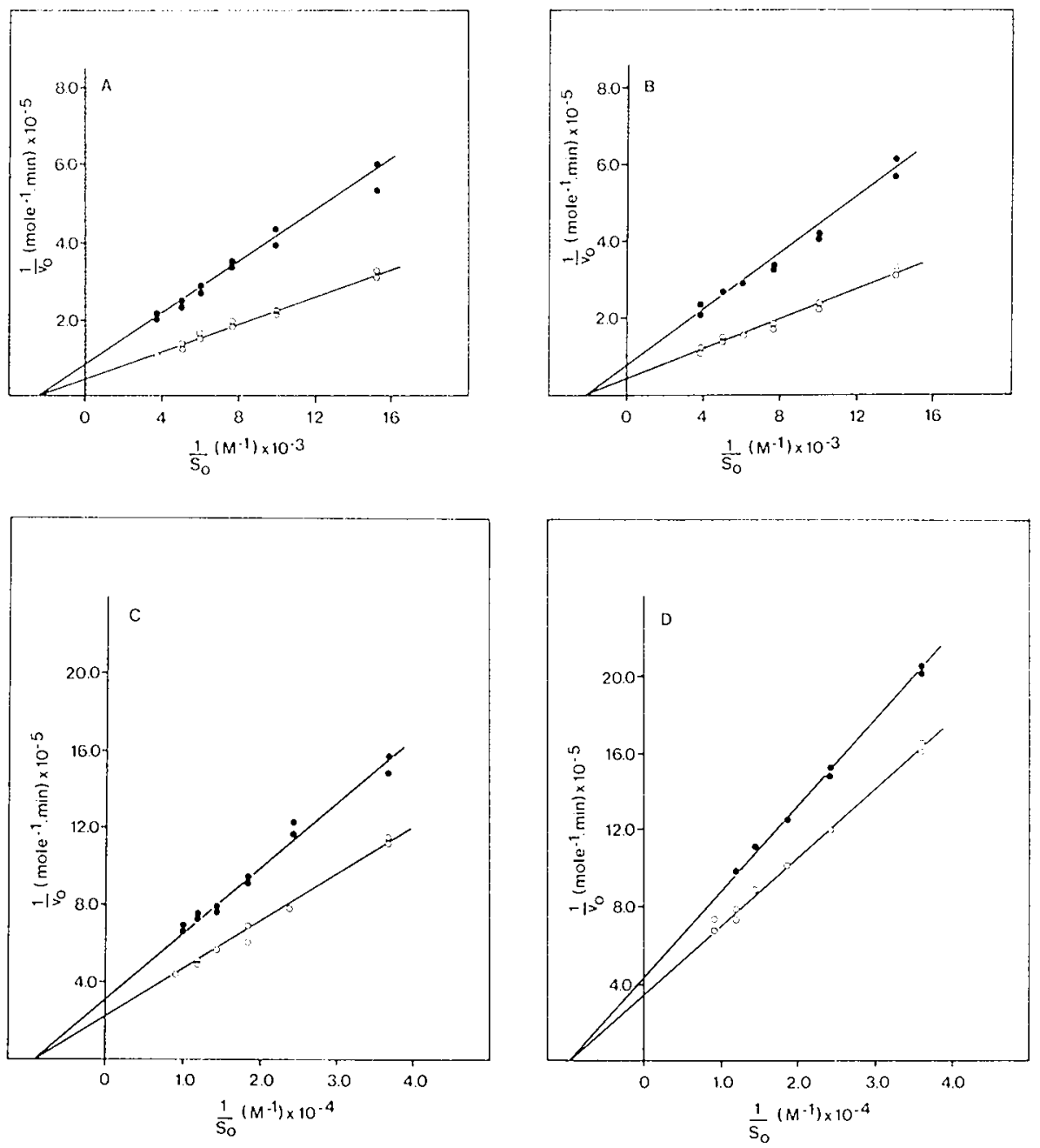

Fig. 5 .

Lineweaver-Burk plots for factor $x_{a}$ and PIVKA- $x_{a}$ using Bz-Phe-Va]-Arg-pNA and Bz-IleGlu-Gly-Arg-pita.

A. Amidolys is of Bz-ile-alu-6iy-rirq-jia by PIVkA- $x_{a}$. Enzyme concentrations: $5.0 \times 10^{-9}$ in (open circles) and $2.5 \times 10^{-9} \mathrm{H}$ (solid circles).

B. Amidolys is of Bz-1le-Glu-Gly-Arg-piA by factor $x_{a}$. Enzyme concentrations: $4.0 \times 10^{-9} \mathrm{~A}$ lopen circles) and $2.0 \times 10^{-9}$ in (solid circles).

C. Amidolys is of Bz-Pfie-Yal-Airg-pikA by PlWKA-X $x_{a}$. Enzyme concentrations: $9.0 \times 10^{-8}$ in (open circles) and $6.1 \times 10^{-8} \mathrm{ir}$ (solid circles).

L. Anidoiys is of Ez-Phe-Val-Arg-pHA by factor $x_{a}$. Enzyme concentrations: $1.9 \times 10^{-7} \mathrm{n}$ (open circles) and $1.3 \times 10^{-7}$ it (solid circles).

Experimental conditions as described under liethods. 


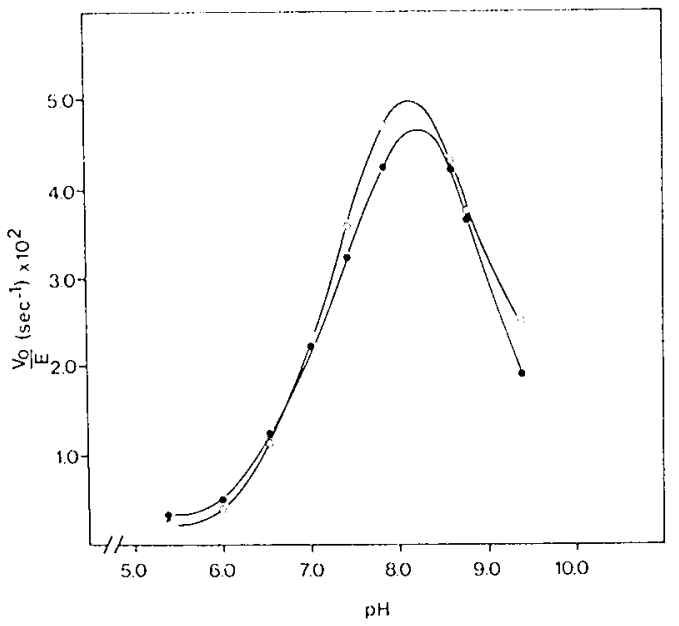

Fig. 6 .

phoptina of factor xa $\left(-0^{-}\right)$and PIGKA-X (-)- with BL-ile-Glu-Gly-Arg-pia. The pit dependence is determined in irisimidazole buffers at varying $\mathrm{pH}$, ionic strength of 0.15 at $37^{\circ} \mathrm{C}$. Substrate concentration is $1.2 \times 10^{-4} \mathrm{H}$, enzyme concentrations are: factor $x_{a}, 1.2 \times$ $10^{-8} \mathrm{H}$ and PIVKA-X $a, 1.1 \times 10^{-8} \mu$. imidase activity assay as described under liethods.
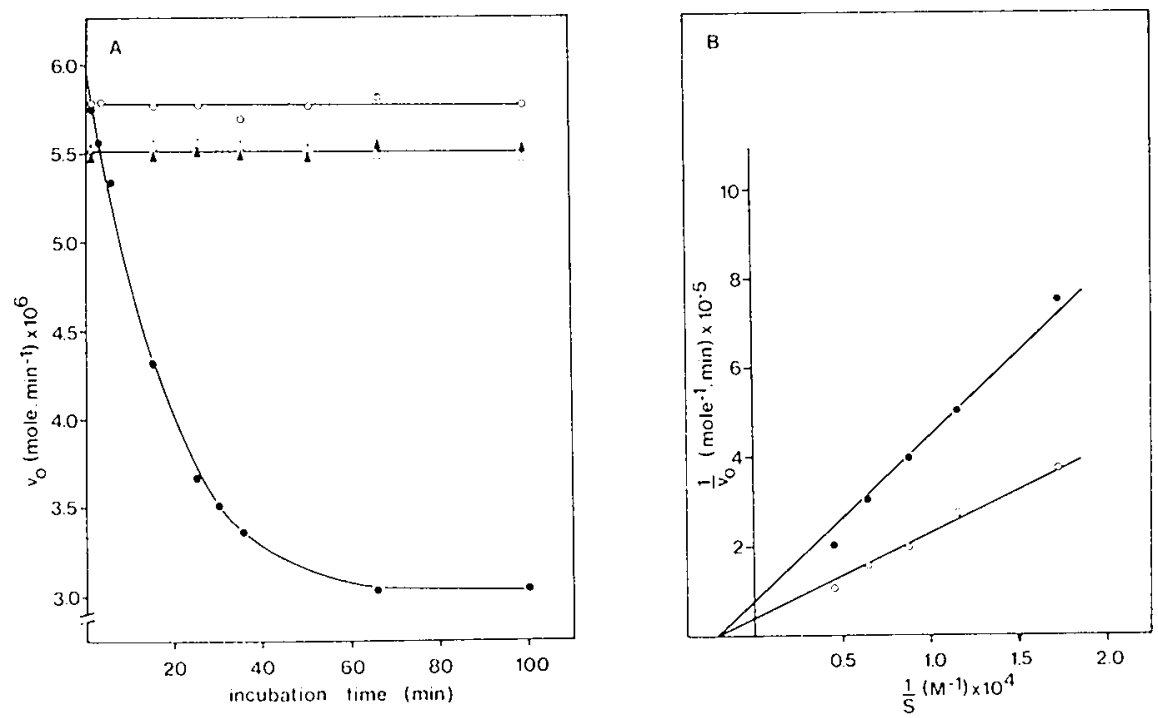

Fig. 7.

Effect of $\mathrm{Ca}^{2+}$ on the amidase activity of factor $X_{a}$ and $P I V K A-x_{a}$ with Bz-1le-Glu-GlyArg-pis.

A. Time courses of inactivation of factor $x_{a}, 50 . \mathrm{g} / \mathrm{m} .1$ (solid circles) and PIVKA- $x_{a}$, $65 \mathrm{ig} / \mathrm{ml}$ (solid triangles) by $\mathrm{Ca}^{2+}(5 \mathrm{mili}$ ). The same experiments in the absence of $\mathrm{Ca}^{2+}$ are presented by open circles for factor $\mathrm{X}_{a}$ and open triangles for PIVKA- $x_{a}$. At intervals aliquots $(4:: 1)$ were subsampled from the incubation limeture into a buffer of $0.025 \mathrm{M}$ Tris-imidazole $0.1 \mathrm{M} \mathrm{NaCl}, \mathrm{pH} 8.2$ and amidase activity was measured as described under liethods.

3. Jouble reciprocal plots of the anidolysis of Bz-!he-Glu-Gly-Arg-pia by factor $x_{a}$. factor $x_{a}$ was preincubated in the presence of $\mathrm{Ca}^{2+}$ for 60 minutes (solid circles) and absence of $\mathrm{Ca}^{2+}$ (open circles). Experimental conditions as described in the legend to fig. $7 \mathrm{~A}$. 


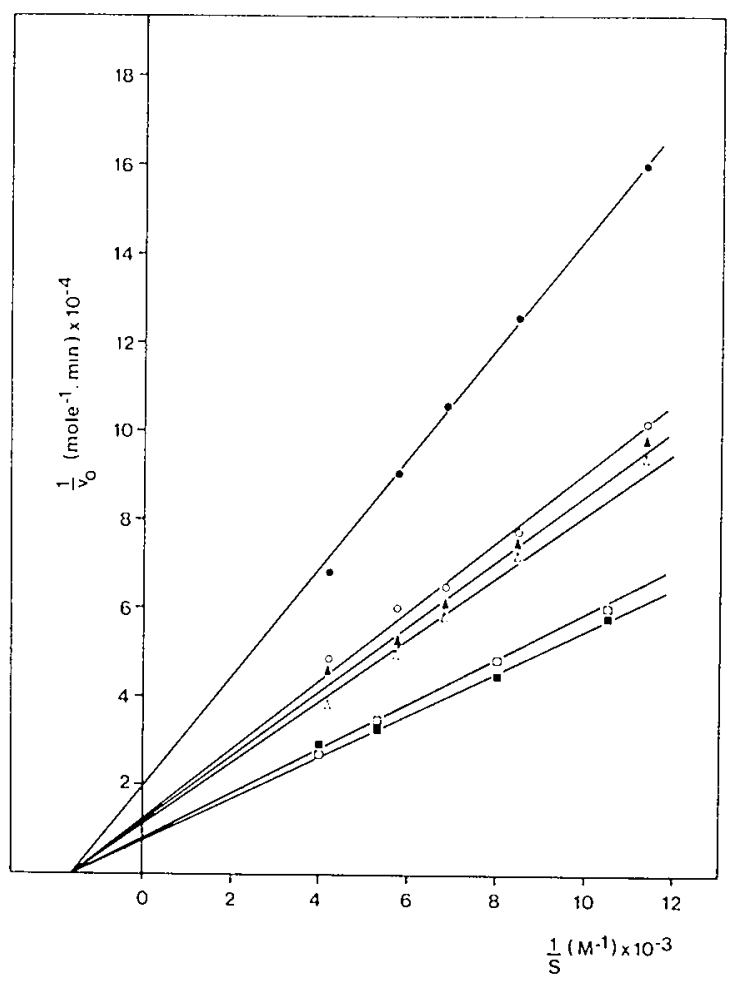

Fig. 3.

Effect of factor $V_{a}$ on the amidase activity of factor $x_{a}$ and PIVKA- $x_{a}$ using Bz-Ile-GluGiy-Arg-pNA as substrate. Lineweaver-Burk plots were constructed from data obtained by amidolys is of Bz-[1]e-6]u-6]y-firg-pNA by: 1. factor $x_{a},-0-; 2$. idem preincubated for $60 \mathrm{~min}$. in the presence of $\mathrm{Ca}^{2+}(5 \mathrm{ml}),-\mathbf{0} ; 3$. iden in the presence of factor $V_{a}$ $(10 \mathrm{U} / \mathrm{ml}),-\Delta_{-} ; 4$. idem in the presence of $\mathrm{Ca}^{2+}(5 \mathrm{~m} \cdot \mathrm{l})$ and factor $\mathrm{V}_{\mathrm{a}}(10 \mathrm{U} / \mathrm{ml}),-\mathbf{\Delta}-$;

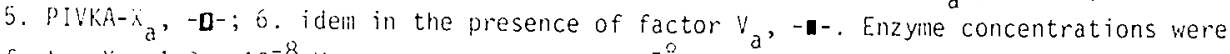
factor $x_{a}: 1.3 \times 10^{-8}$ in and PIVKA- $x_{a}: 1.0 \times 10^{-8}$. Substrate concentrations ranging from $8.7 \times 10^{-3}$ lif to $2.3 \times 10^{-4} \mathrm{il}$.

Experimental conditions were the same as described in the legend to fig. 7A. 
$k_{\text {cat }}=v_{\text {max }} / r_{0}{ }^{j}$

An excess, at least 150 fold for Bz-Phe-Val-Arg-pNA and at least 10,000 fold of Bz-I1e-Glu-Gly-Arg-pNA over enzyme concentration was used.

pH dependence. For both factor $X_{a}$ and PIVKA-X $X_{a}$ the $\mathrm{pH}$ optimum was found to be between 8.0 and 8.5 (fig. 6). It also appears from those results that variation of the $\mathrm{pH}$ in the range indicated, did not have any influence on the $k_{\text {cat }}$ (factor $\left.x_{a}\right) / k_{\text {cat }}\left(P I V K A-x_{a}\right.$ ) ratio. Experimental conditions were as described under fig. 6. Effect of factor $V_{a}$ on amidase activity. As shown in fig. $7 \mathrm{~A}$, the initial velocity of the hydrolys is of Bz-Ile-Glu-Gly-Arg-pNA catalyzed by factor $X_{a}$, decreases during incubation in the presence of $\mathrm{Ca}^{2+}(5 \mathrm{mM})$. After about 60 minutes the amidase activity remains unaltered. The amidase activity then found is about one half of the control value. Double reciprocal plots of the hydrolysis of Bz-Ile-Glu-Gly-Arg-pNA by factor $X_{a}$, preincubated during 90 minutes in the presence of $5 \mathrm{mM} \mathrm{CaCl} 2$ and factor $x_{a}$ treated in the same way in the absence of $\mathrm{Ca}^{2+}$ are shown in fig. 7B.

It was found that in the absence of $\mathrm{Ca}^{2+}$ the $V_{\text {max }}$ value was $2.5 \times 10^{-5}$ mole.min ${ }^{-1}$ and in the presence of Ca2t the $V_{\max }$ value was $1.2 \times 10^{-5}$ mole.min ${ }^{-1}$. The $x_{M}$ value for factor $x_{a}$ preincubated with $\mathrm{Ca}^{2+}$ was the same as in case of factor $x_{a}$ preincubated in the absence of $\mathrm{Ca}^{2+}$. Upon incubation of PIVKA-X with $\mathrm{Ca}^{2+}$ under identical conditions as described for factor $\mathrm{X}_{a}$ no alteration was found in the amidase activity.

Effect of factor $v_{2}$ on amidase activity. Factor $v_{a}$ has no significant effect upon the $K_{M}$ and $V_{\max }$ values of the hydrolys is of Bz-Ile-Glu-Gly-Arg-pNA catalyzed by factor $X_{a}$ and PIVKA-X $X_{a}$ under the conditions as described in the legend to fig. 8. However, no decrease in anidase activity of factor $x_{a}$ upon incubation with $\mathrm{Ca}^{2+}(5 \mathrm{~m} \cdot 4)$ was found when factor $v_{a}(1.0 \mathrm{mg} / \mathrm{ml})$ was 

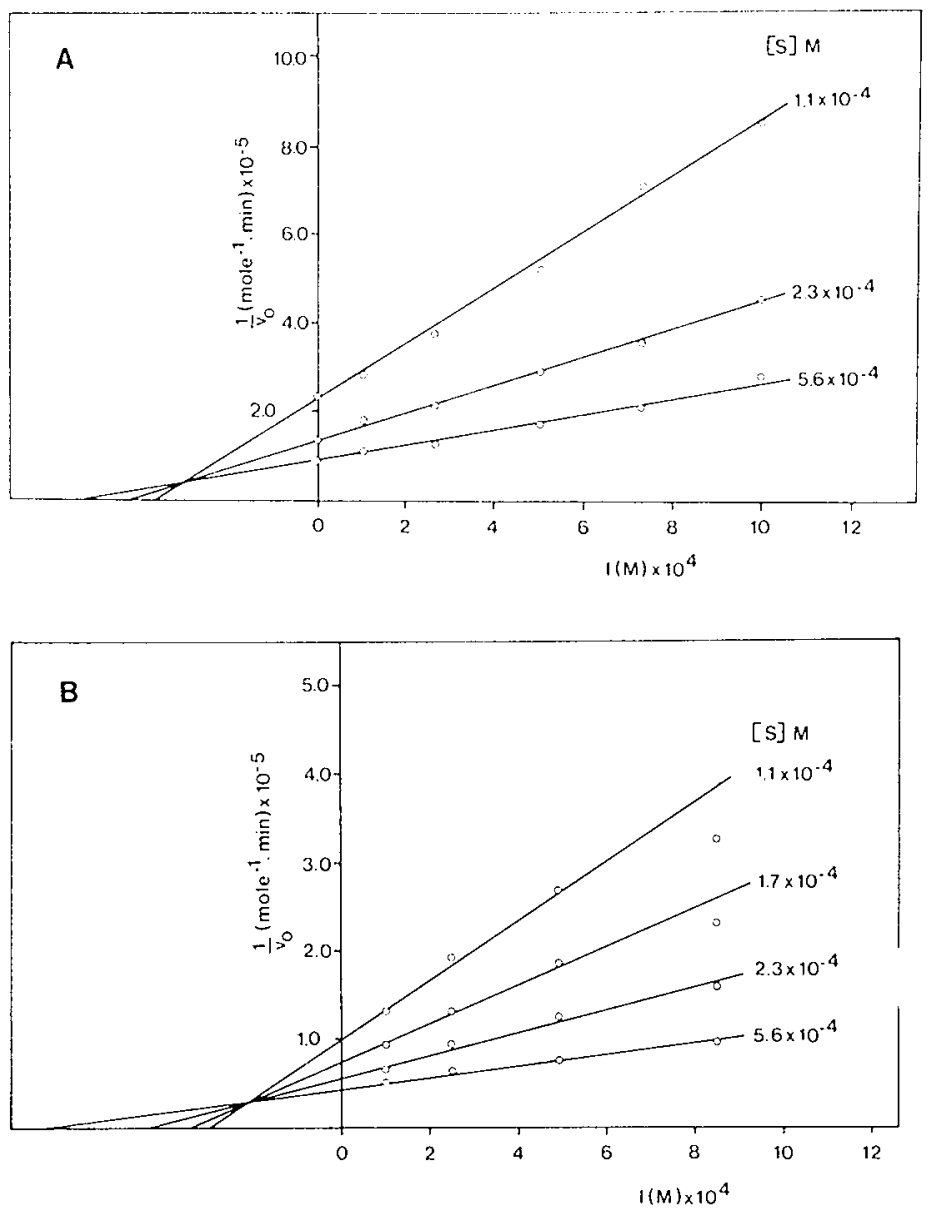

fig. 9

Inhibition of amidase activity of factor $x_{a}$ and PIVKA- $x_{a}$ by benzanidine. Dixon plot was constructed by plotting the reciprocal initial rate of Bz-:le-Glu-Gly-Arg-p:A hydrolysis by factor $x_{a}$ (panel $A$ ) and PIVKA-X (panel B) versus inhibitar concentration at fixed concentrations of substrate as indicated. Enzyme concentrations were $1.0 \times 10^{-3}$ in for PIVkn- $x_{a}$ and $0.4 \times 10^{-6}$ in for factor $x_{a}$. hmidase activity was measured as described under Hethods. 
present in the incubation mixture. This effect could, however, be duplicated by the addition of bovine serum albumin to a concentration of $0.5 \mathrm{mg} / \mathrm{ml}$ (results not shown).

Inhibition of amidase activity by benzamidine. A plot of the reciprocal initial rates of factor $X_{a}$ and $P I V K A-X_{a}$ hydrolys is of $B z-I l e-G l u-G l y-A r g-P N A\left(1 / v_{0}\right)$ versus inhibitor concentration (I) at different substrate concentrations is shown in fig. 9. For both factor $x_{a}$ and PIVKA-X straight lines were obtained. The inhibition by benzamidine was competitive. Competitive inhibition was also found in a double reciprocal plot of $v_{0}$ versus substrate concentration at different inhibitor concentrations. The $K_{j}$ values for inhibition of the hydrolys is of Bz-Ile-GluGly-Arg-pNA detemined from fig. 9 by regression analysis were found to be $2.4 \times 10^{-4} \mathrm{M}$ and $3.0 \times 10^{-4} \mathrm{M}$ for respectively factor $x_{a}$ and PIVKA-X $x_{a}$.

The proteolytic action of factor $X_{a}$ and PIVKA-X on prothrombin and prethrombin 1

Time course of activation of prethrombin 1. The time courses of activation of prethrombin 1 by factor $x_{a}$ and PIVKA- $x_{a}$ are shown in fig. 10. Similar and linear rates of thrombin formation were obtained. It can be concluded that in the presence of $\mathrm{Ca}^{2+}$, factor $x_{a}$ and PIVKA-X $x_{a}$ have the same catalytic activity towards prethromb in 1 . Time course of activation of prothrombin. The time courses of activation of prothrombin in the absence of $\mathrm{Ca}^{2+}$ by factor $\mathrm{X}_{\mathrm{a}}$ and PIVKA- $x_{a}$ are shown in fig. 11A. It can be seen that identical activation curves were obtained. An interesting feature of these time courses is that two phases can be distinguished, e.g.: an apparent slow rate of thrombin formation, followed by a faster linear reaction rate. The final rate of thrombin formation per mole enzyme, was found to be the same as was obtained with prethrombin 1 in the presence of $\mathrm{Ca}^{2+}$ (table IV). The time courses of prothrombin activation under the same conditions, but visual- 
TABLE III. Kinetic constants [1] for the hydrolysis of synthetic amide substrates by activated factor $X$ and activated PIVKA-X.

\begin{tabular}{|c|c|c|c|c|}
\hline \multirow[t]{2}{*}{ Substrate } & \multicolumn{2}{|c|}{ factor $x_{a}$} & \multicolumn{2}{|l|}{ PIVKA-X $a$} \\
\hline & $K_{M}(M)$ & $k_{\text {cat }}\left(\min n^{-1}\right)$ & $K_{M}(M)$ & $k_{\text {cat }}\left(\min ^{-1}\right)$ \\
\hline $\begin{array}{l}\text { Bz-Phe-Val- } \\
\text { Arg-pNA } \\
\text { Bz-Ile-Glu- } \\
\text { Gly-Arg-pNA }\end{array}$ & $\begin{array}{l}(0.9 \pm 0.1) 10^{-5} \\
(0.44 \pm 0.06) 10^{-3}\end{array}$ & $\begin{array}{c}16 \pm 1 \\
(6.6 \pm 0.1) 10^{3}\end{array}$ & $\begin{array}{l}(1.20 \pm 0.1) 10^{-5} \\
(0.5 \pm 0.06) 10^{-3}\end{array}$ & $\begin{array}{l}55 \pm 5 \\
(5.7 \pm 0.1) 10^{3}\end{array}$ \\
\hline
\end{tabular}

[1] Results of duplicate experiments using two different enzyme concentrations.

TABLE IV. Rate of thrombin formation [1] on prothrombin and prethrombin 1 activation by factor $x_{a}$ and PIVKA- $X_{a}$. Experimental conditions as described in the legend to figures 10 and 11 .

\begin{tabular}{|c|c|c|}
\hline Activator & Substrate & Activation rate/mole enzyme [2] \\
\hline $\begin{array}{l}\text { factor } X_{a} \\
\text { PIVKA-X } \\
\text { factor } x_{a}+C a^{2+} \\
\text { PIVKA-X } x_{a}+a^{2+} \\
\text { factor } x_{a}+C a^{2+} \\
\text { PIVKA-X }+C a^{2+}\end{array}$ & $\begin{array}{l}\text { prothromb in } \\
\text { prothromb in } \\
\text { prothromb in } \\
\text { prothromb in } \\
\text { prethromb in } 1 \\
\text { prethromb in } 1\end{array}$ & $\begin{array}{l}0.85 \pm 0.05 \\
0.84 \pm 0.01 \\
1.18 \pm 0.03 \\
1.03 \pm 0.04 \\
0.93 \\
0.85\end{array}$ \\
\hline
\end{tabular}

[1] Determined at two enzyme concentrations, except in case of prethrombin 1.

[2] Unit thrombin/min/mole, where 1 unit is defined as the amount of thromb in which hydrolysis 1 mole substrate/min under the conditions used. 

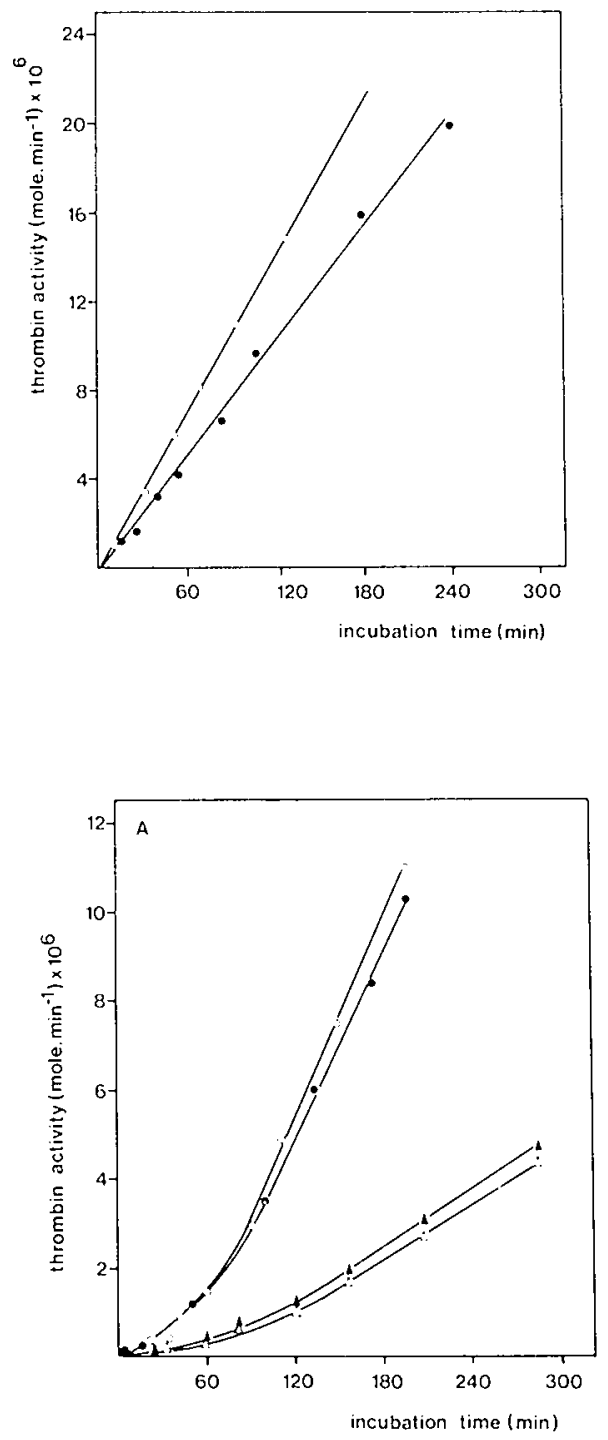

Fig. 10 .

Tine courses of the activation of prethrombin 1 by factor $x_{a}$ and PIVKA- $x_{a}$ in the presence of $\mathrm{Ca}^{2+}$. Prethrombin $1(0.5 \mathrm{mg} / \mathrm{ml})$ was incubated with factor $x_{a}, 1.3 \times 10^{-7} M$ (open circles) and PIVKA$x_{a}, 1.0 \times 10^{-7}$ if (solid circles). The incubation mixtures contain $5 \mathrm{mll} \cdot \mathrm{CaCl}_{2}$. Thrombin assay and experimental conditions as described under ire thods.

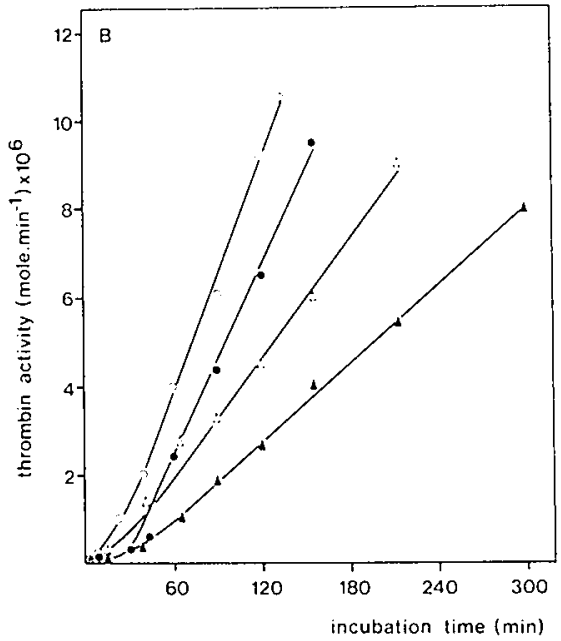

Fig. 11 .

Time courses of activation of prothrombin by factor $X_{a}$ and PIWKA-X $x_{a}$.

A. Comparison of prothrombin activation by factor $x_{a}$ and PIVkA- $x_{a}$. Prothrombin (1.4 mg/ inl) was incubated with factor $x_{a}, 7.2 \times 10^{-8} \mathrm{M},-0-$; and $3.1 \times 10^{-8} \mathrm{ir},-\Delta-$; PIVKA-X $x_{a}, 7.2 \times 10^{-8} \mathrm{H}, \rightarrow-;$ and $2.9 \times 10^{-8} \mathrm{M},-\mathbf{A}$ -

3. Comparison of activation of prothrombin by factor $x_{a}$ and PIKKA- $x_{a}$ in the presence of $5 \mathrm{mll} \mathrm{Ca}^{2+}$. Prothrombin $(1.4 \mathrm{mg} / \mathrm{ml})$ was incubated with factor $\mathrm{x}_{a}, 7.2 \times 10^{-6} \mathrm{H}$, -o-; and $3.1 \times 10^{-8} \mathrm{H},-\Delta-;$ PIVKA-X $, 7.2 \times 10^{-8} \mathrm{H},-\bullet-;$ and $2.9 \times 10^{-8} \mathrm{in}, \mathbf{\Delta -}$. Thrombin assay and experimental conditions as described under Hethods. 
ized by sodium dodecyl sulfate gel electrophoresis, as shown in fig. $12 \mathrm{~A}$, revealed that prethrombin 1 becomes the substrate after about 30 minutes.

No differences in the evolution of activation products were found between factor $x_{a}$ and PIVKA-X $x_{a}$. loreover, the distribution of the activation products agrees very well with the data reported by owen et al. (19). That is, prothrombin the largestmolecular weight component (mol.wt. around 74,000) at the initial stage of the reaction is rapidiy converted into prethrombin 1 (mol.wt. around 48,000) and fragment 1 (nol. wt. around 24,000 ). Prethromb in 1 is converted into prethrombin 2 (mol. wt. around 38,000 ) by splitting off fragment 2 (mol. wt. around 13,000), which is, however, not adequately stained and barely visible. Finally prethrombin 2 is converted into thrombin (mol.wt. around 38,000), visible in the electrophoresis as the B-chain (mol.wt. around 35,000). The time courses of activation of prothrombin in the presence of $\mathrm{Ca}^{2+}$ is shown in fig. 11B. A comparison with the time courses in the absence of $\mathrm{Ca}^{2+}$ revealed that the lag-time in thrombin formation is obviously shortened by $\mathrm{Ca}^{2+}$ in case of factor $X_{a}$ and to a much lesser extent for PIVKA-X ${ }_{a}$. A slight increase of the final linear rate of thrombin formation is observed, 1.5 and 1.2 times respectively for factor $x_{a}$ and PIVKA-X $x_{a}$ (table IV).

The time courses of prothrombin activation in the presence of $\mathrm{Ca}^{2+}$ were also monitored by sodium dodecyl sulfate gel electrophoresis (fig. 12B). The activation product fragment 1.2 (mol.wt. around $36,000)$, not detectable in the time course in the absence of $\mathrm{Ca}^{2+}$, appears just above prethrombin 2. As yet known, in all probability only the prothrombin activation pathway by factor $x_{a}$, defined by the cleavage order $2-3$ (see fig. 1) occurs. However, when thromb in proteolys is was allowed to occur (fig. $12 A-B$ ) the cleavage order seems to be 1-2-3, in addition to the pathway $2-3$. 
In order to eliminate the conversion of prothrombin and fragment 1.2 by the proteolytic action of thrombin, activation of prothromb in was performed in the presence of diisopropylphosphofluoridate (DFP). The time course of activation, as visualized by sodium dodecyl sulfate gel electrophores is is shown in fig. 12C. DFP inhibits factor $x_{a}$ much less effectively than it inhibits thrombin. It was found that under the conditions used ( $1 \mathrm{mM} \mathrm{DFP}$ ) no thrombin activity developed. The amidase activity of factor $x_{a}$ and PIVKA-X $x_{a}$ dropped to $85 \%$ in the course of one hour. Examination of the gels (fig. 12C) revealed that when thrombin activity is inhibited, prethrombin 2 is directly formed from prothrombin upon activation with factor $x_{a}$ and PIVKA- $x_{d}$. The absence of any stained material in the fragment 1 region obviously confirmed this. Unlike than the time courses shown in fig. 11B, no visible differences can be observed in the time courses as monitored by sodium dodecyl sulfate gel electrophoresis (fig. 12C).

A comparison of the effectiveness of phospholipids on the prothrombin activation by factor $x_{a}$ or decarboxy factor $x_{a}$ in the presence of $\mathrm{Ca}^{2+}$ is show in fig. 13. It is clearly demonstrated that only in case of factor $x_{a}$, phospholipids markedly increase the rate of activation of prothromin.

In view of the observations that $\mathrm{Ca}^{2+}$ mediates the binding of factor $X$ to phospholipids (40) and the role of $\gamma$-carboxyglutamic acid in the $\mathrm{Ca}^{2+}$ binding properties of the protein, it is reasonable to conclude that the phospholipids are ineffective in the activation of prothrombin by decarboxy factor $x_{a}$ because of the absence of $y$-carboxyglutamic acids in the latter. 


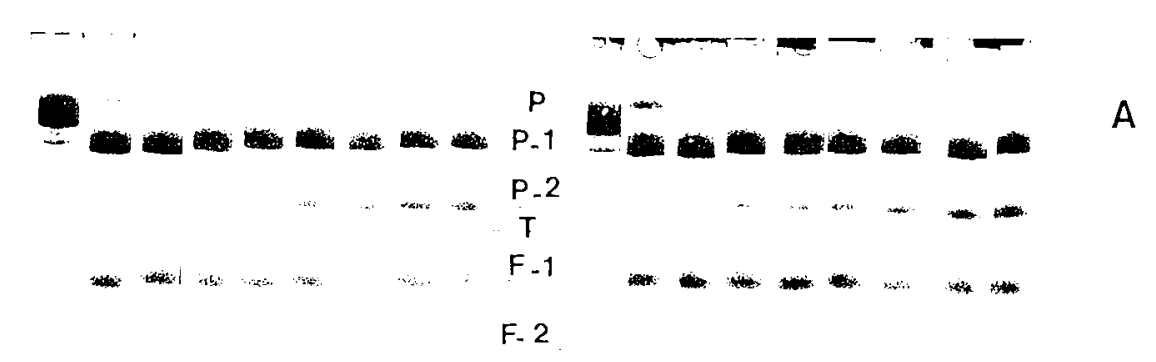

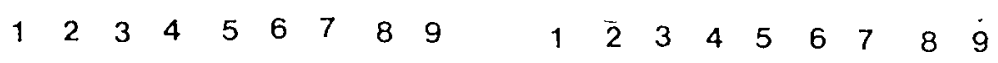

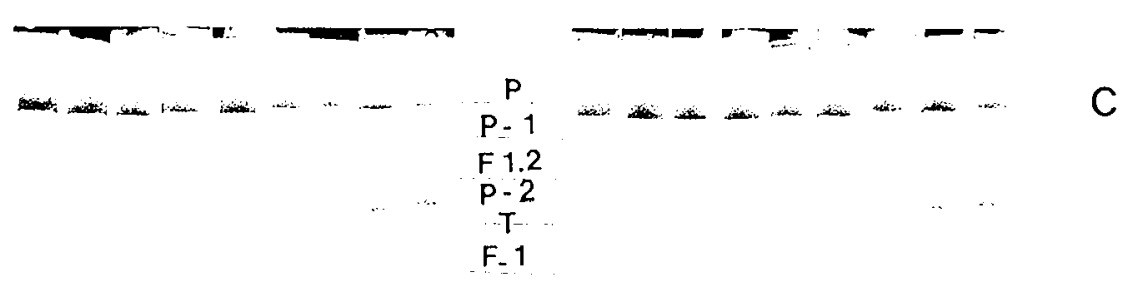

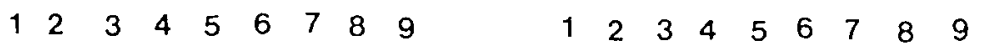

Abbreviations:

$\begin{array}{ll}P & \text { prothrombin } \\ \text { P-1 } & \text { prethrombin 1 } \\ \text { P-2 } & \text { prethrombin 2 } \\ T & \text { thrombin } \\ \text { F-1 } & \text { fragment } 1 \\ \text { F-2 } & \text { fragment 2 } \\ \text { F 1.2 } & \text { fragment } 1.2\end{array}$




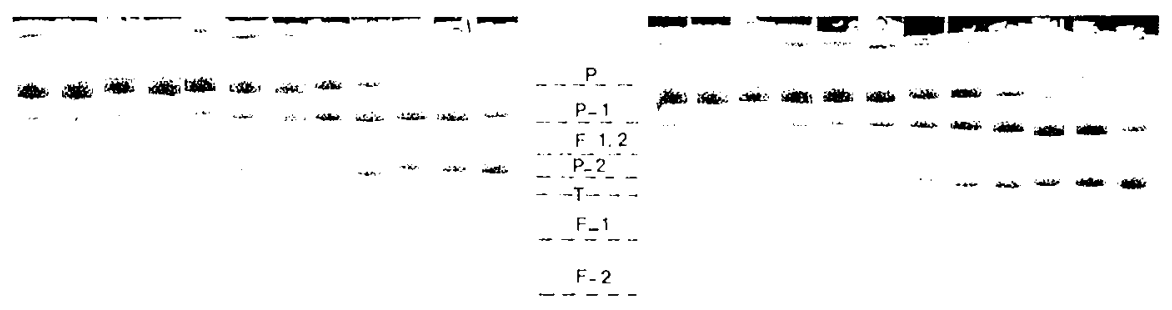

$\begin{array}{lllllllllllll}1 & 2 & 3 & 4 & 5 & 6 & 7 & 8 & 9 & 10 & 11 & 12\end{array}$

$\begin{array}{llllllllllll}1 & 2 & 3 & 4 & 5 & 6 & 7 & 8 & 9 & 10 & 11 & 12\end{array}$

Fig. 12 .

Time course of prothromin activation by factor $z_{a}$ and $p: y f_{i-z_{a}}$. hit several time intervals aliquots were removed from the activation mixture and analyzed by sodiuil doctecyl sulfate gel electrophoresis after disulfide reductior betaled conditions are given under Hethods.

A. Left:prothrombin $(1.3 \mathrm{mg} / \mathrm{ml})$ was incubated with $6.3 \times 10^{-3} \because$ ractor $x_{a}$, : : o win.,

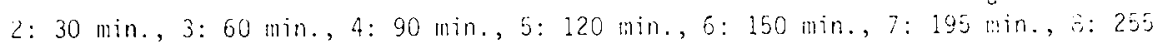
min., 9: 305 min.

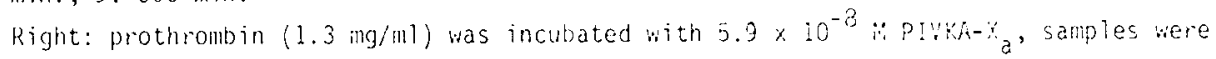
removed from the activation mixture at the times given for factor $x_{a}$.

B. Left: prothrombin $(1.3 \mathrm{mg} / \mathrm{ml})$ ) was incubated with $7.0 \times 10^{-6}$ in factor $x_{a}$ in the presence of $10 \mathrm{mll}^{2+} \mathrm{ca}^{2+} ; 1: 0 \mathrm{~min}, 2: 30 \mathrm{sec}, 3: 2 \mathrm{~min}, 4: 5 \mathrm{~min}, 5: 10 \mathrm{~min}$, o: 20 min., 7: 30 min., B: 40 min., 9: 50 min., 10: 90 min., :1: 120 min., 12: 240 min.

Right: prothrombin $(1.3 \mathrm{mg} / \mathrm{ml})$ was incubated with $7.0 \times 10^{-3} \because \mathrm{DI} \cdot \mathrm{k}-\mathrm{g}_{\mathrm{a}}$ in the presence of $10 \mathrm{mill} \mathrm{Ca}^{2+}$. The samples were removed from activation mixture at times given for factor $\ddot{x}_{a}$.

c. Left: prothrombin $(1.3 \mathrm{mg} / \mathrm{ml})$ was incubated $u$ ith $6.2 \times 13^{-3}$ if factor $\mathrm{a}_{a}$ in the

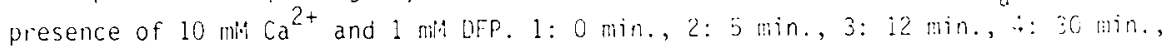
5: 60 min., 6: 105 min., 7: 168 min., 7: 268 min., s: 175 min., 3: 255 min.

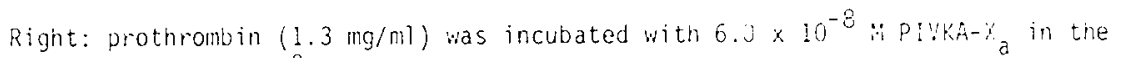
presence of $10 \mathrm{~m} \mathrm{Ca}^{2+}$ and $1 \mathrm{mM}^{2+} \mathrm{DFP}$, samples were removed fromactivation mixture at times as given for factor $x_{a}$. 


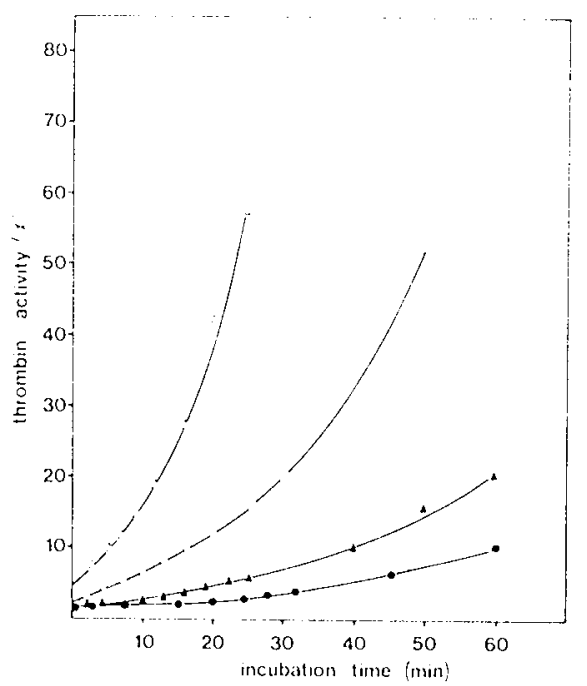

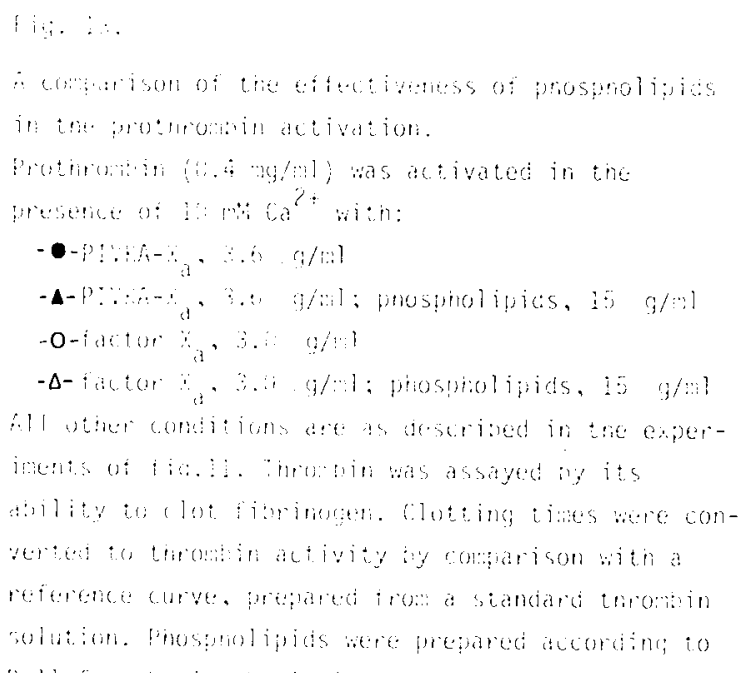

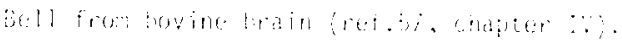

\section{DISCUSSION}

Titani (68) has shown that there exists a high degree of identity (greater than 55 , ) between the heavy chain of factor $x_{a}$ and trypsin in a region (73 residues) which includes the active site serine. A1) components of the "charge-relay system" of pancreatic serine proteases are present in the corresponding loci of the heavy chain of factor $x_{a}$. However, the trypsin-like proteases of the blood coagulation system, e.g. thrombin, factor $I X_{a}$ and factor $x_{a}$ possess a narrow substrate specificity compared to trypsin. It is also known that these proteases possess an extra chain not found in trypsin and it is suggested that this chain might be the source of the specificity (8, 69). Recently, Hageman (70) found evidence that the A-chain of thrombin does not play a significant role in determining the catalytic specificity of thrombin. By studying the specificity of thrombin and factor $X_{a}$ towards small synthetic substrates it was found that 
there exists a narrow tolerance of thrombin and factor $x_{a}$ for recognition of amino acids in either of the two adjacent amino-terminal residues of the Arg- $X$ peptide bond to be split. For thrombin $V a l$ or $A l a$ and for factor $X_{a}$ an acidic amino acid $(G / u)$ is found in either of the two residues $(18,72,72)$.

It was our purpose to elucidate the role of $\gamma$-carboxyglutamate residues in the catalytic action of factor $x_{a}$ by comparing the catalytic properties of the native molecule (factor $x_{a}$ ) and an analogous decarboxy species (PIVKA- $x_{a}$ ). This is immediately linked to the question of the role of $\mathrm{Ca}^{2+}$, since the binding of these ions to the $\gamma$-carboxyglutamate residues appears to be essential in their function.

There is no doubt that $\mathrm{Ca}^{2+}$ acts in blood coagulation because it binds factor $x_{a}$ to a phospholipid-water interface (40). $\mathrm{Ca}^{2+}$ does also play a role in other liquid-phase proteolytic reactions though. It is thus conceivable that it has more than one function in the catalytic reactions of factor $x_{a}$. This is more feasible as the binding of $\mathrm{Ca}^{2+}$ to factor $x$ brings about allosteric conformational changes (chapter III).

The hydrolys is of $p-N P G B$, catalyzed by factor $x_{a}$ or PIVKA-X $x_{a}$, showed roughly the same kinetic parameters for both enzymes (table II). We concluded from these results that all functional species of the active site of PIVKA-X $x_{a}$ are comparable with that of factor $X_{a}$. The kinetic parameters found were in a good agreement with these reported for factor $x_{a}$ by Smith (16).

Our investigations on the catalytic efficiency of factor $X_{a}$ and PIVKA-X $X_{a}$ were extended with two more substrates: Bz-Phe-ValArg-pNA and Bz-Ile-Glu-Gly-Arg-pNA. The $K_{M}$ and $k_{\text {cat }}$ values of the activity of factor $X_{a}$ and PIVKA- $X_{a}$ towards Bz-Phe-Val-ArgpNA and Bz-Ile-Glu-Gly-Arg-pNA were determined (table III). Our results suggest that both enzymes have an identical affinity towards Bz-Phe-Val-Arg-pNA as measured by $K_{M}$. The $K_{M}$ values found 
were of the same order of magnitude as was reported for trypsin, $6.7 \times 10^{-5} M(72)$ and thrombin $4.8 \times 10^{-5} M(25)$. Also the affinity of factor $X_{a}$ and PIVKA-X for Bz-Ile-Glu-Gly-Arg-PNA were found to be equal. $K_{M}$ values respectively $4.4 \times 10^{-4} \mathrm{M}$ and $5.0 \times 10^{-4} \mathrm{M}$ and agrees very well with the data supplied by Kabi Diagnostica, Sweden $\left(3.10^{-4} \mathrm{M}\right)$.

A comparison of the $K_{M}$ values determined for both substrates shows that the enzymes bind Bz-Phe-Val-Arg-pNA more effectively than Bz-Ile-Glu-Gly-Arg-pNA by one order of magnitude. However, under the conditions used in these experiments, factor $x_{a}$ hydrolyzes Bz-Ile-GIU-Giy-Arg-pNA approximately 400 times faster than it does $B z-P h e-V a l-A r g-p N A$ and so did PIVKA-X $a$ 100 times faster.

This discrepancy found between factor $X_{a}$ and PIVKA-X $X_{a}$ is due to the less catalytic efficiency of factor $X_{a}$ towards Bz-Phe-ValArg-pNA in comparison to PIVKA-X ${ }_{a}$ ( $k_{\text {cat }}$ values respectively $16 \mathrm{~min}^{-1}$ and $55 \mathrm{~min}^{-1}$ ). This was not due to the presence of thrombin in the PIVKA-X $x_{a}$ preparations.

A comparison of the inhibition constants of factor $X_{a}$ and PIVKA-X $X_{a}$ for benzamidine, using Bz-Ile-Glu-Gly-Arg-pNA as the substrate, shows that both enzymes have an identical affinity for the inhibitor and that inhibition was competitive (fig. 9).

Recently, Suomela (73) reported that factor $x_{a}$ had a considerable susceptibility towards the substrate Bz-Ile-Glu-Gly-Arg-pNA. Among the other coagulation factors only thrombin appeared to hydrolyse this substrate at a low rate. Therefore, it may be concluded that both enzymes have the same catalytic activity towards small synthetic substrates and the same affinity to amidine and guanidine inhibitors. Without $\mathrm{Ca}^{2+} \gamma$-carboxyglutamate residues do not seem to influence the catalytic activity with those substrates. $\mathrm{Ca}^{2+}$ was found to be a non-competitive inhibitor of the amidase activity of factor $x_{a}$ towards Bz-Ile-Glu-Gly-Arg-pNA. The time 
course of inactivation suggests that it finally reaches an equilibrium. It was already shown by Jesty (74) that $\mathrm{Ca}^{2+}$ mediates a concentration dependent association of factor $x_{a}$, resulting in the precipitation of factor $x_{a}$ aggregates. Prendergast (75) reported a concentration dependent association of prothrombin fragment 1 by $\mathrm{Ca}^{2+}$. Since it has been shown that $\mathrm{Ca}^{2+}$ has no effect upon the amidase activity of PIVKA-X $x_{a}$, the results suggest that the $\gamma$-carboxyglutamate residues are involved in the $\mathrm{Ca}^{2+}$ mediated association of factor $x_{a}$.

of particular interest was the observation that factor $V_{a}$ protects the association of factor $x_{a}$ (fig. 8). The finding that also bovine serum albumin protects factor $x_{a}$ for inactivation, may suggest that a non-specific protein-protein interaction prevents factor $x_{a}$ for inhibition. In the absence of $\mathrm{Ca}^{2+}$, factor $v_{a}$ does not enhance the amidase activity. The increase in the catalytic efficiency of factor $x_{a}$ towards $p$-toluene sulfonyl-L-arginine methyl ester (TAMe) caused by factor $V$ as reported by Coleman (76) may be due to the presence of $\mathrm{Ca}^{2+}$. No evidence from prothrombin activation experiments has been obtained that peptide bonds in prothrombin are more susceptible to factor $x_{a}$ when bound to factor $v_{a}$.

To investigate the activity of factor $x_{a}$ and PIVKA- $x_{a}$ towards prothrombin is more complicated than in case of small synthetic substrates for two reasons:

1. the activation of prothrombin occurs via a multiple step mechanism;

2. the high susceptibility of prothrombin for proteolysis by its own activation product, thrombin.

In the absence of $\mathrm{Ca}^{2+}$ the activation of prothrombin by factor $x_{a}$ and PIVKA-X $x_{a}$ is similar (fig. 11A). It can be assumed that both enzymes have an identical activity towards the substrate. The finding also indicates that $\mathrm{Ca}^{2+}$ is not absolutely necessary in this reaction. 
Of particular interest is the demonstration of a lag-phase in the activation, that hitherto, as far as we know, has passed unnoticed.

This phenomenon merits further investigations, because this lagphase is shortened by $\mathrm{Ca}^{2+}$ and more so when factor $\mathrm{X}_{a}$ is the enzyme than when PIVKA-X $X_{a}$ is the enzyme (fig. 11B).

From our experimental results, we are unable to give a straight forward explanation for the origin of the lag-phase. Nevertheless, they provide a few indications. It is known that prethrombin 2 is converted by factor $x_{a}$ in thrombin approximately four times faster than prothrombin (51). However, it is observed that prethrombin 2 accumulates during the time course of activation (fig. 12C). This fact can be accounted for the competition of prothrombin and prethrombin 2 for factor $x_{a}$. At the initial stage of the reaction, prothrombin is far in excess over prethrombin 2. It is likely that the lag-phase can be explained in terms of a competitive effect between prothrombin and prethrombin 2 . This is consistent with the following findings:

1. activation of prethrombin 1 by factor $x_{a}$ or PIVKA-X does not show any lag-phase (fig. 10);

2 . the rate of thrombin formation becomes 1 inear after all prothrombin is converted into prethrombin 1 (fig. $11 \mathrm{~A}$ and $12 \mathrm{~A}$ ).

From these experiments, an other important conclusion can be drawn. As shown in table IV, the final rate of thrombin formation from prothrombin by factor $x_{a}$ or PIVKA- $x_{a}$ in the absence of $\mathrm{Ca}^{2+}$ (actually the prethrombin 1 activation) is similar to the rate of thrombin formation from prethrombin 1 in the presence of $\mathrm{Ca}^{2+}$. This indicates that the interaction between $\gamma$-carboxyglutamate residues of factor $x_{a}$ with $\mathrm{Ca}^{2+}$ does not influence the factor $x_{a}$ activity. The question arises then, by what mechanism $\mathrm{Ca}^{2+}$ effects the lag-phase. It is tempting to speculate about an interaction via $\mathrm{Ca}^{2+}$ between factor $\mathrm{X}_{\mathrm{a}}$ and the $\mathrm{Ca}^{2+}$ binding $r$-carboxyglutamate residues in prothrombin. It could explain at least the differences between prethrombin 1 and prothrombin activation. 
Prethrombin 2 is assumed to be non-covalently associated with $\mathrm{Ca}^{2+}$ binding fragment 1.2 (53). Therefore, $\mathrm{Ca}^{2+}$ may also effect the conversion of prethrombin 2 by factor $x_{a}$.

Jackson et al. (53) have shown that only the fragment 2 part of fragment 1.2 is able to associate with prethrombin 2. Therefore, when thrombin proteolysis exceeds the factor $x_{a}$ proteolysis, the $\mathrm{Ca}^{2+}$ binding properties of the prethrombin 2-fragment 1.2 complex have been lost. The identical rates of thrombin formation determined after the lag-phase in all time courses may therefore be explained by the proteolytic action of thrombin. The appearance of this proteolytic action of thrombin is clearly demonstrated in fig. $11 \mathrm{~B}$. During the time course the protein bands in the prethrombin 1 fragment 1 and fragment 2 regions increase in density. It is also shown that fragment 1.2 is a transient component. Unfortunately, the results obtained in the time course, as was determined by the thrombin activity assay (fig. 11B) cannot be related to the results shown in fig. 12B, because of the crudeness of the technique used in the latter experiment. However, two important features can be mentioned:

1. at the early stage of the reaction, when factor $x_{a}$ activity was expected to exceed the thrombin activity, $\mathrm{Ca}^{2+}$ enhances the activation of prothrombin;

2. at the end of the time course, in the reverse situation, the rate of thrombin formation is nearly the same in the presence as in the absence of $\mathrm{Ca}^{2+}$ (table IV).

In conclusion can be said that

1. Interaction between $\mathrm{Ca}^{2+}$ and $r$-carboxyglutamate residues has no influence in the active centre of factor $x_{a}$ per se;

2. In the interaction of prothromb in and/or prethrombin 2-fragment 1.2 complex with factor $x_{a}$, $r$-carboxyglutamate residues likely play a role in a $\mathrm{Ca}^{2+}$ mediated complex formation. 


\section{REFERENCES}

1. Blow, D.M., Birktoff, J.J. and Hardley, B.S. Nature 221 (1963) 337

2. Freer, S.T., Krant, J., Robertus, J.D., Wright, H.T. and Xyong, W.H. Biochem. 9 (1970) 1997

3. Shotton, D.M. and Watson, H.C. Nature 225 (1970) 811

4. Titani, K., Hermodson, M.A., Fujikawa, K., Ericsson, L.H., Walsh, K.A., Neurath, H. and Davie, E.W. Biochem. 11 (1972) 4899

5. Walsh, K.A. and Neurath, H. Proc.Natl.Acad.Sci.USA 52 (1964) 884

6. Hartley, B.S. Nature 201 (1964) 1284

7. Hartley, B.S. and Shotton, D.M. Enzymes 3 (1971) 323

8. Magnusson, S. Enzymes 3 (1971) 277

9. De Haen, C., Neurath, H. and Teller, D.C. J.Mol.Biol. 92 (1975) 225

10. Lundblad, R.L. and Davie, E.W. Biochem.4 (1965) 113

11. Jackson, C.M. and Hanahan, D.J. Biochem. 7 (1968) 4506

12. Fujikawa, K., Legaz, M.E. and Davie, E.W. Biochemistry 11 (1972) 4892

13. Johnson, V.A. and Smith, R.L. Arch.Biochem.Biophys. 175 (1976) 190

14. Adams, R.W. and Elmore, D.T. Biochem. J. 124 (1971) 66

15. Esnouf, M.P. and Williams, W.J. Biochem.J. 84 (1962) 62

16. Smith, R.L. J.Biol.Chen. 248 (1973) 2418

17. Kosow, D.P. Thrombos.Res. 9 (1976) 565

18. Magnusson, S., Sottrup-Jensen, L., Petersen, T.E. and Claeys, H. In "Prothrombin and related coagulation factors" (1975) Eds. H.C.Hemker and J.J.Veltkamp. Leiden Univ.Press, 25

19. Owen, W.J., Esmon, C.T. and Jackson, C.M. J.Biol.Chem. 249 (1974) 594

20. Kisiel, W. and Hanahan, D.J. Biochem.Biophys.Res.Commun. 59 (1974) 570 
21. Esmon, C.T., Owen, W.G., Jackson, C.M. J.Biol.Chem.249 (1974) 606

22. Hageman, T.C. and Scheraga, H.A. Arch.Biochem.Biophys. 164 (1974) 707

23. Berger, A. and Schlechter, I. Philos.Trans.R.Soc.London Ser.B 257 (1970) 249

24. Thompson, A.R. Biochim. Biophys. Acta 422 (1976) 200

25. Gorman, J.J. Biochim.Biophys.Acta 412 (1975) 273

26. Bender, M.L. and Kezdy, F.J. Ann.Rev.Biochem. 34 (1965) 49

27. Bender, M.L., Kezdy, F.J. and Gunter, C.R. J.Am.Chem.Soc. 86 (1964) 3714

28. Brandt, K.G., Himoe, A. and Hess, G.P. J.Biol.Chem. 243 (1967) 3973

29. Baumann, W.K., Bizzozero, S.A. and Dutler, H. Eur.J.Biochem. 39 (1973) 381

30. Bizzozero, S.A., Baumann, W.K. and Dutler, H. Eur.J.Biochem. 58 (1975) 167

31. Fasco, M.J. and Fenton, J.W. Arch.Biochem.Biophys. 159 (1973) 802 32. Erlanger, B.F., Wassermann, N.H., Cooper, A.J. and Monk, R.J. Eur.J.Biochem. 61 (1976) 287

33. Ryan, R.J., Fenton, J.W., Chang, T. and Feissman, R.D. Biochem. 15 (1976) 1337

34. Heldebrant, C.M., Butkowski, R.J., Bajaj, S.P. and Mann, K.G. J.Biol.Chem. 248 (1973) 7149

35. Milstone, J.H. Fed.Proc. 23 (1964) 742

36. Barton, P.G., Jackson, C.M. and Hanahan, D.J. Nature 214 (1967) 923

37. Jobin, F. and Esnouf, H.P. Biochem.J. 102 (1967) 666

38. Deggeller, K. and Vreeken, J. Thrombos.Diathes.haemorrh. 22 (1969) 45

39. Seegers, W.H., Sakuragawa, N., McCoy, L.E., Sedensky, J.A. and Dombrose, F.A. Thrombos.Res. 1 (1972) 293

40. Gitel, S.N., Owen, W.G., Esmon, C.T. and Jackson, C.M. Proc.Natl. Acad.Sci.USA 70 (1973) 1344

41. Jackson, C.M., Owen, W.G., Gitel, S.N. and Esmon, C.T. Thrombos. Diathes.haemorrh. 57 (Supplement) (1974) 273 
42. Esmon, C.T., Owen, W.G. and Jackson, C.M. J.Biol.Chem. 249 (1974) 8045

43. Stenn, K.S. and Blout, E.R. Biochem. 11 (1972) 4502

44. Jesty, J. and Esnouf, M.P. Biochem. J. 131 (1973) 791

45. Heldebrant, C.M., Noyes, C., Kingdon, H.S. and Mann, K.G.

Biochem.Biophys. Res.Commun. 54 (1973) 135

46. Heldebrant, C.M. and Mann, K.G. J.Biol.Chem. 248 (1973) 3642

47. Benson, B.J., Kisiel, W. and Hanahan, D.J. Biochim.Biophys. Acta 329 (1973) 81

48. Fass, D.H. and Mann, K.G. J.Biol.Chem. 248 (1973) 3280

49. Kisiel, W. and Hanahan, D.J. Biochim. Biophys.Acta 329 (1973) 221

50. Engel, A.M. and Alexander, B. Biochim. Biophys.Acta 320 (1973) 687

51. Esmon, C.T. and Jackson, C.M. J.Biol.Chem. 249 (1974) 7782

52. Esmon, C.T. and Jackson, C.M. J.Biol.Chem. 249 (1974) 7791

53. Esmon, C.T., Owen, W.G. and Jackson, C.M. J.Biol.Chem. 249 (1974) 7798

54. Hemker,H.C., Esnouf, M.P., Hemker, P.W. Swart, A.C.W. and MacFarlane, R.G. Nature 215 (1967) 248

55. Lundblad, R.L. Biochem. 10 (1971) 2501

56. Cuatrecasas, P. J.Biol.Chem. 245 (1970) 3059

57. Smith, C.M. and Hanahan, D.J. Biochem. 15 (1976) 1830

58. Bender, M.L., Begué-Canton, M.L., Blakely, R.L., Brubacher, L.J., Feder, J., Gunter, C.R., Kezdy, F.J., Killheffer, J.V., Marchal1, T.H., Miller, C.G., Roeske, R.W. and Stoops, J.K. J.Am.Chem.Soc. 88 (1966) 5890

59. Chase, T. and Shaw,E. Biochem. Biophys.Res.Commun. 29 (1966) 5890

60. Gutfreund, H. and Sturtevant, J.M. Biochem.J. 63 (1956) 656

61. Gutfreund, H. and Sturtevant, J.M. Proc.Natl.Acad.Sci.USA 42 (1956) 719

62. Bernhard, S.A., Lau, S.J. and Noller, H. Biochem. 4 (1965) 1108

63. Brandt,K.G. and Hess, G.P. J.Biol.Chem. 242 (1967) 3963

64. Weber, K. and Osborn, M. J.Biol.Chem. 244 (1969) 4406 65. Fairbanks, G., Steck, L.T. and Wallach, D.F.H. Biochem. 10 (1971) 2606 
66. Dixon, 4 . and Webb, E.C. (1964) Enzymes. 2nd ed. p 315. Longmans and Green, London

67. Dixon, M. Biochem.J. 55 (1953) 170

68. Titani, K.m Fujikawa, K., Enfield, D.L., Lowe11, H.E., Walsh, K.A. and Neurath, H. Proc.Nat1.Acad.Sci.USA 72 (1975) 3082

69. Fujikawa, K., Legaz, M.E., Kato, H. and Davie, E.W. Biochem. 13 (1974) 4508

70. Hageman, T.C., Endres, G.F. and Scheraga, H.A. Arch.Bioch. Biophys. 171 (1975) 327

71. Takagi, T. and Doolittle, R.F. Biochem. 13 (1974) 750

72. Svendsen, L., Blombäck, B., Blombäck, M. and 01sson, P.I. Thrombos. Kes. 1 (1972) 267

73. Suomela, H., Blombäck, M. and Blombäck, B. Thrombos.Res. 10 (1977) 267

74. Jesty, J. and Esnouf, M.P. Biochem.J. 131 (1973) 791

75. Prendergast, F.G. and Mann, K.G. J.Biol.Chem. 252 (1977) 840 76. Coleman, R.W. Brit.J.Haematol. 19 (1970) 675. 
A vitamin $K$ deficiency results in a decrease in the concentration of the four blood coagulation factors II, VII, IX, and $X$. The possibility to affect the concentration of blood coagulation factors is used in oral anticoagulation therapy in order to prevent and combat arterial and venous thrombosis. Parallel with the disappearance of blood coagulation activity, precursors of these factors appear in the blood circulation. These precursors differ from the normal factors by lacking y-carboxyglutamic acids, essential for their proper function. These precursors are called decarboxy coagulation factors or Proteins Induced by Vitamin $K$ Absence (PIVKAs).

This thesis compared the enzymatic properties of factor $X$ and decarboxy factor $x$, isolated from bovine plasma. This offers the opportunity to study the role of r-carboxyglutamic acids in the mechanism of blood coagulation.

Chapter I is a review of the investigations that have lead to the elucidation of the function of vitamin $k$ in the biosynthesis of the blood coagulation factors.

In chapter II we describe the induction, purification and characterization of decarboxy factor $X$. A homogeneous preparation, as judged by different gel electrophoretic techniques, was obtained by a purification procedure slightly different from that used for the purification of factor $X$.

According to our investigations no other differences are found between factor $X$ and decarboxy factor $X$ than the presence of about $12 \gamma$-carboxyglutamyl residues in the former, where unmodified glutamyl residues are found in decarboxy factor $x$. In contrast to factor $x$, decarboxy factor $x$ has no blood coagulation activity and a very low affinity for $\mathrm{Ca}^{2+}$.

Studies on the interaction between $\mathrm{Ca}^{2+}$ and factor $\mathrm{X}$ and decarboxy factor $X$ by a flow rate dialysis technique and ultraviolet difference spectroscopy are described in chapter III. It is shown that 3-4 moles $\mathrm{Ca}^{2}+$ bind per mole factor $X$ in a positive cooperative manner. A total of $20 \mathrm{Ca}^{2+}$ binding sites was determined. The decarboxy factor $x$ has a very low affinity for $\mathrm{Ca}^{2}+$ without any sign of cooperativity.

Changes in the ultraviolet spectrum caused by $\mathrm{Ca}^{2+}$ were demonstrated in case of factor $x$ but not with decarboxy factor $X$. These findings suggest a conformational change upon interaction of $\mathrm{Ca}^{2+}$ with $\gamma$-carboxyglutamic acids in factor $X$.

The role of $Y$-carboxyglutamic acid in the activation of factor $X$ by a protease from Russel1's Vipervenom was investigated as described in chapter IV. Similar experiments with decarboxy factor $X$ makes it clear that the specific interaction between $\mathrm{Ca}^{2+}$ and $\gamma$-carboxyglutamic acid is not an absolute requirement for the conversion of the zymogen. However, the large enhancement of the rate of activation of factor $x$ by $\mathrm{Ca}^{2}+$ compared with decarboxy 
factor $X$ points to the importance of the $\mathrm{Ca}^{2+}$ binding sites in factor $x$, i.c. the $y$-carboxy glutamic acids. Also the sigmoidal relationship between $\mathrm{Ca}^{2}+$ concentration and rate of activation agrees with the $\mathrm{Ca} 2+$ binding properties of factor $X$.

The only difference between activated decarboxy factor $X$ and normal activated factor $X$ is the presence of y-carboxy glutamic acids in the latter which very likely causes the inability of decarboxy factor $x_{a}$ to participate in blood coagulation. As a consequence, decarboxy factor $x_{a}$ has no blood coaguiation activity. Furthermore, it is shown that the activity of decarboxy factor $x_{a}$ towards small synthetic substrates is similar to that of factor $x_{a}$.

The enzymatic properties of factor $x_{a}$ and decarboxy factor $x_{a}$ are reported in chapter $V$. Kinetic experiments on both enzymes with different synthetic substrates revealed similar kinetic parameters. In addition both enzymes also have the same catalytic efficiency towards prothrombin in the absence of $\mathrm{Ca}^{2+}$. These findings indicate that there are no differences in the active center of normal factor $x_{a}$ and decarboxy factor $x_{a}$.

In contrast to factor $x_{a}$, activation of prothrombin by decarboxy factor $x_{a}$ is not stimulated by phospholipids and $\mathrm{Ca}^{2+}$. This finding confirms the proposed role of the $\gamma$-carboxyglutamic acids in the $\mathrm{Ca}^{2+}$ mediated binding of prothrombin to phospholipids.

However, we also observed that $\mathrm{Ca}^{2}+$ has a marked influence on the reaction rate of the activation of factor $X$ by $R V V-X$ and the activation of prothrombin by factor $x_{a}$, but not in the analogous situation with decarboxy factor $x_{a}$. This strongly suggests that $\mathrm{Ca}^{2+}$, apart from its well documented role in the binding of vitamin $K$ dependent clotting factors to phospholipids, also functions by inducing conformational changes via its binding to $\gamma$-carboxyglutamic acids. 
Bij een vitamine $K$ deficiëntie is de lever niet in stat de vier stollingsfaktoren II, VII, IX, en X voldoende aan te maken. Hiervan wordt gebruik gemaakt bij de zgn. orale antistollingstherapie ter bestrijding en preventie van arteriële en veneuze thrombose. Niet alleen neemt de konsentratie van de stollingsfaktoren af, ook komen voorstadia van deze faktoren in het bloed. Deze onderscheiden zich van de normale faktoren doordat zij niet de $\gamma$-carboxyglutaminezuren bevatten die voor een normale funktie noodzakelijk zijn. Zij worden decarboxy stolfaktoren genoemd of ook Proteins Induced by Vitamin $K$ Absence or Antagonists (PIVKAs).

Dit proefschrift vergelijkt de enzymatische eigenschappen van faktor $X$ en van decarboxy faktor $X$, geïsoleerd uit runderplasma. Dit maakt het mogelijk de rol van de $\gamma$-carboxyglutaminezuren in het stollingsproces nader te omschrijven en een nader inzicht te krijgen in het bloedstollingsdefekt dat wordt geïnduceerd door orale antistollingstherapie.

Hoofdstuk I geeft een literatuuroverzicht van het onderzoek dat uiteindelijk geleid heeft tot de opheldering van de funktie van vitamine $K$ in de biosynthese van stollingsfaktoren.

In het tweede hoofdstuk wordt het induceren, isoleren en karakteriseren van het decarboxy faktor $X$ beschreven. Een homogeen preparaat, zoals aangetoond met verschillende gel elektroforetische technieken, werd verkregen d.li.v. een zuiveringsmethode, welke op enkele punten afwijkt van die welke gebruikt wordt voor de zuivering van faktor $x$.

Voor zover wij hebben kunnen nagaan bestaan er geen strukturele verschillen tussen de normale faktor $X$ en het decarboxy faktor $X$, anders dan een twaalftal $\gamma$-carboxyglutaminezuren in de eerst genoemde, waar in decarboxy faktor $X$ glutaminezuren worden gevonden. In tegenste $]-$ 1 ing tot faktor $X$ heeft het decarboxy faktor $X$ geen bloedstollingsaktiviteit en geen affiniteit voor $\mathrm{Ca}^{2+}$ ionen. Ook remt het de bloedstolling niet, zoals dat voor menselijk decarboxy faktor $X$ wel wordt beschreven.

Onderzoek naar de interaktie tussen $\mathrm{Ca}^{2+}$ en faktor $x$ en decarboxy faktor X d.m.v. de "flow rate dialysis" techniek en ultraviolet spectroscopie wordt beschreven in hoofdstuk III. De $\mathrm{Ca}_{2}+$ bindings experimenten met faktor $X$ laten zien dat 3-4 $\mathrm{Ca}^{2}+$ ionen per mole faktor $X$ positief cooperatief binden. Een total aantal van $20 \mathrm{Ca}^{2+}$ bindingsplaatsen werd gevonden. Het decarboxy faktor $X$ daarentegen heeft een lage affiniteit voor $\mathrm{Ca}^{2}+$ zonder enig teken van cooperativiteit.

Een verandering in het ultraviolet spectrum onder invloed van $\mathrm{Ca}^{2+}$ wordt gevonden met faktor $X$ en niet met decarboxy faktor $X$. Dit doet vermoeden dat de interaktie tussen $\gamma$-carboxyglutaminezuren in faktor $\mathrm{X}$ met $\mathrm{Ca}_{2}+$ een conformatieverandering teweeg brengt. 
De rol van $\gamma$-carboxyglutaminezuren in de aktivatie van faktor $X$ door een protease uit het gif van de ipera husselzi werd onderzocht zoals beschreven in hoofdstuk IV. Analoge experimenten met decarboxy faktor $X$ maken duidelijk dat de specifieke interaktie tussen $\mathrm{Ca}^{2+}$ en $\gamma$-carboxyglutaminezuren geen strikte voorwaarde is voor de omzetting van het zymogen in enzym. De snelheid van de aktivatie is echter sterk afhankelijk van de mogelijkheid van het zymogen om $\mathrm{Ca}^{2}+$ ionen te binden. Anders gezegd, de interaktie tussen $\mathrm{Ca}^{2+}$ en $\gamma$-carboxyglutaminezuren in faktor $X$ verhoogt de reaktiesnelheid van de enzymvorming. Het sigmoidale karakter van de relatie tussen $\mathrm{Ca}_{2}+$ konsentratie en reaktiesnelheid is in overeenstemming met de gevonden Catt bindings eigenschappen van faktor $X$.

Het geaktiveerde decarboxy faktor $x$ (decarboxy faktor $x_{a}$ ) is struktureel identiek met het geaktiveerde faktor $x$ (faktor $x_{a}$ ), met dit verschil dat in de laatst genoemde een tiental $\gamma$-carboxyglutaminezuren gevonden worden waar in decarboxy faktor $x_{a}$ glutaminezuren voorkomen. Het gevolg hiervan is dat het decarboxy faktor $x_{a}$ geen bloedstollingsaktiviteit heeft. Aanwijzingen werden gevonden dat de aktiviteit van decarboxy faktor $x_{a}$ war het kleine synthetische substraten betreft, identiek is aan die van faktor $x_{a}$.

In hoofdstuk $V$ wordt hier nader op ingegaan. Kinetische experimenten van faktor $x_{a}$ en decarboxy faktor $x_{a}$ met verschillende synthetische substraten resulteerden in gelijke kinetische parameters. 0ok werd een identieke katalytische efficiëntie van beide enzymen t.a.v. het natuurlijke substraat van faktor $x_{a}$, i.c. prothrombine, wargenomen. Dit alles wijst er op dat er geen funktionele verschillen bestaan tussen het aktieve centrum van nornaal faktor $x_{a}$ en de decarboxy vorm. $\mathrm{Ca}_{2}+$ ionen hebben geen invloed op het aktivatiemechanisme van prothrombine door faktor $x_{a}$ in oplossing, noch op het funktioneren van het aktieve centrum per se.

Er werden evenwel aanwijzingen verkregen dat $\mathrm{Ca} 2+$ ionen de omzetting van prothrombine door faktor $x_{a}$ versnellen. Het is waarschijnlijk dat $\mathrm{Ca}^{2+}$ een rol speelt bij de vorming van het enzym-substraat komplex. De specifieke $\mathrm{Ca}^{2+}$ bindingseigenschappen van de $\gamma$-carboxyglutaminezuren in zowel het substraat als het enzym hebben hierin een zekere funktie.

In tegenstelling tot factor $x_{a}$ wordt de aktivatie van prothrombine door decarboxy factor $x_{a}$ niet gestimuleerd door fosfolipiden en $\mathrm{C}_{2}{ }^{2+}$.
Hiermee bevestigen we de rol van $\gamma$-carboxyglutaminezuren in de $\mathrm{Ca}^{2+}$ afhankelijke binding van vitamine $K$ afhankelijke stolfactoren aan fosfolipiden.

We namen bovendien waar dat $\mathrm{Ca}^{2+}$ een sterke invloed heeft op de sne Theid van aktivatie van factor $X$ door RVV-X en de aktivatie van prothrombine door factor $x_{a}$. Dit geeft aan dat naast de bekende rol van $\mathrm{Ca}^{2+}$ in de fosfolipide binding, $\mathrm{Ca}^{2}+$ ook een funktie heeft in het induceren van een conformatie verandering via hun binding met $\gamma$-carboxyglutaminezuren. 
Dankwoord

Bij de voltooiing van dit proefschrift wil ik graag mijn dank betuigen aan allen die aan de aan de totstandkoming een daadwerkelijke, danwel morele steun hebben gegeven. In het bijzonder wil ik Bernadette Kop danken voor haar waardevolle bijdrage aan dit onderzoek.

Prof.Dr.H.C.Hemker ben ik zeer erkentelijk voor zijn stimilerende invloed en de geboden faciliteiten, welke van wezenlijk belang zijn geweest.

Dr.P.P.M.Reekers, beste Paul, de wijze warop jij mij ingewijd hebt in de bloedstolling heb ik erg gewardeerd.

Dr.M.P.Esnouf en Prof.Dr.G.H. de Haas wil ik danken voor hun bereidheid om als co-referenten op te treden.

Jan Rosing en George Willems dank ik voor de stimilerende diskussies. De prettige samenwerking met de leden van de capaciteitgroep Biochemie waardeer ik erg.

Verder gaat mijn dank uit naar:

Jos kop voor de aminozuur analyses;

Helene Vermeer voor het typen van het manuscript;

Piet Laterveer, Ruud Krüger, Kees Verlaan en K.Limpens voor hun onmisbare bijdrage aan de dierexperimenten.

ook de niet genoemde medewerkers van het Biomedisch Centrum wil ik graag bedanken. 
Curriculum vitae

Zoals gebruikelijk in de faculteit der geneeskunde volgt hier een kort overzicht van mijn academische studie.

$\mathrm{Na}$ het behalen van het eind-examen H.B.S.-B aan de Rijks-h.b.s. te Bergen op Zoom in 1963, begon ik in 1965 met de scheikundestudie aan de Rijksuniversiteit in Utrecht. Het candidaatsexamen, letter $S_{2}$, werd afgelegd in januari 1969. Het doctoraalexamen scheikunde, met als hoofdvak biochemie (Prof.Dr.L.L.M. van Deenen) en als bijvak klinische chemie (Dr.S.K.Wadman) werd behaald in juni 1971 .

Van 1972 tot juli 1975 was ik als wetenschappelijk medewerker verbonden aan het laboratorium voor Cardiobiochemie en Bloedstol1ingsbiochemie van het Academisch Ziekenhuis in Leiden, onder leiding van Prof.Dr.H.C. Hemker.

Sinds juli 1975 ben ik als wetenschappelijk medewerker verbonden aan de Rijksuniversiteit Limburg. 